Aus der Klinik für Kardiologie und Pneumologie

(Prof. Dr. med. G. Hasenfuß)

der Medizinischen Fakultät der Universität Göttingen

\title{
Über die potenziell \\ kardioprotektive Rolle des \\ Hitzeschockproteins A4
}

\author{
INAUGURAL-DISSERTATION \\ zur Erlangung des Doktorgrades \\ der Medizinischen Fakultät der \\ Georg-August-Universität zu Göttingen
}

vorgelegt von

Svante Sören Gersch

aus

Mannheim-Neckarau

Göttingen 2020 
Dekan:

\section{Betreuungsausschuss}

Betreuer:

Ko-Betreuerin:

\section{Prüfungskommission}

Referent

Ko-Referentin:

Drittreferent:
Prof. Dr. med. W. Brück

Prof. Dr. med. K. Toischer

Prof. Dr. rer.nat. S. Lutz

Prof. Dr. med. K. Toischer

Prof. Dr. rer.nat. S. Lutz

Prof. Dr. med. M. Oppermann

Datum der mündlichen Prüfung: 06.10.2020 
Hiermit erkläre ich, die Dissertation mit dem Titel „Über die potenziell kardioprotektive Rolle des Hitzeschockproteins A4“ eigenständig angefertigt und keine anderen als die von mir angegebenen Quellen und Hilfsmittel verwendet zu haben.

Göttingen, den 


\section{Inhaltsverzeichnis}

Abbildungsverzeichnis ...........................................................................II

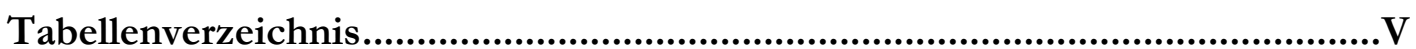

Abkürzungsverzeichnis .............................................................................. VI

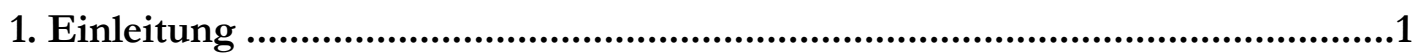

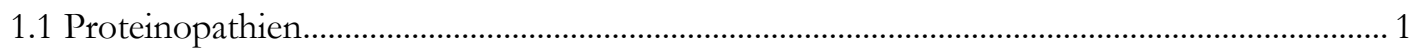

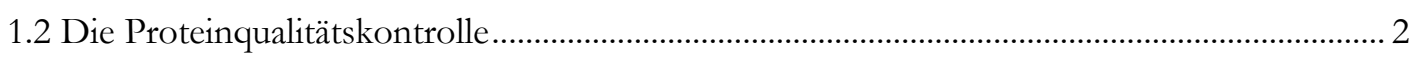

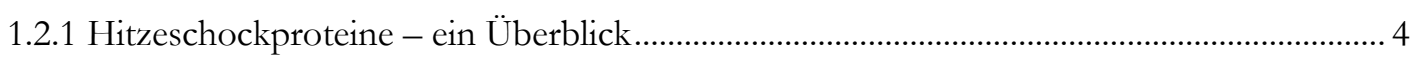

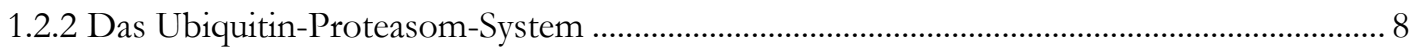

1.2.3 Chaperonvermittelte Autophagie..................................................................................... 10

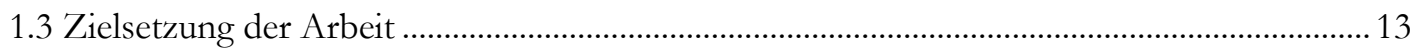

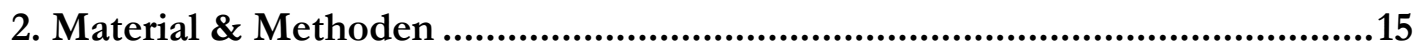

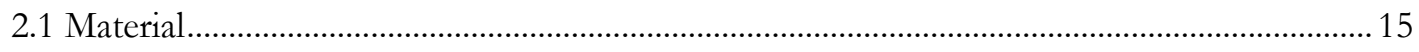

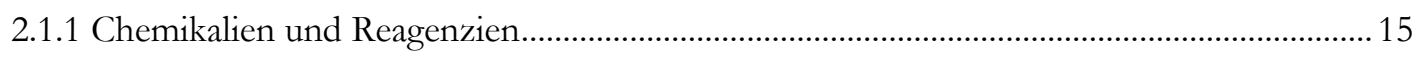

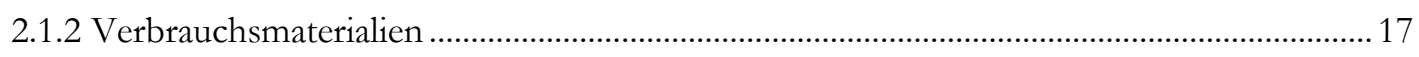

2.1.3 Gebrauchsfertige Reaktionssysteme …………………..................................................... 17

2.1.4 Lösungen, Medien \& Puffer .......................................................................................... 18

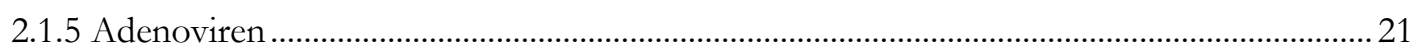

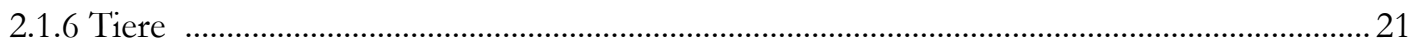

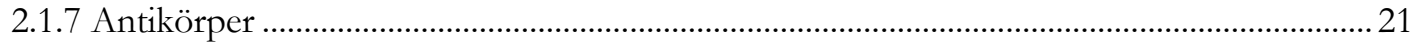

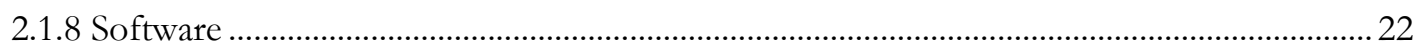

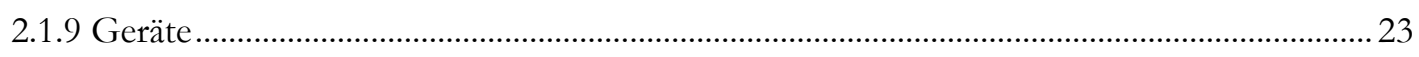

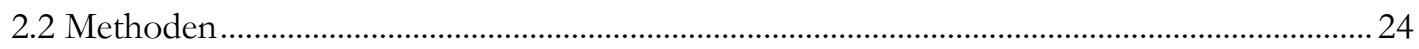

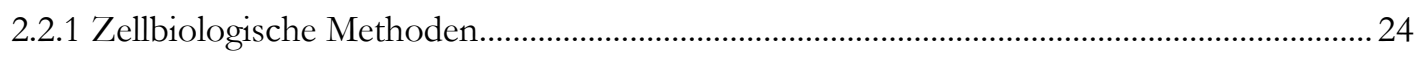

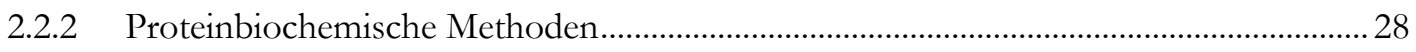

2.2.3 Bestimmung der Genexpression mittel qPCR ……………………………………........ 30

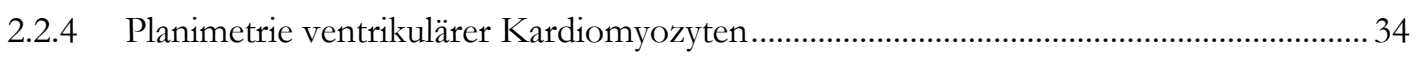




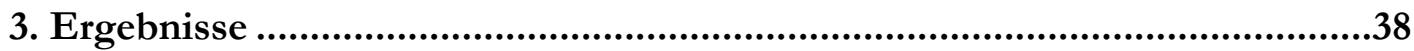

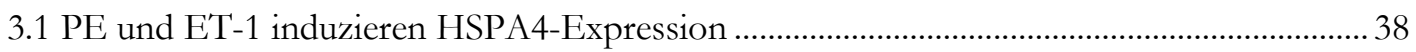

3.2 ET-1 stimuliert nicht die HSPA4-Expression in Fibroblasten............................................. 40

3.3 Bestimmung der optimalen Ad-HSPA4-Konzentration ........................................................ 42

3.4 ANP- und BNP-Level unter PE und ET-1 in HSPA4-überexprimierten Kardiomyozyten

3.5 HSPA4 verringert die Menge ubiquitinierter Proteine ........................................................ 46

3.6 HSPA4-Überexpression reduziert die PE- und ET-1-induzierte Hypertrophie .................. 48

3.7 Relative Fluoreszenzintensität unter Stimulation mit PE und ET-1 .................................51

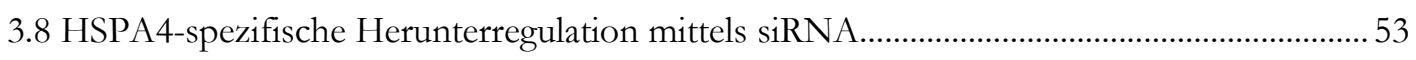

3.9 ANP- und BNP-Level unter PE und ET-1 in HSPA4-herunterregulierten Kardiomyozyten

3.10 HSPA4-Herunterregulation fördert die Akkumulation ubiquitinierter Proteine ............... 56

3.11 HSPA4-Herunterregulation begünstigt PE- und ET-1-induzierte Hypertrophie ...............58

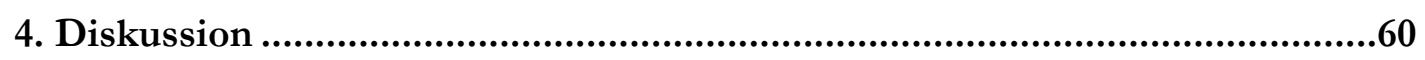

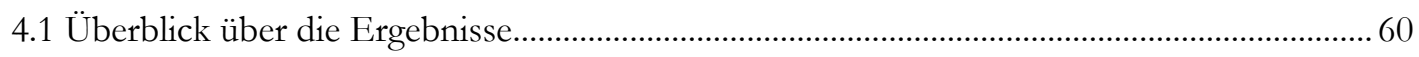

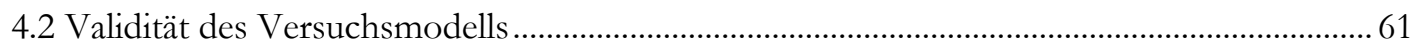

4.3 Der Einfluss von HSPA4 auf die Expression von ANP und BNP ...................................61

4.4 Der Einfluss von HSPA4 auf die Entwicklung der Zellgröße ..................................................63

4.5 Der Einfluss von HSPA4 auf ubiquitinkonjugierte Proteine ...............................................69

4.6 Potenzielle Mechanismen der HSPA4-vermittelten Kardioprotektion.................................71

4.7 Chancen, Limitationen und Ausblick ................................................................................. 74

5. Zusammenfassung ..................................................................................76

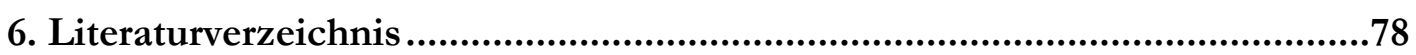




\section{Abbildungsverzeichnis}

Abb. 1: Proteinopathienassoziierte Erkankungen .................................................................... 1

Abb. 2: Illustration der Proteinqualitätskontrolle in der Zelle ......................................................... 3

Abb. 3: Modell für die Kooperation von HSP110 und HSP70 .................................................... 7

Abb. 4 Zellulärer Stress als Grund für die Proteinfehlfaltung.................................................. 9

Abb. 5: Einzelne Schritte der chaperonvermittelten Autophagie ................................................ 11

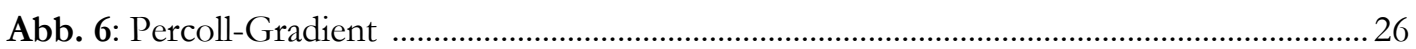

Abb. 7: Darstellung des HSPA4-Adenovirus-DNA-Konstrukts...............................................22

Abb. 8: Quantitative Auswertung der HSPA4-Expression in einer rt-PCR unter Stimulation

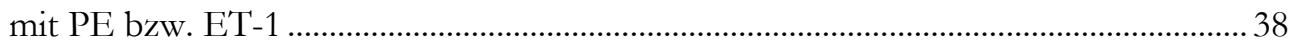

Abb. 9: HSPA4-Expression unter Stimulation mit $10 \mu \mathrm{M}$ PE und 50 nM ET-1 in NRCM.....39

Abb. 10: Western Blot zur Überprüfung der HSPA4-Expression in Kardiomyozyten und Fibroblasten unter 48-stündiger Inkubation mit ET-1

Abb. 11: Fluoreszenzmikroskopisches Bild von Kardiomyozyten nach adenoviraler Transduktion mit $1 \mu \mathrm{L}$ des Ad-HSPA4 nach 24 Stunden.

Abb. 12: Quantitative Auswertung der HSPA4-Expression in einer rt-PCR nach adenoviraler Transduktion mit Ad-HSPA4

Abb. 13: Western Blot von NRCM nach adenoviraler Transduktion zur Untersuchung der HSPA4-Expression

Abb. 14: Quantitative Auswertung der ANP- und BNP-Expression nach adenoviraler Transduktion und Stimulation mit $10 \mu \mathrm{M}$ PE und 50 nM ET-1....

Abb. 15: Nachweis ubiquitinierter Proteine in adenoviral transduzierten Kardiomyozyten unter Stimulation mit $10 \mu \mathrm{M}$ PE bzw. 50 nM ET-1

Abb. 16: Graphische Auswertung der Zelloberfläche nach adenoviraler Transduktion zur Überexpression und Stimulation mit $10 \mu \mathrm{M}$ PE und 50 nM ET-1.

Abb. 17: Graphische Auswertung der Fluoreszenzintensität nach adenoviraler Transduktion zur Überexpression von HSPA4 und Stimulation mit $10 \mu \mathrm{M}$ PE und 50 nM ET-1 ... 52

Abb. 18: Überprüfung der HSPA-Herunterregulation mittels rt-PCR.

Abb. 19: Überprüfung der HSPA-Herunterregulation mittels Western Blot und rt-PCR......... 54

Abb. 20: Quantitative Auswertung der ANP-mRNA- und BNP-Expression nach siRNAvermittelter HSPA4-Herunterregulation und Stimulation mit $10 \mu \mathrm{M}$ PE und $50 \mathrm{nM}$ ET-1: 
Abb. 21: Nachweis ubiquitinierter Proteine in HSPA4-herunterregulierten Kardiomyozyten unter Stimulation mit $10 \mu \mathrm{M}$ PE bzw. 50 nM ET-1. 57

Abb. 22: Graphische Auswertung der Zelloberfläche nach Herunterregulation von HSPA4 und Stimulation mit $10 \mu \mathrm{M}$ Phenylephrin und $50 \mathrm{nM}$ Endothelin-1. 58

Abb. 23: HSPA4-vermittelte Kardioprotektion. 71

Abb. 24: Graphische Übersicht der Ergebnisse . 74 


\section{Tabellenverzeichnis}

Tab. 1: Vorbereitung des Enzymmix für die Isolierung von NRCM .........................................24

Tab. 2: Vorbereitung von Top- \& Bottom-Percoll Stock ................................................................2 25

Tab. 3: Vorbereitung der Transfektionslösungen für siRNA-Transfektion von NRCM...........28

Tab. 4: Zusammensetzung des Trenn- und Sammelgels für die SDS-Page-Gelelektrophorese

Tab. 5: Zusammensetzung der cDNA-Synthese ……………………………………………....... 31

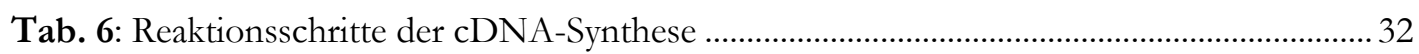

Tab. 7: Zusammenstellung der verwendeten Primer ........................................................................ 33

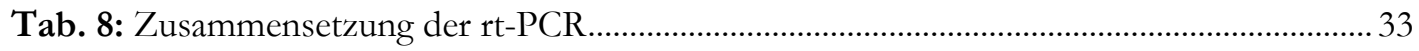

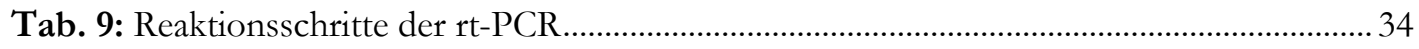




\section{Abkürzungsverzeichnis}

Ad

AK

ANP

APS

ATP

AZ

BCA

Bcl-2

BNP

BRDU

BSA

CaMKII

$\mathrm{CBFHH}$

cDNA

CHIP

CMV

Da

DAG

DAPI

dd

DMEM

DNA

DPBS

EDTA

EGFP

ET-1

ERK 1/2

FCS

GAPDH

GFP

HCC

$\mathrm{HCl}$

HDAC
Adenovirus

Antikörper

atriales natriuretisches Peptid

Ammoniumpersulfat

Adenosintriphosphat

Aktenzeichen

Bicinchoninsäure

B-cell lymphoma 2

brain natriuretic peptide (B-natriuretisches Peptid)

Bromdesoxyuridin

bovine serum albumin (Rinderserumalbumin)

$\mathrm{Ca}^{2+} /$ Calmodulin abhängige Proteinkinase II

calcium and bicarbonate free Hanks Hepes buffer

komplementäre DNA

carboxyl-terminus of Hsp70 interacting protein

Cytomegalivirus

Dalton (Molekülmasse)

Diacylglycerol

4',6-Diamidin-2Phenylindol

doppelt destilliert, bidestilliert

Dulbecco's Modified Eagle's Medium

Desoxyribonukleinsäure

Dulbecco's phosphatgepufferte Salzlösung

Ethylendiamintetraessigsäure

enhanced green fluorescent protein

Endothelin-1

extracellular responsive kinase 1/2

fetal calf serum (fetales Kälberserum)

Glycerinaldehyd-3-Phosphat-Dehydrogenase

green fluorescent protein

hepatozelluläres Karzinom

Salzsäure

Histon-Deacetylase 
HEPES 2-(4-(Hydroxyethal)-1-piperazinyl)-ethansulfonsäure

HPRT Hypoxanthin-Guanin-Phosphoribosyltransferase

HRP borseradish peroxidase

HSP

Hitzeschockproteine

HSP40

Hitzeschockprotein 40

HSP70

Hitzeschockprotein 70

HSPA4

Hitzeschockprotein A4

HSPB5

Hitzeschockprotein B5

I.E.

Internationale Einheiten

$\mathrm{I} / \mathrm{P}$

Ischämie/Perfusion

$\operatorname{Ig} G$

Immunglobulin $G$

$\mathrm{KO}$

knockout

LAVES

Landesamt für Verbraucherschutz und Lebensmittelsicherheit

LAMP-2A lysosome-associated membrane protein type $2 \mathrm{~A}$

M

Molarität

MEF2

myocyte enhancer factor- 2

MAPK

mitogen-activated protein kinase

MOI

multiplicity of infection (Viruslast pro Zelle)

mRNA

messenger ribonucleic acid

NBD

nukleotidbindende Domäne

NFAT

nuclear factor of activated T-cells

NKM

Nicht-Kardiomyozyten-Medium

NRCM

neonatale Rattenkardiomyozyten

PAGE

Polyacrylamidgelelektrophorese

PBS

phosphate-buffered saline

PE

Phenylephrin

Pen/Strep

Penicillin / Streptomycin

PFA

Paraformalaldehyd

PKC

Proteinkinase C

PDK1

Proteinkinase D1

PLN

Phospholamban

PP1

Proteinphosphatase 1

PQC

Proteinqualitätskontrolle

RIPA

Radioimmunopräzipitationassay 


$\begin{array}{ll}\text { rpm } & \text { revolutions per minute (Umdrehungen pro Minute) } \\ \text { RT } & \text { Raumtemperatur } \\ \text { rt-PCR } & \text { realtime-polymerase chain reaction } \\ \text { SDS } & \text { Sodiumdidecylsulfat, Natriumdodecylsulfat } \\ \text { SEM } & \text { standard error of the mean (Standardfehler) } \\ \text { SERCA } & \text { sarcoplasmic/ endoplasmic reticulum calcium ATPase } \\ \text { siRNA } & \text { small interfering ribonucleic acid } \\ \text { TAC } & \text { transverse aortic contriction } \\ \text { TBST } & \text { Tris-buffered saline with Tween (TBS-Tween) } \\ \text { TEMED } & \text { N,N,Tetrametylethylendiamin } \\ \text { TRIS } & \text { Trishydroxymethylaminomethan } \\ \text { TSA } & \text { Trichostatin A } \\ \text { UPS } & \text { Ubiquitin-Proteasom-System } \\ \text { v/v } & \text { Volumen pro Volumen } \\ \text { w/v } & \text { Gewicht pro Volumen } \\ \text { ZTE } & \text { Zentrale Tierexperimentelle Einrichtung }\end{array}$




\section{Einleitung}

\subsection{Proteinopathien}

Unter Proteinopathien werden verschiedene Erkrankungen zusammengefasst, in denen sich Proteine strukturell abnormal falten und hierdurch die Funktion von Zellen, Geweben und Organen einschränken (Carrell und Lomas 1997; Walker und LeVine 2000; Su und Wang 2010). In den meisten Proteinopathien erhöht eine Änderung der Konformation von Proteinen die Wahrscheinlichkeit, dass diese an sich selbst binden und dadurch aggregieren (Carrell und Lomas 1997). Aggregierende Proteine können größenbedingt nicht über das Ubiquitin-Proteasom-System (UPS) proteolytisch aufgespalten werden und aktivieren weitere Abbauwege, wie den Autophagie-Lysosomen-Abbauweg (Tannous et al. 2008). In diesem Stadium verlieren die Proteine ihre Funktion und können toxisch auf Zellen einwirken (Bence et al. 2001; Bennett et al. 2005; Goldberg 2007; Kristiansen et al. 2007; Luheshi et al. 2008; Thibaudeau et al. 2018). Mehrere neurodegenerative Erkrankungen, wie Morbus Alzheimer (Jucker und Walker 2013), Morbus Parkinson (Goedert et al. 2013), Chorea Huntington (Orr und Zoghbi 2007) oder auch genetisch bedingte Erkrankungen, darunter die cystische Fibrose (Meng et al. 2017) oder Sichelzellanämie (Stuart und Nagel 2004), werden unter dem Begriff der Proteinopathien subsumiert (Abb.1). Zudem ist gut erforscht, dass diese Proteinaggregate direkt die Proteasomaktivität inhibieren und damit auch auf alle proteasomabhängigen Signalwege Einfluss nehmen (Kristiansen et al. 2007; Dantuma und Lindsten 2010; Ciechanover und Kwon 2015).

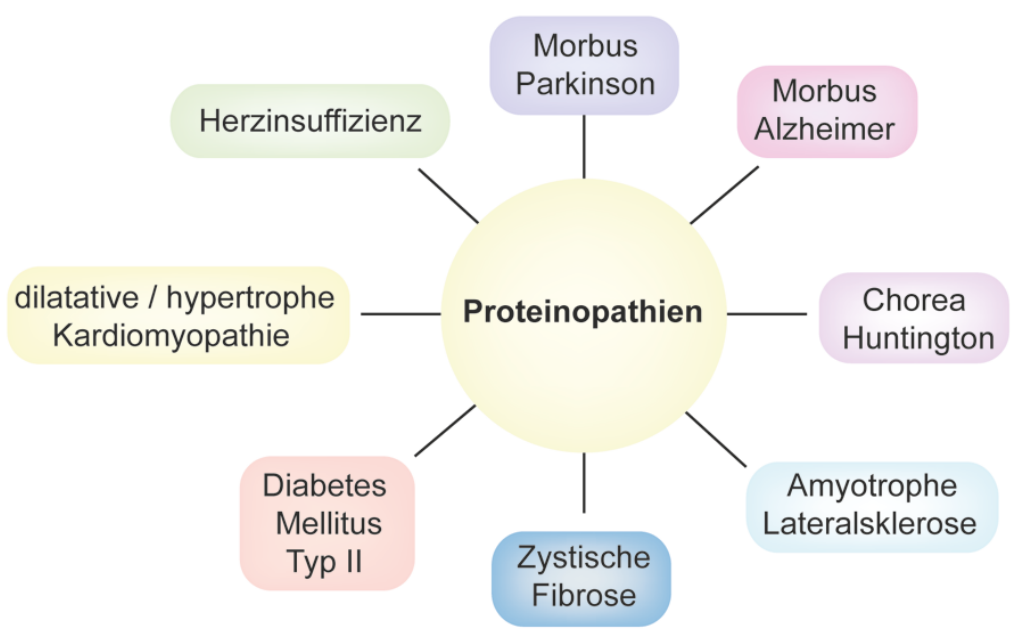

\section{Abb. 1: proteinopathien- assoziierte Erkrankungen}

In den vergangenen Jahren fanden sich immer mehr Hinweise, dass Proteinakkumulation und -aggregation als Teil des pathophysiologischen Prozesses in verschiedenen 
kardiovaskulären Krankheitsbildern eine Rolle spielt (Willis und Patterson 2013), darunter ischämische, hypertrophe und dilatative Kardiomyopathien (Kostin 2003; Weekes et al. 2003; Ayyadevara et al. 2016), fortgeschrittene Herzinsuffizienz (Pattison et al. 2008; Pattison und Robbins 2008) und Aortenklappenstenosen (Tannous et al. 2008). All diesen Erkrankungen ist trotz unterschiedlicher Ätiologie gemein, dass sich vermehrt polyubiquitinierte Proteine nachweisen lassen, die erfolglos ubiquitiniert wurden, um via UPS degradiert zu werden (Labbadia und Morimoto 2015). Die Annahme, dass fehlgefaltete, ubiquitinierte Proteine ebenfalls in den oben aufgeführten Erkrankungen zur pathophysiologischen Entwicklung beitragen, wird durch Studien zu verschiedenen Arten von Kardiomyopathien (Sanbe et al. 2004; Predmore et al. 2010) und Herzinsuffizienz (Pattison et al. 2008) gestützt. Da das UPS den Hauptweg für den Proteinabbau darstellt ( $>80 \%$ der intrazellulären Proteine) (Wang und Maldonado 2006), nimmt es in Kardiomyozyten, in denen myofibrilläre Proteine mehr als 80\% des Zellvolumens einnehmen (Wang et al. 2008), eine fundamentale Stellung in der Erhaltung der Proteinhomöostase in der Zelle ein (Willis und Patterson 2006; Patterson et al. 2007; Villarreal und Lew 2010; Willis und Patterson 2013; Quarles et al. 2015). Kardiomyozyten haben als enddifferenzierte Zellen ein geringes regeneratives Potential. Sowohl in adulten Mäuse- als auch humanen Herzen ließ sich lediglich eine Neubildung von Kardiomyozyten von ca. 1\% pro Jahr nachweisen (Bergmann et al. 2009; Mollova et al. 2013; Senyo et al. 2013). Zudem fehlt Kardiomyozyten als enddifferenzierten Zellen die Möglichkeit über asymmetrische Zellteilung dem proteotoxischen Stress zu entgehen (Bergmann et al. 2009; Henning und Brundel 2017). Während durch die Mitose eine Tochterzelle frei von Aggregaten ist, wird in der „,beladenen“ Zelle Apoptose eingeleitet (Rujano et al. 2006). Da das Herz dauerhaftem mechanischem Stress durch lebenslange Kontraktion und Relaxation ausgesetzt ist, der die Effizienz der Faltung negativ beeinflussen kann, entwickelte sich im Herzen eine mehrschichtige Proteinqualitätskontrolle, die vorwiegend von Chaperonen, dem UPS und autophagievermittelter Proteolyse durchgeführt wird (Wang et al. 2008).

\subsection{Die Proteinqualitätskontrolle}

Die Proteinqualitätskontrolle (PQC) beschreibt ein entscheidendes Zusammenspiel zwischen Chaperonen, dem UPS und der Autophagie in der Erhaltung der Proteinhomöostase (Sandri und Robbins 2014). Eine Schädigung einer oder mehrerer daran beteiligter Komplexe führt zur Akkumulation fehlgefalteter oder beschädigter Proteine, die die zelluläre Integrität und Funktion beeinträchtigen (Wang und Wang 2015). Die negativen Auswirkungen dieser Proteine auf die Zelle werden durch den Begriff der Proteotoxizität umschrieben (Willis und 
Patterson 2013). In den letzten Jahren gab es vermehrt Hinweise auf einen kausalen Zusammenhang zwischen der Proteintoxizität und der Pathogenese verschiedener Herzerkrankungen, darunter in der Entwicklung der Herzinsuffizienz und in der ischämischem Herzerkrankung (Li et al. 2011). Als gemeinsames pathologisches Merkmal ließen sich eine erhöhte Anzahl ubiquitinierter Proteine und aberrante Proteinaggregate in Kardiomyozyten nachweisen (Sanbe et al. 2004; Day 2013).

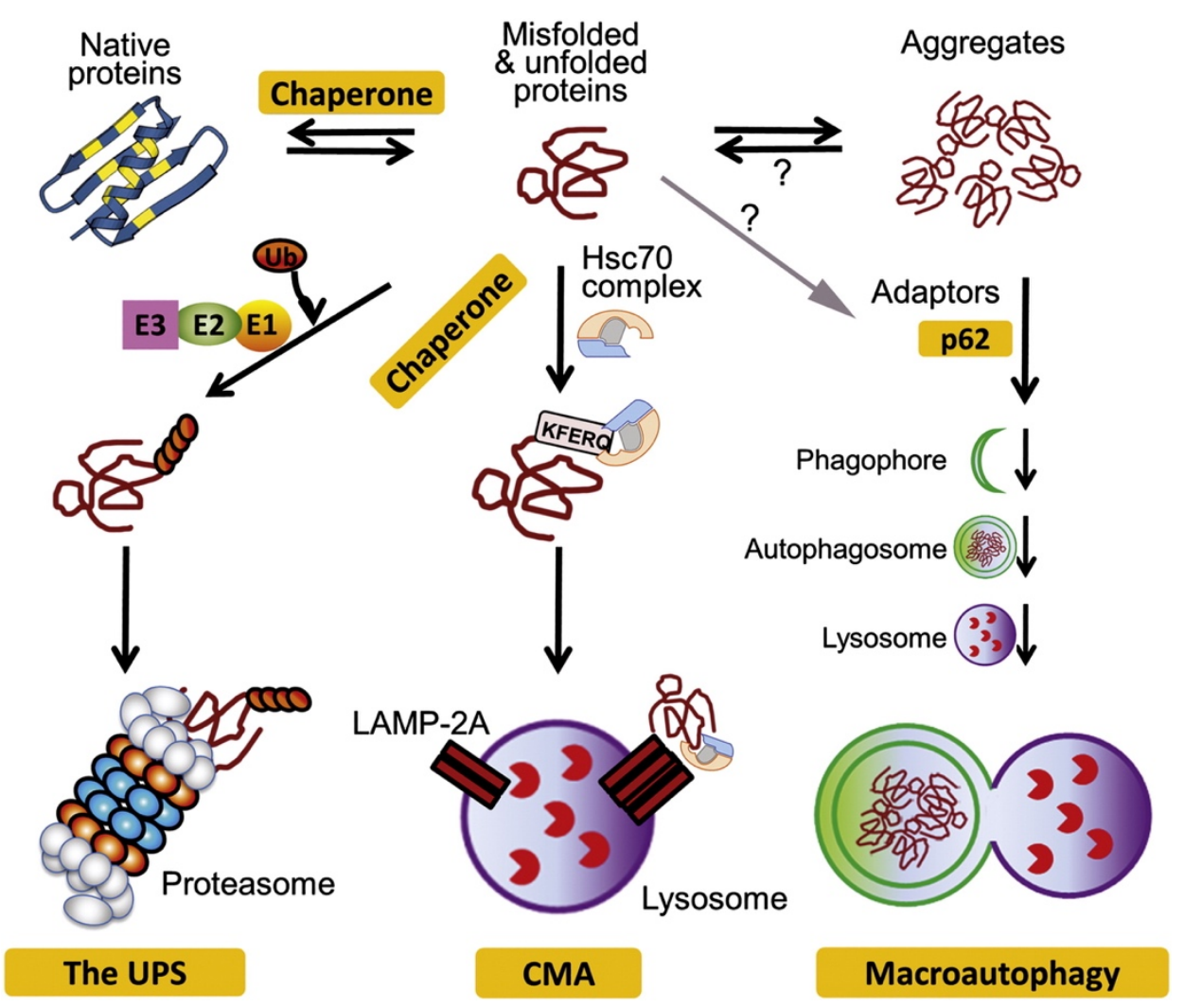

Abb. 2: Illustration der PQC in der Zelle.

Chaperone vermitteln die korrekte Konformation von neuentstehenden oder fehlgefalteten Polypeptiden und leiten die Degradation terminal fehlgefalteter Proteine über das UPS oder CMA ein. Fehlgefaltete Proteine bilden hydrophobe Interaktionen aus, die selektiv durch Makroautophagie degradiert werden können (Wang et al. 2013). Die Verwendung dieser Abbildung erfolgte mit freundlicher Genehmigung der Zeitschrift Circulation Research (Lippincott Williams \& Wilkins).

Vor diesem Hintergrund kommt der Aufrechthaltung der Proteinhomöostase durch selektive Proteindegradierung in Kardiomyozyten eine erhebliche Bedeutung zu (Willis und Patterson 2013; Wang und Hill 2015). Die PQC ist von der Zusammenarbeit zwischen korrekter Proteinfaltung, die hauptsächlich durch molekulare Chaperone vermittelt wird, und gezielter Proteolyse, die durch das UPS und die Autophagie vermittelt wird, abhängig. 


\subsubsection{Hitzeschockproteine - ein Überblick}

Molekulare Chaperone sind eine Klasse von Proteinen, die im Verbund die Faltung von neusynthetisierten Proteinen unterstützen, die korrekte Neufaltung von denaturierten Proteinen durchführen oder terminal fehlgefaltete Proteine dem Proteasom zuführen. Mitglieder dieser Proteinfamilien werden oft als Stressproteine oder Hitzeschockproteine (HSPs) bezeichnet, da sie unter Stressbedingungen, bei denen die Konzentrationen von aggregationsanfälligen Faltungsintermediaten zunehmen, hochreguliert werden.

HSPs nehmen eine bedeutende Rolle in der Proteinhomöostase ein und werden als Antwort der Zelle auf stressreiche Bedingungen, einschließlich verschiedener Virusinfektionen (Collins und Hightower 1982; La Thangue und Latchman 1988), Exposition von Schwermetallen wie Natriumarsenat (Li 1983) oder Cadmium (Li und Laszlo 1985), vermehrt exprimiert (Ellis und van der Vies 1991; Mathew und Morimoto 1998). HSPs wurden erstmalig 1962 vom italienischen Genetiker Ferrucio Ritossa in Drosophila-Fliegen als Proteine identifiziert, die unter metabolischem Stress (2,4-Dinitrophenol) oder erhöhten Temperaturen akkumulierten (Ritossa 1962). HSPs sind weitläufig in den meisten Zellen von Prokaryonten und Eukaryonten konstitutiv exprimiert (Vos et al. 2008). Im Herzen kommt es unter anderem in hypoxischen bzw. ischämischen Situationen ebenfalls zu einer vermehrten Expression diverser HSPs, darunter HSP70 (Mestril et al. 1994), HSP60 (Hammerer-Lercher et al. 2001) und HSP27 (Efthymiou et al. 2004). Unter physiologischen, „ungestressten“ Bedingungen unterstützen sie neu synthetisierte Polypeptide bei der korrekten Faltung. Als „Stress-Proteine“ (Whitley et al. 1999) assistieren sie bei der Wiederherstellung denaturierter Proteine bzw. fördern deren Abbau und nehmen damit die Funktion molekularer Chaperone ein (Whitley et al. 1999; Frydman 2001; Walter und Buchner 2002; Borges und Ramos 2005).

Gemäß ihrem Molekulargewicht und dem Grad struktureller Ähnlichkeit werden Hitzeschockproteine in verschiedene Klassen eingestellt. Unter anderem in kleine HSPs (25-28 kDa), HSP40 (40 kDa), HSP60 (60 kDa), HSP70 (68-80 kDa), HSP90 (83-99kDa) und HSP110 (110kDa) (Vos et al. 2008; Jee 2016).

In Kardiomyozyten kommen Chaperone in hoher Anzahl vor und sind dort teilweise spezifisch mit Proteinen des kontraktilen Apparats assoziiert. Das Hitzeschockprotein B5 ( $\alpha$ BCrystallin) ist mit Desmin assoziiert und verhindert dessen Fehlfaltung und Aggregation. Mutationen von Desmin oder $\alpha$ B-Crystallin können in einer arrhytmogenen, rechtsventrikulären Kardiomyopathie münden (Wang et al. 2001; Wang et al. 2003; Lorenzon et al. 2013), wohingegen Mutationen in Myosin, das mit dem Chaperon UNC-45 in Verbindung steht (Barral et al. 2002), eine hypertrophe oder dilatative Kardiomyopathie bedingen können 
(Maron et al. 2006; Melkani et al. 2011; Czepluch et al. 2018). Daher wirken Hitzeschockproteine an der Proteastase in der Zelle mit und modulieren die Proteintoxizität (Brehme und Voisine 2016).

\subsubsection{Die HSP110-Familie}

Mehrere zytosolische Isoformen werden der HSP110-Familie zugeordnet, darunter HSPH1, HSPA4 und HSPA4L (Mukai et al. 1993; Kaneko et al. 1997b; Kaneko et al. 1997a). Die Isoform Grp170 wurde am endoplasmatischen Retikulum lokalisiert (Easton et al. 2000). Trotz einer hohen Homologie in der Aminosäurenabfolge, gemittelt über alle Mitglieder der HSP110-Familie zu HSP70 in Höhe von 27\%, lassen sich funktionelle Unterschiede zu HSP70 identifizieren (Yakubu und Morano 2018). Allen Mitgliedern der Familie ist gemein, dass sie als Nukleotidaustauscher für HSP70 fungieren (s.1.2.2) (Andréasson et al. 2008). HSPA4L wird vorwiegend in testikulären Keimzellen exprimiert und nimmt eine bedeutende Rolle in der Spermatogenese und Fertilisation ein. Untermauert wird dies durch Studien von Held et al. der 2006 zeigen konnte, dass männliche HSPA4L ${ }^{-/-}$-KO-Mäuse eine erhöhte Rate apoptotischer Spermatozyten und eine beeinträchtigte Spermienmotilität aufwiesen (Held et al. 2006; Held et al. 2011). HSPH1 ${ }^{-/}-$KO-Mäuse sind mit zerebraler Tauopathie und einer Neurodegeneration vergesellschaftet, die eine neuroprotektive Rolle von HSPH1 in zerebralen Tauopathien stützen (Eroglu et al. 2010).

\subsubsection{Physiologische Rolle des Hitzeschockproteins A4}

Erstmals wurde das Gen für das Hitzeschockprotein A4 (HSPA4) 1997 durch Klonierung aus einer murinen cDNA-Bibliothek isoliert (Kaneko et al. 1997b). In der Maus wurde das Gen auf Chromosom 11 der Region B1.3 lokalisiert und besteht aus 19 Exons, welche für 841 Aminosäuren kodieren (Kaneko et al. 1997b; Nonoguchi et al. 1999). Das humane HSP70RY weist in der Aminosäurenabfolge eine 94\%ige Homologie zum murinen HSPA4 auf, welches sich durch eine verlängerte Sequenz von 140 Aminosäuren am C-Terminus auszeichnet. Aufgrund des Molekulargewichts von $94,1 \mathrm{kDa}$ und einer Übereinstimmung der Aminosäurensequenz von 63\% bzw. 60\% verglichen mit anderen HSP110-Mitgliedern wie HSPA4L bzw. HSP110, zählt das murine HSPA4 zur HSP110-Familie (Kaneko et al. 1997a; Kaneko et al. 1997b; Vos et al. 2008). HSPA4-mRNA-Replikate finden sich in den meisten Geweben, mit der höchsten Expression in Milz, Ovarien und Hoden (Kaneko et al. 1997a; Kaneko et al. 1997b; Xue et al. 1998; Nonoguchi et al. 1999). Entgegen der meisten Hitzeschockproteine führt eine Temperaturerhöhung nicht zu einer kompensatorischen Hochregulation von HSPA4, wohingegen saurer $\mathrm{pH}$ und radioaktive Strahlung eine verstärkte 
Expression von HSPA4 bewirken (Kaneko et al. 1997b; Nonoguchi et al. 1999; Kang et al. 2002; Rafiee et al. 2006). Zudem führt eine zerebrale Ischämie in pyramidalen Neuronen im Hippocampus von Ratten zu einer reaktiven Erhöhung von HSPA4, das vermehrt von reaktiven Astrozyten gebildet wird (Yagita et al. 1999; Koh et al. 2000; Kim et al. 2001; Lee et al. 2002). Sowohl im Zebrafisch als auch in Mausmodellen führen entzündliche Darmerkrankungen zu einer Hochregulation von HSPA4, wobei diese eine verstärkte Expression von anti-apoptotischen Proteinen wie Bcl-2 und IL-17 initiiert, die mit einer verminderten Ansprechrate auf Steroide und dadurch verlängerten Heilung assoziiert ist (Crawford et al. 2011; Adachi et al. 2015; Sakurai et al. 2015). Ergänzend führt eine verstärkte Expression von HSPA4 in Gastritiden zu einer verlängerten Heilung (Park et al. 2015; Sakurai et al. 2015). Eine erhöhte HSPA4-Expression wurde zudem in kolorektalen Karzinomen und in hepatozellulären Karzinomen (HCC) gemessen, die in HCCs mit einer früheren Rezidivrate vergesellschaftet waren (Yang et al. 2015).

Mohamed et al. konnten 2012 zeigen, dass eine Nachlasterhöhung sowohl in einem transverseaortic-contriction-Mausmodell (TAC) als auch in Patienten mit Aortenklappenstenose eine kompensatorische HSPA4-Erhöhung induziert, wohingegen eine erhöhte Vorlast im Rahmen eines Shunt-Mausmodells zu keiner Veränderung des HSPA4-Expressionsmusters führte. Dies zeigte erstmalig auf, dass Nachlast einen wichtigen Induktor für die HSPA4Expression in Kardiomyozyten darstellt und eine ähnliche Funktion in murinen und humanen Kardiomyozyten einnimmt. Weiterhin entwickelte sich in HSPA4 ${ }^{-/-}-\mathrm{KO}-\mathrm{Mäusen} \mathrm{eine}$ konzentrische Hypertrophie (Größenzunahme der Herzmuskelzellen) mit einer Fibrosierung einhergehend mit einer Akkumulation von ubiquitinierten Proteinen und erhöhten mRNAWerten kardialer Hormone, wie dem atrialen natriuretischen Peptid (ANP) und dem B-natriuretischen Peptids (BNP), verglichen mit $\mathrm{HSPA}^{+/+}-$Mäusen.

Die Wirkung von ANP und BNP zielt auf eine Verringerung der Vor- und Nachlast durch ihre natriuretische und diuretische Wirkung an der Niere ab (Atlas und Maack 1987; Jensen et al. 1998) und dient unter anderem als Marker für hypertrophierende Kardiomyozyten (Holtwick et al. 2003). Auch zeigten HSPA4 ${ }^{-/-}$-KO-Mäuse keine kompensatorische Hochregulation von an der Proteinfaltung beteiligten Hitzeschockproteinen, darunter HSPA4L, HSPAH1 und HSP70. Als Antwort auf eine Nachlasterhöhung mittels TAC verschärfte sich die Hypertrophie sowie das kardiale Remodeling in Knockout-Mäusen, gemessen sowohl an ANP- bzw. BNP-Werten als auch Fibrosemarkern (Col1 $\alpha 1$, Col3 $\alpha 1$ and Tgf $\beta 1)$ verglichen zu Wildtypmäusen (Mohamed et al. 2012). Weiterhin fand sich eine erhöhte Aktivität von pro-hypertrophen Signalwegen darunter dem Calcineurin-NFAT-Signalweg, dem gp130- 
STAT3-Signalweg und der $\mathrm{Ca}^{2+} /$ Calmodulin-abhängigen-Kinase II, die unmittelbar am kardialen Remodeling in $\mathrm{HSPA} 4^{-/-}-\mathrm{KO}-\mathrm{Mäusen}$ beteiligt sind.

\subsubsection{Molekulare Struktur und Funktion des Hitzeschockproteins A4}

HSP70-Chaperone spielen eine zentrale Rolle in der Proteinfaltung in eukaryotischen Zellen im Komplex mit zwei Co-Chaperonen (HSP40 und HSP110) (Mayer und Bukau 2005; Polier et al. 2008).

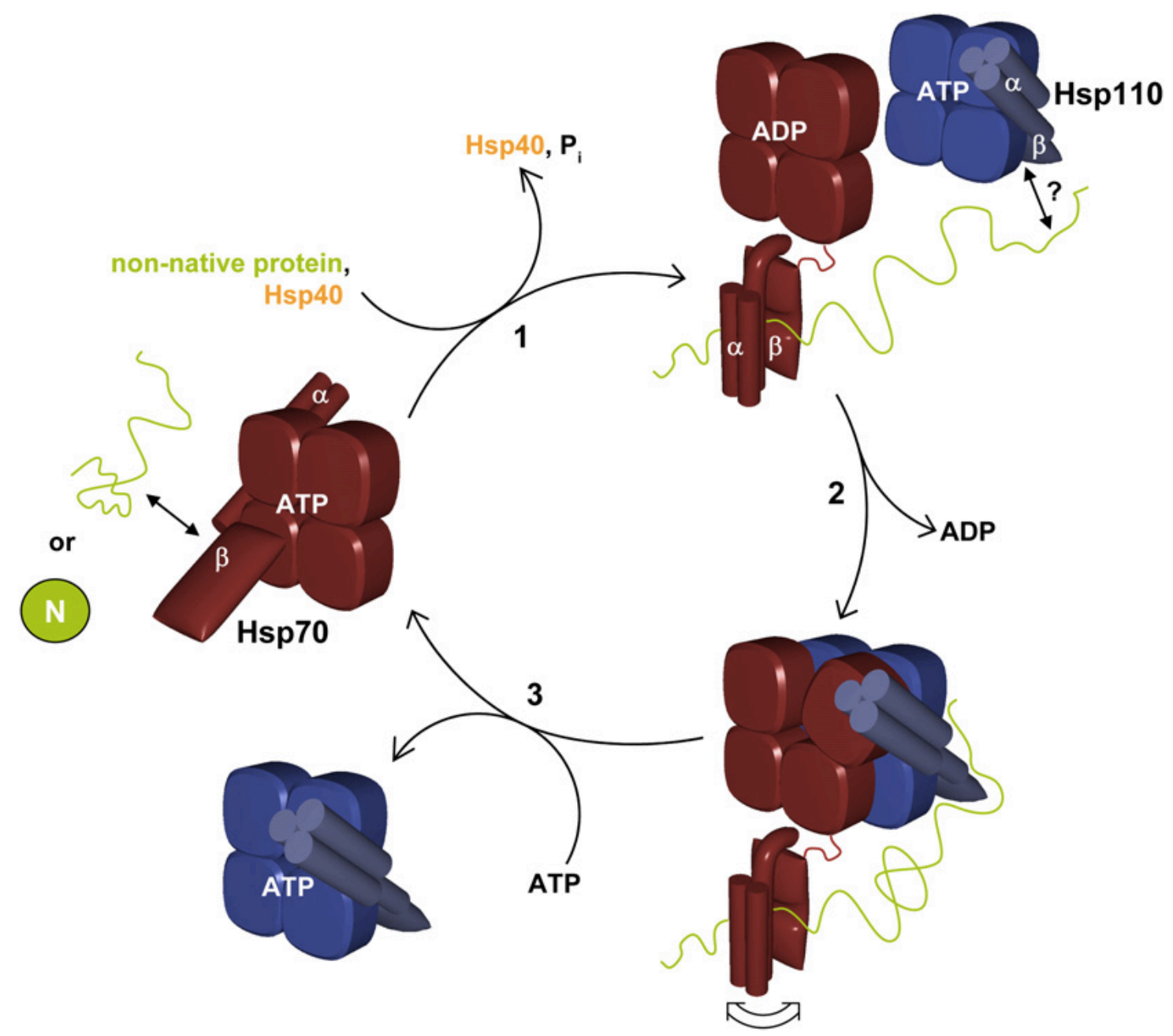

Abb. 3: Modell für die Kooperation von HSP110 und HSP70.

Während HSP40 die ATP-Hydrolyse stimuliert, fungiert HSP110 als Nukleotidaustauschfaktor (Raviol et al. 2006; Schuermann et al. 2008). Eine schematische Darstellung der HSP70-vermittelten Proteinfaltung zeigt Abbildung 1. Neuentstehende bzw. fehlgefaltete Proteine werden erkannt und mithilfe von J-Domänen (HSP40) zu einem HSP70-Komplex rekrutiert. J-Domänen stellen die Verbindung zwischen dem HSP70-Komplex und HSP40 her. Die Verwendung dieser Abbildung erfolgte mit freundlicher Genehmigung der Zeitschrift Cell (Elsevier).

HSP110 und HSP70, die strukturell verwandt sind, bestehen aus einer N-terminalen nukleotidbindenden Domäne (NBD), die über eine flexible Verbindungsregion (linker region) mit 
einer substratbindenden Domäne (SBD) verbunden ist, in der sie sich unterscheiden (Mayer und Bukau 2005; Liu und Hendrickson 2007; Polier et al. 2008; Schuermann et al. 2008).

Im ATP-gebundenen Stadium bindet HSP70 nur mit geringer Affinität an ungefaltete Proteine. Sowohl Substrat-, als auch J-Domänenbindung stellen einen Trigger der ATPHydrolyse dar, die zu einer strukturellen Umlagerung des HSP70-Komplexes führt, die wiederum eine hohe Affinität zum Substrat bewirkt (Mayer und Bukau 2005; Raviol et al. 2006; Polier et al. 2008). Um den Zyklus zu vervollständigen, führt die Bindung von HSP110 an HSP70 zu einer Dissoziation von ADP. Ob in diesem Schritt HSP110 ebenfalls an das Substrat bindet, ist nicht abschließend geklärt. Dieser ternäre Komplex aus Substrat-HSP70HSP110 erleichtert mithilfe der freigewordenen Energie aus der ATP-Hydrolyse die Faltung von Proteinen mit Neigung zu einer intramolekularen Fehlfaltung. Die erneute Bindung von ATP an HSP70 bewirkt die Dissoziation von HSP110 und dem gefalteten Protein (Dragovic et al. 2006; Raviol et al. 2006; Shaner et al. 2006; Polier et al. 2008; Schuermann et al. 2008). Lässt sich ein Protein trotz mehrerer dieser obengenannten Zyklen nicht erneut korrekt falten, interagiert HSP70 unter anderem mit der E3-Ligase carboxyl-terminus of Hsp70 interacting protein (CHIP), die wiederum in direkter Verbindung mit proteolytischen und regulatorischen Proteinen des Proteasoms steht und die Proteasom-vermittelte Degradierung terminal fehlgefalteter Peptide bewirkt (Lüders et al. 2000; McDonough und Patterson 2003; Smith et al. 2013).

\subsubsection{Das Ubiquitin-Proteasom-System}

\subsubsection{Die Ubiquitinierung}

Ubiquitin ist ein kleines, aus 76 Aminosäuren bestehendes Protein, mit einem Molekulargewicht von $8,6 \mathrm{kDa}$, welches ubiquitär in eukaryotischen Zellen vorkommt (Goldstein et al. 1975). Abzubauende Proteine werden in mehreren Schritten mit Ubiquitin markiert, das unter anderem als Erkennungssignal als Substrat für das 26S-Proteasom fungiert und dort proteolytisch aufgespalten wird (Hershko und Ciechanover 1998). Eine schematische Abfolge der Ubiquitinierung und der proteolytischen Degradierung zeigt Abbildung 4. Der Prozess der Ubiquitin-Konjugation an fehlgefaltete Proteine umfasst 3 Schritte, in denen E1-, E2und E3-Enzyme eine entscheidende Rolle spielt.

In einem mehrstufigen Prozess vermitteln diese E1-E3-Enzyme die Ubiquitinierung. Im fakultativen Zusammenspiel mit einer E4-Ligase mit den E1-E3-Ligasen kann das Zielsubstrat polyubiquitiniert werden (Koegl et al. 1999). Die Länge der Ubiquitinkette und die Art der 
Verknüpfung der Ubiquitine miteinander kodiert das Substrat für unterschiedliche Ziele. So dient eine Kette mit vier oder mehr Ubiquitin-Einheiten an der Aminosäure Lysin an Stelle 48 (Lys48), an der Ubiquitin-Moleküle verknüpft sind, als Erkennungssignal für das 26SProteasom, das das Substrat proteolytisch aufspaltet und Ubiquitin recycelt (Pickart 2001; Wójcik 2002). Derzeit sind zwei unterschiedliche E1-, ungefähr 30 E2- und deutlich mehr als 600 E3-Enzyme im menschlichen Genom identifiziert worden, wobei sich letztere durch Substratspezifität auszeichnen (Drews und Taegtmeyer 2014).

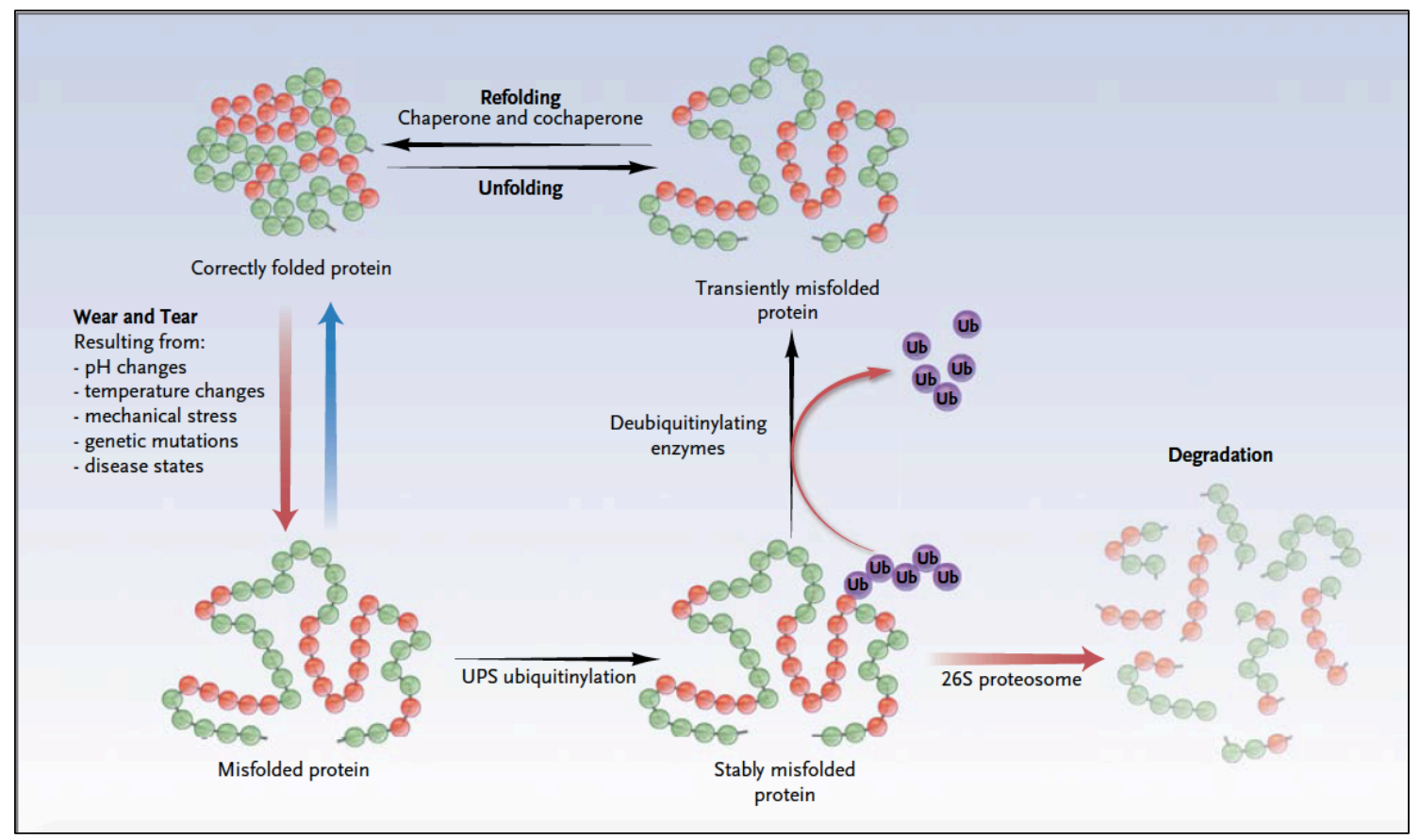

\section{Abb. 4: Zellulärer Stress als Grund für die Proteinfehlfaltung.}

Molekulare Chaperone stabilisieren und falten neu synthetisierte Proteine und spielen eine bedeutende Rolle in der Neufaltung geschädigter Proteine. Terminal fehlgefaltete Proteine werden polyubiquitiniert und via des UPS in kleinere Peptide degradiert (Willis und Patterson 2013). Die Verwendung dieser Abbildung erfolgte mit freundlicher Genehmigung der Zeitschrift New England Journal of Medicine (Massachusetts Medical Society).

Bisher wurden mindestens 9 herzspezifische Ligasen identifiziert (Willis und Patterson 2013), darunter die RING-finger-protein 1 und 3 (MuRF-1 und MuRF-3), die den Abbau spezifischer Proteine des kontraktilen Apparats ( $\beta$-slow-MHC / MHCIIa) via des UPS vermitteln (Fielitz et al. 2007). MuRF-1 ist zudem mit Troponin I am kontraktilen Apparat assoziiert. Interessanterweise ließen sich diese Proteine sowohl nach Phenylephrin (PE) als auch ET-1Inkubation (ET-1) in neonatalen, ventrikulären Kardiomyozyten als kugelförmige Strukturen entlang der Myofibrillen nachweisen (Kedar et al. 2004). Die Autoren um Kedar et al. stellten 
daher die Hypothese auf, dass unter Stimulation mit diesen Substanzen diese kugeligen Strukturen via UPS vermehrt degradiert werden.

\subsubsection{Aufbau und Funktion des Proteasoms}

Das Proteasom besteht aus einer heterogenen Gruppe mehrerer Proteine, die katalytische Untereinheiten miteinander vereinen (Gomes et al. 2006; Drews et al. 2007; Gomes et al. 2009). Hinsichtlich des intrazellulären Proteinabbaus nimmt das Proteasom eine fundamentale Stellung ein, da hierüber ein Großteil der abzubauenden Proteine endoproteolytisch aufgespalten werden (Rock et al. 1994). In Eukaryonten besteht das 26S-Proteasom aus einer 20S- und ein bis zwei 19S-Untereinheiten (Finley 2009; Wehmer et al. 2017).

Die Kernstruktur des Proteasoms nimmt der 20S-Komplex ein. Dieser besteht aus zwei Duplikaten von jeweils $7 \alpha\left(\alpha_{1}-\alpha_{7}\right)$ und $7 \beta\left(\beta_{1}-\beta_{7}\right)$ Einheiten, die sich zu zwei inneren $\beta$ Heptamer-Ringen und zwei äußeren $\alpha$-Hepatmer-Ringen zusammenlagern (Lowe et al. 1995; Groll et al. 1997). Dadurch ähnelt die Form der 20S-Untereinheit einem hohlen Zylinder, in dessen Inneren vom Zytosol abgeschirmt die regulierte Proteolyse stattfindet (Murata et al. 2009). Als Deckel liegen mit regulatorischer Funktion auf einer oder auf beiden Seiten 19SUntereinheiten dem 20S-Komplex an. Mit der durch die Hydrolyse von ATP freiwerdenden Energie wird der $\alpha$-Ring der 20S-Einheit geöffnet und die Substrate entfaltet, da der Innendurchmesser der ungebundenen 20S-Einheit für Proteine mit Tertiärstrukturen zu gering ist (Liu et al. 2006; Smith et al. 2007; Bar-Nun und Glickman 2012). Die im Inneren liegenden $\beta$-Untereinheiten $\beta 1, \beta 2$ und $\beta 5$ besitzen jeweils eine spezifische Proteaseaktivität. So spaltet die B1-Untereinheit die Peptidkette nach sauren Aminosäuren (Caspase-ähnliche Aktivität), die B2-Untereinheit nach basischen Aminosäuren (Trypsin-ähnliche Aktivität) und die B5Untereinheit nach hydrophoben Aminosäuren (Chymotrypsin-ähnliche Aktivität) (Wilk und Orlowski 1983; Orlowski und Wilk 2000). Die Substrate werden in kleine Peptide gespalten, wohingegen mittels 19S-assoziierten DUBs Ubiquitin recycelt wird (Wójcik 2002; Hanna et al. 2007).

\subsubsection{Chaperonvermittelte Autophagie}

Neben dem UPS stellt die Autophagie den zweiten wesentlichen Abbauweg von fehlgefalteten Proteinen dar (Eskelinen und Saftig 2009). Die Autophagie umfasst drei Abbauwege. Erstens den Prozess der Makroautophagie, über den vorwiegend Zellorganellen abgebaut werden. Wie beim UPS werden zu degradierende Proteine durch E3-Ligasen polyubiquitiniert. Die Ubiquitinierung an Lys63 kodiert zum Beispiel für eine lysosomale Degradierung 
(Welchman et al. 2005). Spezifische Proteine, wie das ubiquitinbindende Protein p62, binden an die K63-markierten Proteine (Kraft et al. 2010) und interagieren mit dem Protein LC3 (Bjørkøy et al. 2005; Shvets et al. 2008), welches mit einer Doppelmembran verbunden ist. Durch die Interaktion zwischen p62 und LC3 werden die zu degradierenden Zellorganellen oder Proteine von der Doppelmembran überzogen. Diesen entstehenden Komplex nennt man Autophagosom. (Mizushima et al. 2002). Dieser fusioniert mit Lysosomen, die den Inhalt mittels saurer lysosomaler Hydrolasen abbauen und die Bestandteile recyceln (Noda et al. 2002; McLendon und Robbins 2015). Im Gegensatz dazu beruht die Mikroautophagie auf direkter Fusionierung zwischen abzubauenden Proteinen und Lysosomen. Im Zentrum der chaperonvermittelten Autophagie steht HSP70 (Chiang et al. 1989). Eine schematische Darstellung der chaperonvermittelten Autophagie zeigt Abbildung 5. Die über diesen Weg abzubauenden Proteine zeichnen sich durch eine spezifische Aminosäurensequenz aus, bspw. dem pentameren KFERQ-Motiv (Dice 1990). HSP70 erkennt dieses Motiv und bindet selektiv an das Zielprotein. Der Komplex bestehend aus Substratprotein und Chaperon bindet an den in der lysosomalen Membran assoziierten lysosome-associated membrane protein type $2 \mathrm{~A}$ Rezeptor (LAMP-2A) (Cuervo und Dice 1996).

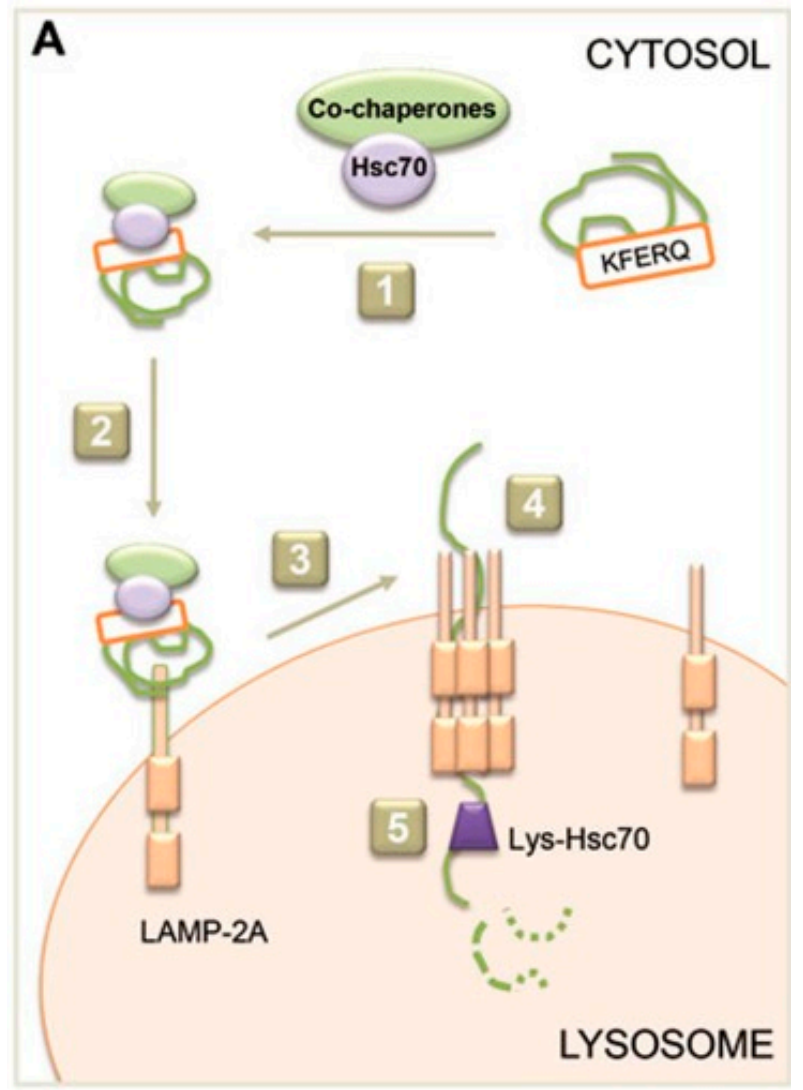
Abb. 5: Einzelne Schritte der chaperon- vermittelten Autophagie.
(1) Proteine werden mittels einer spezifi- schen Aminosäurensequenz erkannt und binden an HSP70. (2) Der Substrat-HSP70- Komplex interagiert mit dem zytosolisch ge- legenen Teil des LAMP-2A-Rezeptors, (3) der durch Bindung einen multimeren Translokationskomplex ausbildet. (4) Das Substrat wird entfaltet und passiert die lyso- somale Membran. (5) Im Lysosom bindet das entfaltete Substrat an das lys-HSP70 und wird proteolytisch degradiert (Cuervo und Wong 2014). Die Genehmigung erfolgte mit freundlicher Genehmigung von Cell Rese- arch (Nature Publishing Group).

Um das Substrat durch den Rezeptor zu internalisieren, muss es unter Zuhilfenahme von HSP70 in Verbindung mehrerer mit der lysosomalen Membran assoziierten Co-Chaperonen, 
wie HSP40, entfaltet werden (Salvador et al. 2000). Die Bindung zwischen Substrat und LAMP-2A initiiert einen Konformationswechsel mehrerer LAMP-2A-Rezeptoren, die einen multimeren Komplex ausbilden, in dessen Inneren ein Translokationskomplex entsteht (Bandyopadhyay et al. 2008). Durch diesen kann das entfaltete Substrat in das Lysosom überführt werden. Im Inneren bindet das Substrat an das lysosomale HSP70 (Agarraberes et al. 1997), das dessen Rücktransport ins Zytosol verhindert. Nach erfolgter Translokation des Substrats bilden sich wieder monomere LAMP-2A-Rezeptoren, an deren zytosolisch gelegener Teil erneut ein Substrat-Chaperon-Komplex binden kann. Im Inneren von Lysosomen herrscht ein saurer $\mathrm{pH}(\mathrm{pH}: 4,5$ - 5,0) vor, der ein optimales Umfeld für diverse Proteasen bietet (Mindell 2012). Diese lysosomalen Proteasen degradieren das Substrat nach der Translokation rasch. (Cuervo und Wong 2014). 


\subsection{Zielsetzung der Arbeit}

Das übergeordnete Ziel ist es einen neuen kardioprotektiven Kandidaten gegen toxische Proteinaggregate zu identifizieren. Die Studie von Mohamed et al. identifizierte 2012 Nachlast als wichtigen Induktor für die HSPA4-Expression in humanen und murinen Kardiomyozyten. Weiterführend akkumulierten in $\mathrm{HSPA}^{-/-}-\mathrm{KO}-\mathrm{Mäusen}$ ubiquitinierte Proteine gepaart mit erhöhten Stresswerten wie ANP bzw. BNP. HSPA4 scheint daher eine wichtige Rolle in der PQC einzunehmen.

Isolierte, ventrikuläre Kardiomyozyten sind ein etabliertes Zellkulturmodell, um mittels siRNA-vermittelter Herunterregulation oder adenoviraler Überexpression die Rolle spezifischer Proteine zu untersuchen (Peter et al. 2016). Kardiomyozyten können mit PE oder ET1 stimuliert werden, um eine pathologische Hypertrophie zu induzieren (Yamazaki et al. 1996; Zobel et al. 2002).

In dieser Doktorarbeit sollen daher folgende Fragestellungen unter Verwendung ventrikulärer Kardiomyozyten neonataler Ratten (NRCM) geklärt werden:

Etablierung eines Zellkulturmodells mit isolierten, ventrikulären Kardiomyozyten neonataler Ratten. Sind PE und ET-1 geeignete Stimulanzien um in NRCM eine kompensatorische HSPA4-Hochregulation zu erzielen? Die HSPA4-Expression wird mittels Western Blot und rt-PCR evaluiert.

Wie wirkt sich die Überexpression von HSPA4 auf die Menge ubiquitinierter Proteine unter Stimulation mit PE oder ET-1 im Western Blot aus? HSPA4 soll mittels adenoviraler Transduktion in ventrikulären Kardiomyozyten neonataler Ratten überexprimiert werden und mit PE bzw. ET-1 eine Hypertrophie induziert werden. Weiterhin soll die zelluläre Antwort auf die Stimulation mittels der Marker für hypetrophierende Kardiomyozyten ANP und BNP in der rt-PCR gemessen werden.

Mittels Immunfluoreszenz-Mikroskopie wird die Zellgrößen-Zunahme unter Stimulation betrachtet. Durch die Messung der Fluoreszenzintensität soll ein Rückschluss auf die Gesamtproteinsynthese in den Kardiomyozyten gezogen werden. Verhindert eine HSPA4Überexpression die PE- oder ET-1-induzierte Hypertrophie? 
Mohamed et al. nutzten eine globale HSPA4 $4^{-1-}-\mathrm{KO}-$ Maus. Um die kardiomyozytenspezifische Herunterregulation von HSPA4 zu charakterisieren, wird mit einer siRNA-vermittelten Transfektion eine Herunterregulation von HSPA4 in Kardiomyozyten erzielt und diese ebenfalls mit PE bzw. ET-1 stimuliert. Welchen Einfluss hat die HSPA4-Herunterregulation auf die Akkumulation ubiquitinierter Proteine? Welchen Einfluss hat die Herunterregulation von HSPA4 auf die PE oder ET-1-induzierte Hypertrophie-Entwicklung? Wie verändern sich die Hypertrophie-Marker ANP und BNP unter Herunterregulation von HSPA4 und Stimulation mit PE oder ET-1? 


\section{Material \& Methoden}

\subsection{Material}

\subsubsection{Chemikalien und Reagenzien}

\section{Chemikalien}

1,4-Dithiothreitol

2-Mercaptoethanol

5-Bromo-2'-deoxyuridine (BrdU)

$5 \mathrm{x}$ iScript reaction mix

Acrylamide solution riphorese gel 30

Aldrich Tetramethylethylenediamine (TEMED)

Ammoniumpersulfat (APS)

Aqua i.a.

DAPI Mountain

Dinatriumhydrogenphosphat

DMEM GlutaMAX $1 \mathrm{~g} / \mathrm{L}$ Glucose, pyruvate

DMEM GlutaMAX $4.5 \mathrm{~g} / \mathrm{L}$ Glucose

DMEM GlutaMAX $1 \mathrm{~g} / \mathrm{L}$ Glucose

Dulbecco's phosphatgepufferte Salzlösung (DPBS)

EDTA-Proteaseinhibitor

Endothelin-1 (ET-1)

Ethanol, (70\%)

Fetales Kälberserum (FCS)

PBS

Penicillin/Streptomycin

Phenolrotlösung

Glucose, wasserfrei

Glycin

Ziegenserum

HEPES

\section{Hersteller}

Carl Roth, Karlsruhe

Sigma-Aldrich, München

Sigma-Aldrich, München

Bio Rad Laboratories, München

Carl Roth, Karlsruhe

Merck, Darmstadt

Sigma-Aldrich, München

B.Braun, Melsungen

Vectorlabs, Burlingame

Carl Roth, Karlsruhe

ThermoFisher Scientific, Carlsbad

ThermoFisher Scientific, Carlsbad

Biochrom, Berlin

Invitrogen, Carlsbad

Roche, Mannheim

Enzo LifeScience, Farmingdale

Carl Roth, Karlsruhe

ThermoFisher Scientific, Carlsbad

ThermoFisher Scientific, Carlsbad

ThermoFisher Scientific, Carlsbad

Sigma-Aldrich, München

Merck Milipore, Burlington

Carl Roth, Karlsruhe

ThermoFisher Scientific, Carlsbad

Sigma-Aldrich, München 
Natriumchlorid

HSPA4-siRNA

iQ SYBR Green Supermix

Kaliumchlorid

Lipofectamine RNAiMAX Transfection Reagent

Magermilchpulver

Magnesiumsulfat

Natronlauge

NuPage LDS Sample Buffer

NuPage MOPS SAS Running Buffer (20x)

OptiMem serumreduced Medium

Paraformaldehyd

Phenylephrin (PE)

Phosphataseinhibitor

Ponceau-S-Lösung
Carl Roth, Karlsruhe

Origene, Maryland

Bio Rad Laboratories, München

Carl Roth, Karlsruhe

ThermoFisher Scientific, Carlsbad

Carl Roth, Karlsruhe

Carl Roth, Karlsruhe

Merck, Darmstadt

Invitrogen, Carlsbad

Invitrogen, Carlsbad

ThermoFisher Scientific, Carlsbad

ThermoFisher Scientific, Carlsbad

Sigma-Aldrich, München

Roche, Mannheim

Sigma-Aldrich, München

Precision Plus Blue (250-10 kDA) All Blue Standards Bio Rad Laboratories, München

Radioimmunoprecipitation Lysis Buffer (RIPA) Merck Milipore, Burlington

Rat Tail No.1 - Kollagen

Corning, Corning

Rhodamine Phalloidin

ThermoFisher Scientific, Carlsbad

Salzsäure ( $\mathrm{HCl})$

Merck, Darmstadt

Trishydroxymethylaminomethan (TRIS)

Carl Roth, Karlsruhe

Triton X-100

Merck, Darmstadt

Tween 20

Carl Roth, Karlsruhe 


\subsubsection{Verbrauchsmaterialien}

\section{Vebrauchsmaterial}

96-Well PCR-Platten, klar

Auslaufpipette

Falcon (15 mL \& $50 \mathrm{~mL})$

Filterpapier

Nitrocellulosemembran

Objektträger und Deckgläser

Pipettenspitzen

Reaktionsgefäße

Sterilfilter

Zellkulturplatten

Zellschaber

\section{Hersteller}

Sarstedt, Nümbrecht

Ratiolab, Dreieich

BioswissTec, Schaffhausen

Bio Rad Laboratories, München

Bio Rad Laboratories, München

ThermoFisher Scientific, Carlsbad

Sarstedt, Nümbrecht

Eppendorf, Hamburg

Merck-Milipore, Burlington

Greiner Cellstar, Kremsmünster

Sarstedt, Nümbrecht

\subsubsection{Gebrauchsfertige Reaktionssysteme}

\section{Reaktionssystem}

BCA Protein Assay Kit

iScript cDNA synthesis Kit

Luminata $^{\text {TM }}$ Western HRP Substrate

Neonatal Heart Dissociation Kit, mouse and rat

RNeasy MiniKit

\section{Hersteller}

Pierce Biotech., Rockford

Bio Rad Laboratories, München

Merck-Milipore, Burlington

Miltenyi Biotec, Bergisch Gladbach

Quiagen Hilden 


\subsubsection{Lösungen, Medien \& Puffer}

\subsubsection{Lösungen für die Zellisolation}

\begin{tabular}{|c|c|}
\hline Lösung & Zusammensetzung \\
\hline \multirow[t]{7}{*}{ CBFHH (Stammlösung) } & $\mathrm{NaCl} 200 \mathrm{~g} / \mathrm{L} ; 3,42 \mathrm{M}$ \\
\hline & $\mathrm{KCl} 40 \mathrm{~g} / \mathrm{L} ; 0,54 \mathrm{M}$ \\
\hline & $\mathrm{MgSO}_{4} \times \mathrm{H}_{2} \mathrm{O} 20 \mathrm{~g} / \mathrm{L} ; 0,081 \mathrm{M}$ \\
\hline & $\mathrm{KH}_{2} \mathrm{PO}_{4} 6 \mathrm{~g} / \mathrm{L} ; 0,044 \mathrm{M}$ \\
\hline & $\mathrm{Na}_{2} \mathrm{HPO}_{4} \times 2 \mathrm{H}_{2} \mathrm{O} 5,97 \mathrm{~g} / \mathrm{L} ; 0,034 \mathrm{M}$ \\
\hline & Glucose wasserfrei $100 \mathrm{~g} / \mathrm{L} ; 0,56 \mathrm{M}$ \\
\hline & HEPES 47,66 g/L; 0,2 M \\
\hline \multirow[t]{8}{*}{ CBFHH (Gebrauchslösung) } & $405 \mathrm{~mL} \mathrm{H}_{2} \mathrm{O}$ steril, (aqua a.i.) \\
\hline & 20 mL NaCl Stammlösung \\
\hline & $5 \mathrm{~mL} \mathrm{KCl} \mathrm{Stammlösung}$ \\
\hline & $5 \mathrm{~mL} \mathrm{MgSO}_{4} \mathrm{xH}_{2} \mathrm{O}$ Stammlösung \\
\hline & $5 \mathrm{~mL} \mathrm{KH}_{2} \mathrm{PO}_{4}$ Stammlösung \\
\hline & $5 \mathrm{~mL} \mathrm{Na}_{2} \mathrm{HPO}_{4} \times 2 \mathrm{H}_{2} \mathrm{O}$ Stammlösung \\
\hline & $5 \mathrm{~mL}$ Glucose Stammlösung \\
\hline & 50 mL HEPES Stammlösung \\
\hline \multirow[t]{2}{*}{ Percoll Stock } & 40,5 mL Percoll Solution \\
\hline & 4,5 mL 10x PBS \\
\hline \multirow[t]{3}{*}{ Percoll-Gradient Top } & $9 \mathrm{~mL}$ Percoll Stock \\
\hline & $11 \mathrm{~mL} \mathrm{1xPBS}$ \\
\hline & $100 \mu \mathrm{L}$ Phenolrot \\
\hline \multirow[t]{2}{*}{ Percoll-Gradient Bottom } & $13 \mathrm{~mL}$ Percoll Stock \\
\hline & $7 \mathrm{~mL} \mathrm{1xPBS}$ \\
\hline
\end{tabular}




\subsubsection{Medien für die Zellkultur}

\section{Medium}

NKM-Medium

NRCM-Medium ohne FCS

NRCM-Medium mit FCS

NRCM-Medium für siRNA

NRCF-Medium ohne FCS

NRCF- Medium mit FCS

\section{Zusammensetzung}

DMEM GlutaMAX $1 \mathrm{~g} / \mathrm{L}$ Glucose

10\% (v/v) FCS (hitzeinaktiviert)

1\% (v/v) 100x Pen/Strep

DMEM F0415

1\% (v/v) 100x Pen/Strep

$1 \%(\mathrm{v} / \mathrm{v})$ BRDU

DMEM F0415

10\% (v/v) FCS (hitzeinaktiviert)

1\% (v/v) 100x Pen/Strep

$1 \%(\mathrm{v} / \mathrm{v}) \mathrm{BRDU}$

DMEM F0415

$2 \%$ (v/v) FCS (hitze-inaktiviert)

$1 \%(\mathrm{v} / \mathrm{v})$ BRDU

DMEM GlutaMAX $1 \mathrm{~g} / \mathrm{L}$ glucose

1\% (v/v) 100x Pen/Strep

DMEM GlutaMAX $1 \mathrm{~g} / \mathrm{L}$ glucose

10\% (v/v) FCS (hitze-inaktiviert)

1\% (v/v) 100x Pen/Strep 


\subsubsection{Puffer für die SDS-Gelelktrophorese und Western-Blot-Analyse}

\begin{tabular}{|c|c|}
\hline Lösung & Zusammensetzung \\
\hline \multirow[t]{4}{*}{ Lysepuffer für Zellen (RIPA) } & $1 \mathrm{~mL}$ RIPA lysis buffer \\
\hline & 1 Tablette EDTA Proteaseinhibitor \\
\hline & 1 Tablette PhosphoStop \\
\hline & $9 \mathrm{~mL}$ ad $\mathrm{ddH}_{2} \mathrm{O}$ \\
\hline \multirow[t]{4}{*}{ 10x TBS $(2 \ell)$} & $24,4 \mathrm{~g} / \mathrm{L}$ TRIS \\
\hline & $19,24 \mathrm{~g} / \mathrm{L} \mathrm{NaCl}$ \\
\hline & $\mathrm{pH} 7,5(\mathrm{HCl})$ \\
\hline & ad $\mathrm{ddH}_{2} \mathrm{O}$ \\
\hline \multirow[t]{3}{*}{ 1x TBS-Tween Puffer } & 1 Anteil 10xTBS \\
\hline & 9 Anteile $\mathrm{ddH}_{2} \mathrm{O}$ \\
\hline & $0,1 \%(\mathrm{v} / \mathrm{v})$ Tween \\
\hline \multirow[t]{4}{*}{ 1x SDS-Page-Laufpuffer } & $15,1 \mathrm{~g} / \mathrm{L}$ TRIS \\
\hline & $72 \mathrm{~g} / \mathrm{L}$ Glycin \\
\hline & $10 \mathrm{~g}$ SDS \\
\hline & $\mathrm{pH} 8,3(\mathrm{NaOH})$ \\
\hline \multirow[t]{3}{*}{$5 \mathrm{x}$ Transferpuffer } & $19,7 \mathrm{~g} / \mathrm{L}$ TRIS \\
\hline & $72 \mathrm{~g} / \mathrm{L}$ Glycin \\
\hline & $\mathrm{pH} 8,3(\mathrm{NaOH})$ \\
\hline \multirow[t]{3}{*}{ 1x Transferpuffer } & 1 Teil 5x Transferpuffer \\
\hline & 1 Teil Methanol \\
\hline & 3 Teile $\mathrm{ddH}_{2} \mathrm{O}$ \\
\hline \multirow[t]{2}{*}{ 5\% Magermilch } & $5 \%(\mathrm{w} / \mathrm{v})$ Magermilchpulver \\
\hline & ad TBS-Tween \\
\hline \multirow[t]{2}{*}{ 1\% Magermilch } & $1 \%(\mathrm{w} / \mathrm{v})$ Magermilchpulver \\
\hline & ad TBS-Tween \\
\hline
\end{tabular}




\subsubsection{Tiere}

Tier

Wistar-Kyoto Ratten P0-P3

\section{Bezugsquelle}

Zentrale Tierexperimentelle Einrichtung,

Universitätsmedizin Göttingen

\subsubsection{Adenoviren}

Adenovirus

Ad-HSPA4

Ad-EGFP

\section{Physikalische Aktivität}

nicht bestimmt

3,10E+10 PFU/mL

\subsubsection{Antikörper}

\subsubsection{Primärantikörper}

\begin{tabular}{|c|c|c|}
\hline Antikörper & Verdünnung & Hersteller \\
\hline Anti-Sarcomeric $\alpha$-Actinin (ab18061) & IF: $1: 500$ & Abcam, Cambridge UK \\
\hline \multicolumn{3}{|l|}{ Monoklonaler AK, Maus } \\
\hline Anti-Ubiquitin (P4D1) & WB: 1:1000 & Santa Cruz, Dallas \\
\hline \multicolumn{3}{|l|}{ Monoklonaler AK, Maus } \\
\hline HSPA4 (Apg-2) (A-7) & WB: 1:2000 & Santa Cruz, Dallas \\
\hline \multicolumn{3}{|l|}{ Monoklonaler AK, Maus } \\
\hline \multicolumn{3}{|l|}{ polyklonaler AK, Kaninchen } \\
\hline GAPDH (AB2302) & WB: 1:10000 & Merck Milipore, \\
\hline Polyklonaler AK, Maus & & Burlington \\
\hline Calsequestrin (PA1-913) & WB: 1:4000 & ThermoFisher Scientific, \\
\hline Polyklonaler AK, Kaninchen & & Waltham \\
\hline
\end{tabular}




\subsubsection{Sekundärantikörper}

\begin{tabular}{|c|c|c|}
\hline Antikörper & Verdünnung & Hersteller \\
\hline $\begin{array}{l}\text { Anti-mouse IgG Horseradish } \\
\text { peroxidase-linked whole }\end{array}$ & WB: 1:10000 & GE Healthcare, Chicago \\
\hline Antibody (from donkey) & & \\
\hline $\begin{array}{l}\text { Anti-mouse IgG Horseradish } \\
\text { peroxidase-linked whole }\end{array}$ & WB: 1:10000 & GE Healthcare, Chicago \\
\hline Antibody (from donkey) & & \\
\hline Alexa Fluor 488 & IF: 1:500 & $\begin{array}{l}\text { ThermoFisher Scientific, } \\
\text { Waltham }\end{array}$ \\
\hline
\end{tabular}

\subsubsection{Software}

\begin{tabular}{lll} 
Software & Hersteller & Verwendung \\
\hline Adobe Illustrator 2015 & Adobe Systems, San Jose & Abbildungen \\
Axiovision SE 64 4.9 & Zeiss, Oberkochen & Fluoreszenzmikroskopie \\
GraphPad Prism (Version7) & GraphPad Software Inc, & Statistische Auswertung \\
ImageJ (Version1.51f) & - & Zellgrößenauswertung \\
ImageLab & bio-rad, Hercules & Densitometrie \\
Xcellence pro & Olympus, Shinjuku & Lebendzell-Mikroskopie \\
Zotero (Version 5.0.12) & Roy Rosenzweig Center & Literaturverwaltung
\end{tabular}




\subsubsection{Geräte}

\section{Gerät}

$-20^{\circ} \mathrm{C}$ Comfort Gefrierschränke

$-80^{\circ} \mathrm{C}$ Ultra-low Gefrierschränke

Autoklav 5075ELV

Axiocam 105 Color

Axiovert 200 Mikroskop

Casy Cell Counter

ChemiDoc XRS+ System

gentleMACS

Heizblock HLC

Inkubator C200

Inkubator MIR-162

Laborwaagen

Mikroskop CM 10 T

Nanodrop 2000c

Power PAC Hd

T100 Thermal Cycler

Transferkammer

VortexGenie 2

XCell SureLock Mini-Cell

Zentrifuge 5804R

\section{Hersteller}

Liebherr, Bulle

Sanyo, Osaka

Tuttnauer, Breda

Carl Zeiss, Oberkochen

Carl Zeiss, Oberkochen

Roche, Mannheim

Bio Rad Laboratories, München

Miltenyi Biotec, Bergisch Gladbach

Dibatis, Aesch

Labotect, Göttingen-Rosdorf

Sanyo, Osaka

Precisa, Dietikon

Olympus, Shinjuku

ThermoFisher Scientific, Waltham

Bio Rad Laboratories, München

Bio Rad Laboratories, München

Bio Rad Laboratories, München

Scientific Industries, Bohemia

ThermoFisher Scientific, Waltham

Eppendorf, Hamburg 


\subsection{Methoden}

\subsubsection{Zellbiologische Methoden}

\subsubsection{Isolation ventrikulärer Kardiomyozyten aus neonatalen Ratten}

Als Grundlage für Experimente in dieser Dissertation wurden isolierte, ventrikuläre Kardiomyozyten neonataler Ratten (NRCM) verwendet, deren Isolation und Kultivierung in der Arbeitsgruppe von Frau Prof. Lutz (Arbeitsgruppenleiterin, Pharmakologie und Toxikologie, Universitätsmedizin Göttingen) etabliert ist. Für die Isolation von ventrikulären -Kardiomyozyten aus neonatalen Ratten wurde das Neonatal Heart Dissociation Kit angewendet.

Die Tiere wurden gemäß den Bestimmungen des Landesamtes für Verbraucherschutz und Lebensmittelsicherheit (LAVES) in der Zentralen Tierexperimentellen Einrichtung (ZTE) gehalten und eine Tötungsanzeige lag vor (Tötungsanzeige: AZ10-13; Projektleiterin: Prof. Dr. Susanne Lutz). Jegliche Oberflächen wurden mit Ethanol (70\%) desinfiziert und alle weiteren Schritte wurden auf Eis ausgeführt. Neonatale Ratten wurden durch Dekapitation getötet. Nach Öffnung des Thorax mittels eines Längsschnitts wurde das Herz mitsamt den anhängenden Gefäßen frei präpariert, extrahiert und in eine 10-cm-Zellkulturschale überführt, welche $4^{\circ} \mathrm{C}$ kalten CBFHH-Puffer mit 1\% Pen/Strep enthielt. Die nachfolgenden Schritte wurden unter einer sterilen Arbeitsbank im S2-Labor durchgeführt. Nach zweimaligem Waschen der Herzen mit CBFHH und dem Entfernen von Vorhöfen und Gefäßen wurden die Ventrikel in kleine Stücke von annähernd $1 \mathrm{~mm}^{3}$ geschnitten. Enzymmix 1 und 2 des Neonatal Heart Dissociation Kit wurden, wie in Tabelle 1 gezeigt, vorbereitet.

Tab. 1: Vorbereitung von Enzymmix 1 und 2 für die Isolierung von 40 neonatalen Rattenkardiomyozyten

\begin{tabular}{c|c|c|c|c|c} 
& \multicolumn{2}{|c|}{ Enzymmix 1 } & \multicolumn{3}{c}{ Enzymmix 2 } \\
\hline $\begin{array}{c}\text { Anzahl von neonatalen } \\
\text { Ratten }\end{array}$ & Enzym P & Puffer X & Puffer Y & Enzym A & Enzym D \\
\hline 40 & & & & & \\
\hline & $125 \mu \mathrm{L}$ & $4600 \mu \mathrm{L}$ & $50 \mu \mathrm{L}$ & $25 \mu \mathrm{L}$ & $200 \mu \mathrm{L}$
\end{tabular}

Enzymmix 1 wurde bei $37^{\circ} \mathrm{C} 5$ min vorgewärmt und zu Enzymmix 2 hinzugegeben und durch mehrmaliges Pipettieren gemischt. Die Ventrikel wurden in ein gentleMACS-C-Tube überführt und $5 \mathrm{~mL}$ des Enzymmixes hinzugefügt. Das C-Tube wurde invertiert und das Gewebe für $15 \mathrm{~min}$ bei $37^{\circ} \mathrm{C}$ inkubiert. Anschließend wurde das C-Tube mit dem gentleMACS Dissociator konnektiert und die Ventrikel mechanisch weiterzerkleinert (Programm: 
h_tumor_03.01). Der Inkubationsschritt und die mechanische Zerkleinerung wurden jeweils viermal wiederholt. Danach wurde die Enzymaktivität durch Zugabe von 7,5-mL $4^{\circ} \mathrm{C}-\mathrm{kaltem}$ NKM-Medium abgestoppt. Die Zellsuspension wurde hiernach auf ein Stahlsieb $(250 \mu \mathrm{M}$ Poren) pipettiert, gesiebt und darauffolgend auf insgesamt $30 \mathrm{~mL}$ NKM-Medium verdünnt. Die verdünnte Suspension wurde bei 1200 rpm für zehn Minuten zentrifugiert, das überstehende Medium abgesaugt und das Zellpellet in $10 \mathrm{~mL}$ PBS mit 1\%Pen/Strep resuspendiert.

\subsubsection{Auftrennung der Zellen mittels Percoll-Gradient}

Die Percoll-Dichte-Zentrifugation ist eine etablierte Methode, um eine Auftrennung zwischen unterschiedlich schweren Zelltypen (Kardiomyozyten, Fibroblasten, Erythrozyten) zu erzielen. Durch vorsichtige Schichtung mehrerer unterschiedlich dichter Lösungen in einem Falcon werden an den Grenzen dieser Lösungen durch einen Zentrifugationsschritt Zellen wie Kardiomyozyten, Fibroblasten und Erythrozyten voneinander getrennt und isoliert. Top- und Bottom-Percoll-Lösung wurde, wie in Tabelle 2 dargestellt, vorbereitet.

Tab. 2: Vorbereitung von Top- \& Bottom-Percoll Stock

\begin{tabular}{c|c|c|c|c}
\multicolumn{3}{c|}{ Top-Percoll Stock } & \multicolumn{2}{c}{ Bottom-Percoll Stock } \\
\hline Percoll Stock & 1x PBS & Phenolrot & Percoll Stock & 1x PBS \\
\hline $9 \mathrm{~mL}$ & $11 \mathrm{~mL}$ & $100 \mu \mathrm{L}$ & $13 \mathrm{~mL}$ & $7 \mathrm{~mL}$
\end{tabular}

In vier $15 \mathrm{~mL}$ Falcons wurden zuerst $4 \mathrm{~mL}$ der Top-Percoll-Lösung pipettiert und dann durch sehr langsames Pipettieren $3 \mathrm{~mL}$ der Bottom-Percoll-Lösung am Boden des Falcons unterschichtet. Pro Falcon wurden $2 \mathrm{~mL}$ der Zellsuspension aus 2.2.1.1 vorsichtig auf den Top-Stock pipettiert und die Falcons bei $1200 \mathrm{rpm} 30$ Minuten bei $20^{\circ} \mathrm{C}$ mit ausgeschalteten Bremsen zentrifugiert (Eppendorf Zentrifuge: 5804R, Rotor: A4-44). Kardiomyozyten wurden so von Nicht-Myozyten wie Fibroblasten bzw. Erythrozyten getrennt und befanden sich nach dem Zentrifugationsschritt in der mittleren Bande zwischen Top- und Bottom-Lösung (Abbildung 6). Die Zelldispersionsschicht sowie die Top-Lösung wurden bis auf einen Zentimeter über der Kardiomyozyten-Bande abgesaugt. Die Kardiomyozyten wurden mit einer weiten Pipette aufgenommen und in vorgewärmtem NRCM-Medium ohne FCS resuspendiert. Es erfolgte ein weiterer Zentrifugationsschritt von fünf Minuten bei $1200 \mathrm{rpm} 20^{\circ} \mathrm{C}$. Das überstehende Medium wurde abgesaugt und das Zellpellet in NRCM-Medium mit 10\% FCS resuspendiert. Die Zellzahl und Vitalität der isolierten Kardiomyozyten in der Lösung wurde mittels eines Casy Cell Counter bestimmt. 


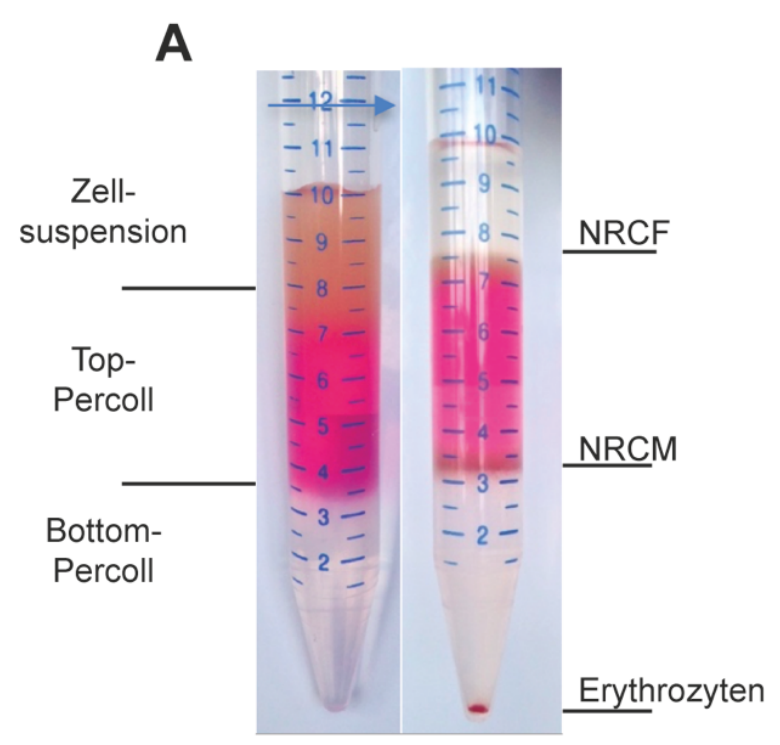

Abb. 6: Percoll-Gradient vor und nach der Zentrifugation. Das Bild zeigt auf der linken Seite die Schichtung der Lösungen vor der Zentrifugation und auf der rechten Seite die Auftrennung in die einzelnen Banden nach dem Zentrifugationsschritt.

Das Messprinzip des Casy Cell Counter beruht auf der elektrischen Erfassung von Zellen, welche eine Messpore durchwandern. Vitale Zellen schließen hier den Stromfluss und erzeugen ein Signal. Tote

Zellen hingegen besitzen keine intakte Zellemembran mehr und schließen den Stromkreis nicht. Diese werden lediglich mit dem Volumen ihres Zellkerns registriert. 12-Well-Platten wurden mit einer 1\%igen Kollagenlösung für zehn Minuten beschichtet, die Kollagenlösung danach abgesaugt und pro Well wurden 200.000 isolierte, ventrikuläre Kardiomyozyten neonataler Ratten in 10\%-FCS-haltigem NRCM-Medium ausplattiert und kultiviert.

\subsubsection{Kultivierung ventrikulärer Kardiomyozyten aus neonatalen Ratten}

Die Kultivierung der Kardiomyozyten erfolgte in Dulbecco's Modified Eagle's Medium (DMEM) mit $1 \mathrm{~g} / \mathrm{L}$ Glucose und 3,7 g/L Natriumhydrogencarbonat. Zudem wurden noch die Antibiotika Penicillin $(10.000 \mathrm{U} / \mathrm{mL})$ und Streptomycin $(10.000 \mu \mathrm{g} / \mathrm{mL})$ und $10 \%$ fetales Kälberserum hinzugefügt. Um ein Überwachsen durch Nicht-Kardiomyozyten, wie Fibroblasten, zu verhindern, wurde Bromdesoxyuridin (BrdU), ein chemisches Analogon des Nukleosids Thymidin, hinzugegeben. Die Zellen wurden nach der Isolation für 24 Stunden in 10\%FCS-haltigem NRCM-Medium bei $37^{\circ} \mathrm{C}$ und $5 \% \mathrm{CO}_{2}$ kultiviert. Hierauf wurden die Zellen mit vorgewärmtem 1x DPBS zweifach gewaschen und das NRCM-Medium mit 10\%-FCS erneuert. Nach weiteren 24 Stunden erfolgte ein wiederholter Spülvorgang mit vorgewärmtem 1xDPBS, um tote und nicht adhärente Zellen zu entfernen. Die Kardiomyozyten wurden auf NRCM-Medium ohne FCS umgestellt.

\subsubsection{Adenovirale Transduktion in isolierten Rattenkardiomyozyten}

$\mathrm{Um}$ in isolierten Kardiomyozyten eine gesteigerte Expression von HSPA4 zu erwirken, wurde ein HSPA4-Adenovirus zum Transfer der HSPA4-DNA in die Zelle unter Kontrolle eines konstitutiv-aktiven Cytomegalie-Virus-Promotors (CMV-Promotor) genutzt (AdHSPA4). Um die adenovirale Transduktionseffizienz bewerten zu können, kodiert der Ad- 
HSPA4 zusätzlich für das enhanced green fluorescent protein (EGFP) als Reportergen. Diese unterliegt einem eigenen ebenfalls konstitutiv-aktiven CMV-Promotor. Das Ad-HSPA4 wurde von Frau Prof. Lutz (Pharmakologie; Universitätsmedizin Göttingen) repliziert, aufgereinigt und freundlicherweise für die Experimente zur Verfügung gestellt.

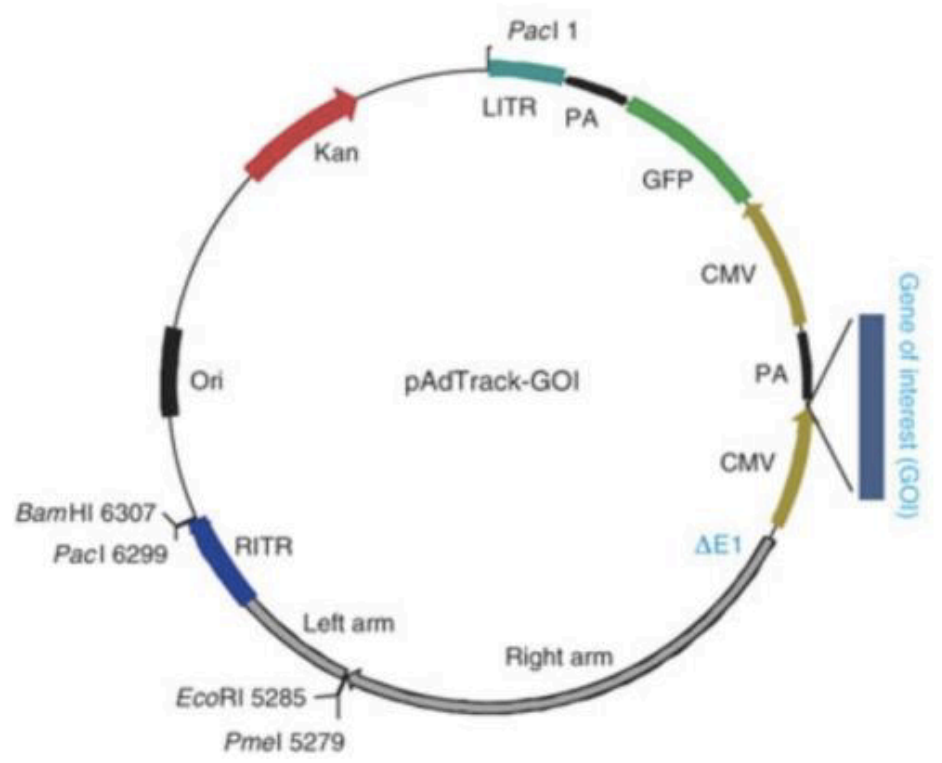
Abb.7: Darstellung des HSPA4-Adenovirus-DNA- Konstrukts. Die HSPA4-DNA wird durch einen CMV-Promotor reguliert. Als Reportergen mit ei- genem CMV-Promotor-Kontrolle kodiert das Virus ebenfalls für EGFP als Fluoreszenzmarker (Mohamed et al. 2012).

\subsubsection{5 siRNA-vermittelte Herunterregulation in isolierten Rattenkardiomyozyten}

Um die Auswirkung der Stimulation mit PE oder ET-1 auf ventrikuläre Kardiomyozyten zu untersuchen, in denen HSPA4 herunterreguliert ist, wurde eine spezifische HSPA4-siRNA (small interfering RNA) genutzt. Die HSPA4-siRNA bestand aus 27 Basenpaaren, die nicht für ein Protein kodieren, sondern sich komplementär an die HSPA4-mRNA anlagert und so die Translation der mRNA in das HSPA4-Protein unterbindet. Zur Transfektion der siRNA in die Kardiomyozyten wurde das Lipofectamin-Transfektionsreagenz verwendet. Dieses kationische Lipid besteht aus einem positiv geladenen Ende und ist mit ein oder zwei Kohlenwasserstoffketten verbunden. Die positiv geladenen Köpfe interagieren mit den negativ geladenen Phosphatgruppen der siRNA. Die positive Oberfläche der sich bildenen Liposomen vermittelt die Fusion des Liposom-siRNA-Komplexes mit der negativ geladenen Zellmembran. Die Lösungen wurden, wie in Tabelle 3 dargestellt, vorbereitet. Beide Lösungen wurden miteinander gemischt, vorsichtig geschüttelt und inkubierten 15 Minuten bei Raumtemperatur. Die Kardiomyozyten wurden zweimalig mit vorgewärmtem PBS gespült und in antibiotikafreies NRCM-Medium mit 2\% FCS überführt. Die Lösung wurde auf die Kardiomyozyten pipettiert und die Zellen für 24 Stunden inkubiert. 
Tab. 3: Vorbereiten der Transfektionslösungen für siRNA-Transfektion von NRCM

\begin{tabular}{c|c|c|c|c} 
& \multicolumn{2}{|c|}{ Lösung 1 } & \multicolumn{2}{c}{ Lösung 2 } \\
\cline { 2 - 5 } & $\begin{array}{c}\text { siRNA } \\
\mathbf{( 1 2} \mathbf{p M})\end{array}$ & Opti-Mem & $\begin{array}{c}\text { Lipofectamine } \\
\text { RNAiMAX }\end{array}$ & Opti-Mem \\
\hline Pro & $1 \mu \mathrm{L}$ & $100 \mu \mathrm{L}$ & $2 \mu \mathrm{L}$ & $100 \mu \mathrm{L}$
\end{tabular}

\subsubsection{Proteinbiochemische Methoden}

\subsubsection{Proteinextraktion und Konzentrationsbestimmung}

Isolierte, ventrikuläre Kardiomyozyten wurden nach jeweiliger Inkubation mit den Stimulanzien zweimalig mit vorgewärmtem DPBS gespült. Danach wurden die Zellen in eiskaltem RIPA-Puffer, zu welchem ein Protease- und Phosphataseinhibitor gegeben wurde, lysiert. Mittels eines Zellschabers wurden die Zellen vollständig von den Platten gelöst und jeweils in ein Tube auf Eis pipettiert. Zur Quantifizierung der Proteinmenge wurde das Pierce Protein Assay Kit gemäß den Herstellerangaben genutzt.

Die zugrundeliegende Biuret-Reaktion reduziert $\mathrm{Cu}^{2+} \mathrm{zu} \mathrm{Cu}^{1+}$ durch Bindung von $\mathrm{Cu}^{2+}$ an Proteine in alkalischem Medium, woraufhin der Kupfer-Proteinkomplex mit Bicinchoninsäure (BCA) bindet und sich ein violetter Farbkomplex bildet. Dieser Farbkomplex besitzt ein Absorptionsmaximum bei $562 \mathrm{~nm}$. Je größer die Proteinmenge in der Probe war, desto stärker fiel der Farbumschlag der Reaktion aus.

Es wurden $200 \mu \mathrm{L}$ von Puffer A und $4 \mu \mathrm{L}$ von Puffer B mit $10 \mu \mathrm{L}$ Proteinlösung versetzt. Es folgte ein Inkubationsschritt von $30 \mathrm{~min}$ bei $37^{\circ} \mathrm{C}$.

Mittels eines Nanodrop-2000c-Spektralphotometers wurde bei zwei Wellenlängen (562 nm; normalisiert bei $750 \mathrm{~nm}$ ) die Absorption der jeweiligen Proben gemessen, welche mit der Höhe der Proteinmenge der Probe korrelierte. Die Lagerung der in RIPA-Puffer gelösten Proteine erfolgte bei $-80^{\circ} \mathrm{C}$.

\subsubsection{SDS-Polyacrylamid-Gelelektrophorese (SDS-PAGE)}

Mittels der SDS-Polyacrylamid-Gelelektrophorese werden Proteine in einem Gel anhand ihres Molekulargewichts in einem elektrischen Feld aufgetrennt. Hierbei fungiert SDS als anionisches Tensid, das die Oberfläche von Proteinen besetzt. Daher korreliert die Menge an gebundenem SDS indirekt über die Ladung mit der Molekülgröße der Proteine. 
Für die Elektrophorese wurden 10\%-Gele verwendet, welche, wie in Tabelle 4 dargestellt, hergestellt wurden:

Tab. 4: Zusammensetzung des Trenn- und Sammelgels für die SDS-Page-Gelelektrophorese

\begin{tabular}{c|c|c} 
& Trenngel & Sammelgel \\
\hline Polyacrylamid & $6,58 \mathrm{~mL}$ & $830 \mu \mathrm{L}$ \\
\hline ddH2O & $8,20 \mathrm{~mL}$ & $2,86 \mathrm{~mL}$ \\
\hline TRIS/SDS pH 8,8 /pH 6,8 & $5,00 \mathrm{~mL}$ & $1,25 \mathrm{~mL}$ \\
\hline APS 10\% (w/v) & $200 \mu \mathrm{L}$ & $50 \mu \mathrm{L}$ \\
\hline TEMED & $20 \mu \mathrm{L}$ & $10 \mu \mathrm{L}$ \\
\hline & $20 \mathrm{~mL}$ & $5 \mathrm{~mL}$
\end{tabular}

Das in RIPA-Puffer gelöste Zelllysat wurde mit einem NuPage-LDS-Sample-Puffer und 5\% 1,4-Dithiothreitol (DTT) versetzt. 1,4-DT'T sorgt durch Reduktion von Protein-Disulfidbrücken für deren Spaltung. Vor dem Auftragen in die Geltaschen wurden die Proben fünf Minuten bei $95^{\circ} \mathrm{C}$ denaturiert, um Sekundär- und Tertiärstrukturen aufzubrechen. Für weitere fünf Minuten wurden die Proben auf Eis gelagert und zentrifugiert. Um die Größe der Proteine bestimmen zu können, wurde in einer Tasche ein Proteinmarker (250-10 kDA) aufgetragen. Die Kammer wurde mit einem SDS-Laufpuffer aufgefüllt und die Elektrophorese bei einer Stromstärke von konstant 0,05 A für 1:15 h bis 1:30 h durchgeführt.

\subsubsection{Western Blot}

Nach der Gelelektrophorese wurden die im Gel aufgetrennten Proteine mittels Wet Blot auf eine Nitrocellulosemembran übertragen. Das im Transferpuffer enthaltene Methanol aktiviert die Nitrocellulosemembran und führt mithilfe des an Proteinen gebundenen SDS zu einem effizienteren Transfer. Zu diesem Zweck wurde die Nitrocellulosemembran mit dem Gel zwischen zwei Filterpapiere in eine Halterung einer Blotkammer eingespannt. Die Kammer wurde mit Transferpuffer aufgefüllt, und bei einer konstanten Stromstärke von 0,5 A ließen sich innerhalb von 120 Minuten die Proteine elektrophoretisch auf die Nitrocellulosemembran übertragen. Durch das Anlegen der Spannung wandern die Proteine in Richtung der Anode und werden so auf die Membran transferiert. Um unspezifische Bindungsstellen auf der Membran zu blockieren, wurde in einem Folgeschritt die Membran eine Stunde in 5\% Milchpulver, gelöst in TBS-Tween, inkubiert. Membranen, welche mit dem Anti- 
Ubiquitin-Antikörper inkubiert wurden, wurden vor dem Blockiervorgang 15 min eingebettet zwischen zwei Filterpapieren in destilliertem Wasser bei $100^{\circ} \mathrm{C}$ gekocht, gefolgt von einer 15-minütigen Abkühlungsphase auf Eis. Im Anschluss wurde der primäre Antikörper in 1\% Magermilch, gelöst in TBS-Tween, verdünnt und die Membran darin über Nacht bei $4^{\circ} \mathrm{C}$ und mit leichter Bewegung inkubiert. Pro Membran wurden zwischen 2-4 mL Lösung verwendet. Am Folgetag wurde nach zweistündiger Inkubation bei Raumtemperatur der überschüssige Antikörper durch einen dreimaligen Waschvorgang von je zehn Minuten mit TBSTween entfernt. Die sekundären Antikörper, die an das Enzym horseradish peroxidase (HRP) gekoppelt waren, wurden in 1\% Magermilch in TBS-Tween verdünnt und die Membran damit zwei Stunden bei Raumtemperatur inkubiert. In drei weiteren Waschvorgängen von je zehn Minuten mit TBS-Tween wurde der sekundäre Antikörper entfernt. Zur Detektion der Proteinmenge wurde die Membran mit dem Luminata ${ }^{\text {TM }}$ Western HRP Substrates für fünf Minuten inkubiert. Die Peroxidase führt zur Oxidation der Reagenzien, und löst dadurch eine Chemilumineszenz aus. Die Detektion der Chemilumineszenz der Banden erfolgte mittels ChemiDoc XRS+ System. Die densitometrische Messung der einzelnen Banden erfolgte mit dem Programm ImageLab.

\subsubsection{Bestimmung der Genexpression mittel qPCR}

\subsubsection{RNA-Extraktion}

Für die RNA-Extraktion wurde das RNeasy MiniKit der Firma Qiagen genutzt. Für die RNAIsolation wurden jeweils die transfizierten bzw. transduzierten Zellen für die definierte Zeit inkubiert. Hiernach wurden sie einmalig mit kaltem PBS gewaschen und durch Zugabe von $343 \mu \mathrm{L}$ RLT-Puffer, welcher mit $7 \mu \mathrm{L}$ 1,4-DTT (1 M) versetzt wurde, lysiert. Mithilfe eines Zellschabers wurden sämtliche Zellen von den Platten gelöst. Das Zellgemisch wurde in ein Reaktionsgefäß überführt und direkt in flüssigem Stickstoff eingefroren. Das RNeasy Mini Kit vereint zwei Prinzipien der RNA-Isolation. Einerseits die selektive Bindungsfähigkeit von RNA an einer Silicamembran und andererseits die Mircospintechnologie. Pro Tube wurden $350 \mu \mathrm{L} 70 \%$ iger Ethanol hinzugefügt und das Lysat durch mehrmaliges Pipettieren gemischt. Das Gemisch wurde in ein Ready Mini Spine Column Tube, welches mit einem 2-mL-Sammelreaktionsgefäß verbunden war, überführt. Das Gemisch wurde für $15 \mathrm{~s}$ bei $\geq 8000 \mathrm{U} / \mathrm{min}$ zentrifugiert. Durch diesen Schritt wurde die RNA an die Membran gebunden. Die durchgetretene Flüssigkeit wurde verworfen. In einem weiteren Schritt wurden $700 \mu \mathrm{L}$ RW1Puffer auf die Membran pipettiert und $15 \mathrm{~s}$ bei $\geq 8000 \mathrm{U} / \mathrm{min}$ zentrifugiert. Erneut wurde 
der Durchfluss verworfen und auf die Membran $500 \mu \mathrm{L}$ des Waschpuffers RPE pipettiert. Abermals wurde $15 \mathrm{~s}$ bei $\geq 8000 \mathrm{U} /$ min zentrifugiert. Nach weiteren $500 \mu \mathrm{L}$ RPE-Puffer auf die Membran wurde die Membran für zwei Minuten bei $\geq 8000 \mathrm{U} / \mathrm{min}$ zentrifugiert. Um die an die Membran gebundene, isolierte RNA zu eluieren, wurden auf die Membran $30 \mu \mathrm{L}$ RNAse-freies Wasser pipettiert und eine Minute bei $\geq 8000 \mathrm{U} / \mathrm{min}$ zentrifugiert. Um sämtliche RNA aus der Membran zu lösen, wurde der Durchfluss des vorherigen Schritts erneut auf die Membran pipettiert und $1 \mathrm{~min}$ bei $\geq 8000 \mathrm{U} / \mathrm{min}$ zentrifugiert.

Die Messung der RNA-Konzentration der Proben erfolgt mit dem Nanodrop-2000c-Spektralphotometer. Die Lagerung der RNA erfolgte bei $-80^{\circ} \mathrm{C}$.

\subsubsection{2 cDNA-Synthese}

Mit der cDNA-Synthese wird aus der extrahierten RNA (siehe 2.2.3.1) mittels des Enzyms reverse Transkriptase, einer rekombinanten RNA-abhängigen DNA-Polymerase, ihre komplementäre DNA synthetisiert. Oligo(dT) $)_{15}$-Primer, welche aus ca. 15 Thymidin-Nukleotiden bestehen, lagern sich an die $3^{6}$-Enden der Poly $(\mathrm{A})^{+}$-mRNA und bedingen so die spezifische cDNA-Synthese. Es wurden 150 ng RNA mit $4 \mu \mathrm{L}$ 5x iScript reaction mix und $1 \mu \mathrm{L}$ iScript reverse Transcriptase gemischt und mit Nuklease-freiem Wasser auf $20 \mu \mathrm{L}$ verdünnt (siehe Tabelle 5).

Tab. 5: Zusammensetzung der cDNA-Synthese

cDNA-Synthese

\begin{tabular}{l|c}
\hline RNA & 150 ng $(\mu \mathrm{L}$ variiert $)$ \\
\hline $5 \mathrm{x}$ iScript reaction mix & $4 \mu \mathrm{L}$ \\
\hline $1 \mu \mathrm{L}$ iScript reverse Transkriptase & $1 \mu \mathrm{L}$ \\
\hline Nuklease-freies $\mathrm{H}_{2} \mathrm{O}$ & variiert $(\mu \mathrm{L})$ \\
\hline & $20 \mu \mathrm{L}$
\end{tabular}

Die Reaktionsmischung enthielt neben dNTPs, Oligo-dT-Nukleotiden, auch $\mathrm{MgCl}_{2}$. Zudem verhinderte ein RNase-Inhibitor den unerwünschten Abbau der RNA während der Reaktion. Durch die fünfminütige Inkubation bei $25^{\circ} \mathrm{C}$ lagerten sich die Primer an. Während einer weiteren Inkubation von 30 Minuten bei $42^{\circ} \mathrm{C}$ wurde die cDNA synthetisiert. Fünfminütiges Erhitzen auf $85^{\circ} \mathrm{C}$ inaktivierte die reverse Transkriptase und stoppte die Reaktion ab. Die cDNA wurde bei $-20^{\circ} \mathrm{C}$ gelagert. 
Tab. 6: Reaktionsschritte der cDNA-Synthese

\begin{tabular}{c|c|c} 
Schritt & Temperatur & Dauer \\
\hline Anlagerung der Primer & $25^{\circ} \mathrm{C}$ & $5 \mathrm{~min}$ \\
\hline cDNA-Synthese & $42^{\circ} \mathrm{C}$ & $30 \mathrm{~min}$ \\
\hline Inaktivierung & $85^{\circ} \mathrm{C}$ & $5 \mathrm{~min}$
\end{tabular}

\subsubsection{Quantitative Real-time-Polymerase-Ketten-Reaktion}

Die quantitative real-time-Polymerase-Ketten-Reaktion beruht auf dem Mechanismus der konventionellen PCR. Durch diese Methode können spezifische Nukleinsäureabschnitte enzymatisch amplifiziert werden. Die Grundlage hierfür bilden DNA-Polymerasen. Ein Zyklus besteht aus der Denaturierung der doppelsträngigen DNA, dem Anlagern von Primern (sog. Annealing) und der Elongation mithilfe einer hitzestabilen DNA-Polymerase (z.B. taq-Polymerase). Die Polymerase kann in Anwesenheit von kurzen Oligonukleotidsequenzen (sog. Primer) und Desoxyribonukleosidtriphosphaten am 3'-OH-Ende die gewünschten Abschnitte vervielfältigen. Um die Menge der entstehenden DNA-Fragmente quantitativ zu bestimmen, wurde der Fluoreszenz-Marker SYBR Green 1 hinzugegeben. SYBR Green interkaliert in doppelsträngiger DNA und fluoresziert bei Anregung mit grünem Licht der Wellenlänge $\lambda_{\max }=521 \mathrm{~nm}$ bei Bindung mit der DNA. Die gemessenen Werte der untersuchten Gene wurden in Relation auf das Enzym Hypoxanthin-Phosphoribosyl-Transferase 1 (HPRT) normalisiert, um eventuelle Konzentrationsunterschiede, die bei der RNA-Isolation bzw. der cDNA-Synthese entstanden, anzugleichen. Für die Versuche wurden das iTaq Universal One-Step rt-qPCR Kit der Firma Bio-Rad verwendet. Der iQ-SYBR-Green-Supermix enthielt dNTPs, die iTaq-Polymerase, $\mathrm{MgCl}_{2}$ als Stabilisator und SBYR Green. Pro Reaktion wurden $2 \mu \mathrm{L}$ cDNA, $10 \mu \mathrm{L}$ Reaktionmix und jeweils $2 \mu \mathrm{L}$ des Forward und Reverse Primers mit

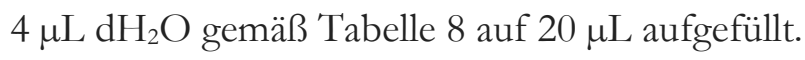


Tab. 7: Zusammenstellung der verwendeten Primer

\begin{tabular}{|c|c|c|c|}
\hline $\begin{array}{l}\text { Bezeich- } \\
\text { nung }\end{array}$ & Oligonukleotidsequenz & $\begin{array}{c}\text { Hybridisierungs- } \\
\text { temperatur }\end{array}$ & Firma \\
\hline $\begin{array}{l}\text { HSPA4- } \\
\text { Forward }\end{array}$ & 5'-CAGGATTTGCCCTATCCA-3' & $57,3^{\circ} \mathrm{C}$ & $\begin{array}{l}\text { Eurofins } \\
\text { Genomics }\end{array}$ \\
\hline $\begin{array}{l}\text { HSPA4- } \\
\text { Reverse }\end{array}$ & $5^{6}$-CTCTACTAAGGCCGCACT-3 & $61,4^{\circ} \mathrm{C}$ & $\begin{array}{c}\text { Eurofins } \\
\text { Genomics }\end{array}$ \\
\hline $\begin{array}{c}\text { ANP- } \\
\text { Forward }\end{array}$ & 5'-GATGGAT'T'TCAAGAACCTGC-3' & $59,4^{\circ} \mathrm{C}$ & $\begin{array}{l}\text { Eurofins } \\
\text { Genomics }\end{array}$ \\
\hline $\begin{array}{l}\text { ANP- } \\
\text { Reverse }\end{array}$ & 5-TTCAAGAGGGCAGATCTATC-3' & $59,4^{\circ} \mathrm{C}$ & $\begin{array}{c}\text { Eurofins } \\
\text { Genomics }\end{array}$ \\
\hline $\begin{array}{c}\text { BNP- } \\
\text { Forward }\end{array}$ & 5- ACAATCCACGATGCAGAAGCT-3' & $58,3^{\circ} \mathrm{C}$ & $\begin{array}{l}\text { Eurofins } \\
\text { Genomics }\end{array}$ \\
\hline $\begin{array}{c}\text { BNP- } \\
\text { Reverse }\end{array}$ & 5'- GGGCCTTGGTCCTTTGAGA-3' & $58,3^{\circ} \mathrm{C}$ & $\begin{array}{c}\text { Eurofins } \\
\text { Genomics }\end{array}$ \\
\hline $\begin{array}{l}\text { HPRT- } \\
\text { Forward }\end{array}$ & 5'-CTTTGCTGACCTGCTGGATT-3' & $57,3^{\circ} \mathrm{C}$ & $\begin{array}{l}\text { Eurofins } \\
\text { Genomics }\end{array}$ \\
\hline $\begin{array}{l}\text { HPRT- } \\
\text { Reverse }\end{array}$ & 5'-CCCGTTGACTGGTCATTACA-3 & $57,3^{\circ} \mathrm{C}$ & $\begin{array}{l}\text { Eurofins } \\
\text { Genomics }\end{array}$ \\
\hline $\begin{array}{l}\text { GAPDH- } \\
\text { Forward }\end{array}$ & 5'-AGACAGCCGCATCT'TCT'TGT-3' & $60,2^{\circ} \mathrm{C}$ & $\begin{array}{l}\text { Eurofins } \\
\text { Genomics }\end{array}$ \\
\hline $\begin{array}{l}\text { GAPDH- } \\
\text { Reverse }\end{array}$ & 5'-CTTGCCGTGGGTAGAGTCAT-3' & $60,2^{\circ} \mathrm{C}$ & $\begin{array}{c}\text { Eurofins } \\
\text { Genomics }\end{array}$ \\
\hline
\end{tabular}

Tab. 8: Zusammensetzung der rt-PCR

Zusammensetzung der rt-PCR

\begin{tabular}{l|c}
\hline cDNA & $2 \mu \mathrm{L}$ \\
\hline iQ SYBR Green Supermix & $10 \mu \mathrm{L}$ \\
\hline Forward Primer & $2 \mu \mathrm{L}$ \\
\hline Reverse Primer & $2 \mu \mathrm{L}$ \\
\hline Nuklease-freies $\mathrm{H}_{2} \mathrm{O}$ & $4 \mu \mathrm{L}$ \\
\hline & $20 \mu \mathrm{L}$
\end{tabular}


Die pipettierte 96-well-Platte wurde mit einer Folie abgedichtet, im Cycler-iQ5-MulticolorRealtime-PCR-Detection-System adjustiert und das Programm gestartet.

Tab. 9: Reaktionsschritte der rt-PCR

\begin{tabular}{c|c|c|c|c} 
& Schritt & Temperatur & Dauer & Zyklen \\
\hline „Hot- & DNA-Polymerase- & & & \\
Start“ & Aktivierung und DNA- & $95^{\circ} \mathrm{C}$ & $60 \mathrm{~s}$ & 1 \\
& Denaturierung & & & \\
\hline PCR & Denaturierung & $95^{\circ} \mathrm{C}$ & $15 \mathrm{~s}$ & \\
& Annealing & $60^{\circ} \mathrm{C}$ & $10 \mathrm{~s}$ & 35 \\
& Elongation & $72^{\circ} \mathrm{C}$ & $15 \mathrm{~s}$ & \\
\hline Melt Curve & Denaturierung & $95^{\circ} \mathrm{C}$ & $15 \mathrm{~s}$ & 1 \\
Analysis & Annealing & siehe Tab. 7 & $10 \mathrm{~s}$ & 72 \\
& Denatuierung & $95^{\circ} \mathrm{C}$ & $15 \mathrm{~s}$ & 1
\end{tabular}

\subsubsection{Planimetrie ventrikulärer Kardiomyozyten}

\subsubsection{HSPA4-siRNA-transfizierte, ventrikuläre Kardiomyozyten}

HSPA4-herunterregulierte Kardiomyozyten wurden mit an F-Actin hochaffin bindendes Phalloidin und DAPI, welches nach Bindung an Adenin-Thymin-reiche DNA blau fluoresziert, gefärbt.

Isolierte, ventrikuläre Kardiomyozyten wurden nach der Inkubation mit PE und ET-1 nach 24 Stunden zweimalig mit PBS (pH 7.4) gewaschen. Hierauf folgte die Fixierung der Zellen bei Raumtemperatur in 4\% Paraformaldehyd (PFA)für 15 Minuten. PFA bildet kovalente chemische Bindungen bzw. Querverbindungen zwischen Proteinen und deren Umgebung und fixiert damit die Zellen. Es folgten drei weitere Waschvorgänge mit PBS, um überschüssiges PFA zu entfernen. Pro Deckglas wurden $5 \mu \mathrm{L}$ Phalloidin-Methanol-Stock in $200 \mu \mathrm{L}$ einer 0,2\%-Triton-PBS-Lösung verdünnt und für 20 Minuten bei Raumtemperatur lichtgeschützt inkubiert. Zur Reduktion von unspezifischen Hintergrundsignalen, wurde der Lösung 1\% (w/v) BSA hinzugefügt. Drei Waschvorgänge mit vorgewärmtem PBS folgten. Pro Deckglas wurden $200 \mu \mathrm{L}$ DAPI-Lösungen pipettiert und die Deckgläser mit den angefärbten Zellen im Mikroskop Zeiss Axiovert 200 adjustiert. Durch Bestrahlung mit spezifischen Wellenlängen mit der Mikroskopkamera Axiocam 105 color wurden die an den Zielstrukturen gebundenen fluoreszierenden Farbstoffen angeregt, so dass spezifische Wellenlängen 
emitiert wurden. (Actin-Tetramethylrhodamin: Anregung/ Emission: 540/565 nm, DAPI: Anregung/Emission: 358/461nm). Dies führte zur farblichen Darstellung der Zielstrukturen. Pro Bedingung wurden zufällig drei repräsentative Stellen bei 40-facher Vergrößerung fotografiert und hinsichtlich der Gruppenverteilung verblindet mithilfe des Programms ImageJ ausgewertet. Es wurden drei unabhängige Versuche durchgeführt $(n=3)$ und dabei pro Bedingung und Versuch zwischen 70-120 Zellen vermessen.

\subsubsection{Adenoviral-transduzierte Kardiomyozyten}

Nach erfolgter adenoviraler Transduktion wurden nach 24 Stunden isolierte, ventrikuläre Kardiomyozyten neonataler Ratten für weitere 24 bzw. 48 Stunden mit PE bzw. ET-1 inkubiert. Darauf folgte ein dreimaliger, lichtgeschützter Waschvorgang mit vorgewärmtem PBS. Die Fixierung der Zellen erfolgte in 4\% PFA. Die Zellen wurden noch dreimal mit PBS gespült. Ad-HSPA4 kodierte nicht nur für das Hitzeschockprotein A4, sondern auch für EGFP. Da EGFP bei Bestrahlung mit blauem oder ultraviolettem Licht grün fluoresziert und zytosolisch lokalisiert ist, können dadurch die Zellgrenzen von Ad-HSPA4transduzierten Rattenkardiomyozyten abgegrenzt werden. Durch Standardisierung von äuBeren Bedingungen, wie dem Ausschalten externer Lichtquellen, gleicher Einstellung der Belichtungszeit, identischer Vergrößerung des Mikroskops, kann die Höhe der gemessenen Fluoreszenz als Maß für die EGFP-Synthese herangezogen werden. Diese wiederum korreliert mit der Gesamtproteinsynthese der Zelle und stellt einen Marker für den Proteinumsatz dar (Soboleski et al. 2005). Pro Bedingung wurden zufällig drei repräsentative Stellen fotografiert und mittels dem Programm ImageJ die Zellgrößen verblindet ausgemessen. Pro Bedingung wurden zwischen 40-70 Zellen bestimmt. Es wurden insgesamt 3 unabhängige Experimente durchgeführt.

\subsubsection{Immunzytochemische $\alpha$-Aktinin-Färbung ventrikulärer Kardiomyozyten}

Mithilfe der Immunfloreszenzmikroskopie können intrazelluläre Bestandteile markiert werden. Das verwendete Protokoll ist an das von Prof. Li, Farmington USA, angelehnt.

Die mit ET-1- bzw. PE-inkubierten Zellen wurden nach der jeweiligen definierten Zeit zweimalig mit vorgewärmtem PBS bei Raumtemperatur gewaschen. Um die Zellen zu fixieren, wurden sie in 4\% PFA inkubiert. Die behandelten Zellen wurden zuerst zweimalig mit PBS gewaschen, um dann mit 0,2\% Triton-X-100, welches in PBS verdünnt war, permeabilisiert zu werden. Hierauf folgte ein dreimaliger Waschvorgang mit PBS bei Raumtemperatur. Durch eine einstündige Inkubation der Kardiomyozyten in einer 0,2\% Triton-X-100-PBSLösung, welcher 10\% Ziegenserum zugesetzt war, wurden unspezifische Bindungsstellen 
blockiert. Nach einem einmaligen Waschvorgang in PBS wurde der primäre Antikörper in einer $0.2 \%$ Triton-X-100-PBS-Lösung mit 1\% Ziegenserum verdünnt und die Zellen darin über Nacht bei $4^{\circ} \mathrm{C}$ inkubiert. Als primäre Struktur wurde $\alpha$-Actinin, welches als Sarkomerprotein zum kontraktilen Apparat der Zelle gerechnet wird und an der Z-Linie lokalisiert ist, ausgewählt. Der zweite Tag begann mit einem dreimaligen Waschvorgang von je zehn Minuten mit 0,2\% Triton-X-100-PBS. Es folgte eine zweistündige, von Lichtquellen abgeschirmte Inkubation mit dem sekundären Antikörper in einer 0,2\% TritonX-100-PBSLösung, welcher 10\% Ziegenserum zugesetzt war. Der sekundäre Antikörper war zusätzlich mit einem Fluorophor gekoppelt. Ein erneuter dreimaliger von jeweils zehn Minuten andauernder, lichtgeschützter Waschvorgang erfolgte. Zur Färbung der F-Actin-Filamente inkubierten die Zellen mit einer Phalloidin-Lösung, welche zu vor mit $5 \mu \mathrm{L}$ Methanol und 200 $\mu \mathrm{L}$ Triton-0,2\%-PBS-Lösung versetzt wurde. Um unspezifische Hintergrundsignale zu reduzieren, wurde 1\% BSA zur Lösung hinzugegeben. Die Deckgläser inkubierten bei Raumtemperatur 20 Minuten bevor sie letztmalig dreifach mit PBS gewaschen wurden. Im letzten Schritt wurden $200 \mu \mathrm{L}$ DAPI-Lösung auf die Deckgläser aufgetragen. 4',6-Diamidino-2-phenylindol reichert sich bevorzugt in Adenin-Thymin-reichen Regionen der doppelsträngigen DNA an und dient somit als Zellkernfärbung Die Mikroskopie erfolgte mit einem Zeiss Axiovert 200 Mikroskop, Lichtquelle war eine Axiocam 105 Color. Als Programm wurde Axiovision SE 644.9 genutzt. 


\subsection{Statistische Auswertung}

Die statistische Auswertung der erhobenen Daten erfolgte in GraphPad PRISM 7.0.

Mit dem einseitigen student's t-Test wurden Werte von unabhängigen Proben auf signifikante Unterschiede überprüft. Als signifikanter Unterschied wurde ein Signifikanzniveau von $\mathrm{p}<0,05$ (Symbol: *), p<0,01(Symbol: **), p<0,001 (Symbol: ***) p<0,0001 (Symbol: ****) betrachtet im Vergleich zur korrespondierenden basalen Gruppe. Um mehrere Gruppen auf signifikante Unterschiede hin zu überprüfen, wurde der One-Way-ANOVA mit BonferroniKorrektur angewendet. Zur Analyse der Einwirkung von zwei Faktoren wurde die zweifaktorielle Analyse (Two-Way-ANOVA) angewendet. Signifikante Unterschiede wurden gegen korrespondiere Behandlung gezeigt: $\mathrm{p}<0,05$ (Symbol: \#), $\mathrm{p}<0,01$ (Symbol: \#\#), p<0,001 (Symbol: \#\#\#) p<0,0001 (Symbol: \#\#\#\#). Die Ergebnisse in den Graphen wurden, soweit nicht anderweitig angegeben, als Mittelwert \pm Standardfehler (mean \pm SEM) aufgetragen. Die Graphiken wurden in Adobe Illustrator Version 2015 erstellt. Der schriftliche Teil der Arbeit wurde in Mircosoft Office 2017 angefertigt. Zur Literaturverwaltung wurde das Programm Zotero 5.0.12 genutzt. 


\section{Ergebnisse}

\subsection{PE und ET-1 induzieren HSPA4-Expression in NRCM}

In vorangegangen Studien konnte gezeigt werden, dass HSPA4 in murinen Herzen als Folge einer Nachlasterhöhung mittels TAC-Operation und Patienten mit Aortenklappenstenose kompensatorisch hochreguliert wird (Mohamed et al. 2012). Um die HSPA4-Expression in isolierten, ventrikulären Kardiomyozyten neonataler Ratten unter Stimulation mit PE und ET-1, die beide eine pathologische Hypertrophie in NRCM induzieren können (Peter et al. 2016), zu evaluieren, wurden NRCM für 24 Stunden und 48 Stunden mit Phenylephrin (PE) und Endothelin-1 (ET-1) stimuliert. 48 Stunden nach Isolierung der Kardiomyozyten wurden diese auf FCS-freies Medium umgestellt. 24 Stunden später erfolgte die Stimulation mit $10 \mu \mathrm{M}$ PE und $50 \mathrm{nM}$ ET-1. Nach weiteren 24 Stunden wurden weitere Kardiomyozyten mit identischen Bedingungen stimuliert. Nach insgesamt 24 bzw. 48 Stunden Inkubation nach Behandlung wurden die Zellen mittels $4^{\circ} \mathrm{C}$-kaltem RIPA-Puffer von den Zellplatten abgelöst und Protein isoliert.

A

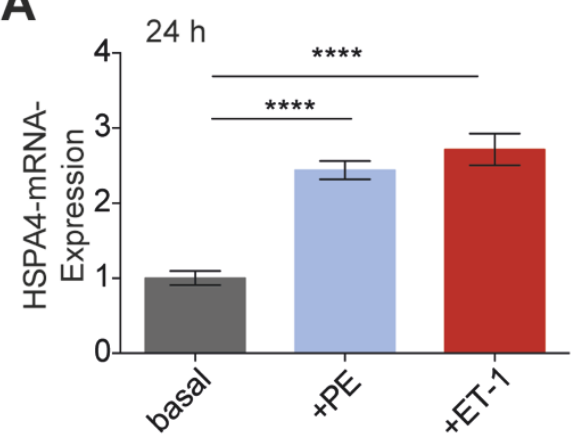

B

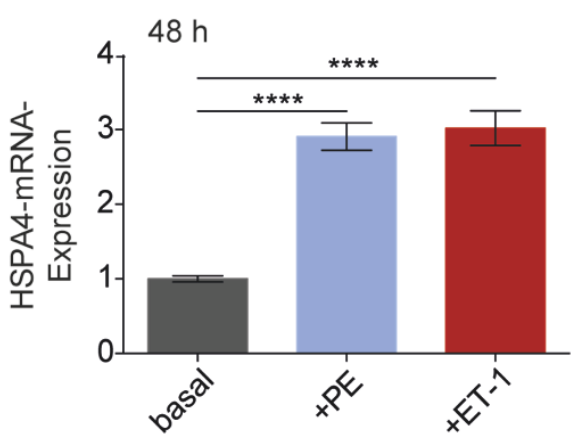

Abb. 8: Quantitative Auswertung der HSPA4-Expression in einer rt-PCR unter Stimulation mit PE bzw. ET-1. (A) Auftragung der HSPA4-mRNA-Expression nach 24 h Stimulation mit 10 $\mu \mathrm{M}$ PE bzw. $50 \mathrm{nM}$ ET-1. Auf HPRT normalisiert. (n=3) (B) Der Graph zeigt die HSPA4Expression nach $48 \mathrm{~h}$ Stimulation. Auf HPRT normalisiert. ( $\mathrm{n}=3$ ) Test: One-Way-ANOVA mit Bonferroni-Post-Hoc-Test. Die Fehlerbalken zeigen den Standardfehler. ${ }^{* * * *} \mathrm{p}<0.0001$ gegen BasalGruppe.

Mittels der rt-PCR wurde die HSPA4-mRNA-Expression von isolierten, ventrikulären neonatalen Kardiomyozyten der Ratte evaluiert, die wie oben beschrieben stimuliert und nach Inkubation der Stimulanzien mithilfe des RLT-Puffers isoliert wurden. Nach RNA- 
Extraktion und cDNA-Synthese zeigte die durchgeführte rt-PCR eine signifikante Hochregulation der HSPA4-mRNA bei 24 Stunden unter PE von 240\% und ET-1 von 270\% gegenüber nicht stimulierten Kardiomyozyten (Abb. 8) [Kontrolle: $1 \pm$ 0,1 vs. +PE: 2,44 \pm 0,11; $(\mathrm{p}<0,0001)]$ [Kontrolle: $1 \pm 0,1$ vs. +ET-1: 2,77 \pm 0,23; $(\mathrm{p}<0,0001)]$.

Nach 48 stündiger Inkubation konnte ein Anstieg der HSPA4-mRNA in PE-behandelten Zellen auf insgesamt $290 \%$ und ET-1-behandelten Zellen auf 300\% beobachtet werden (Abb. 8) [Kontrolle: $1 \pm 0,04$ vs. + PE: 2,90 \pm 0,18; $(\mathrm{p}<0,0001)]$ [Kontrolle: 1,0 \pm 0,04 vs. +ET-1: 3,02 \pm 0;23 (p<0,0001)].
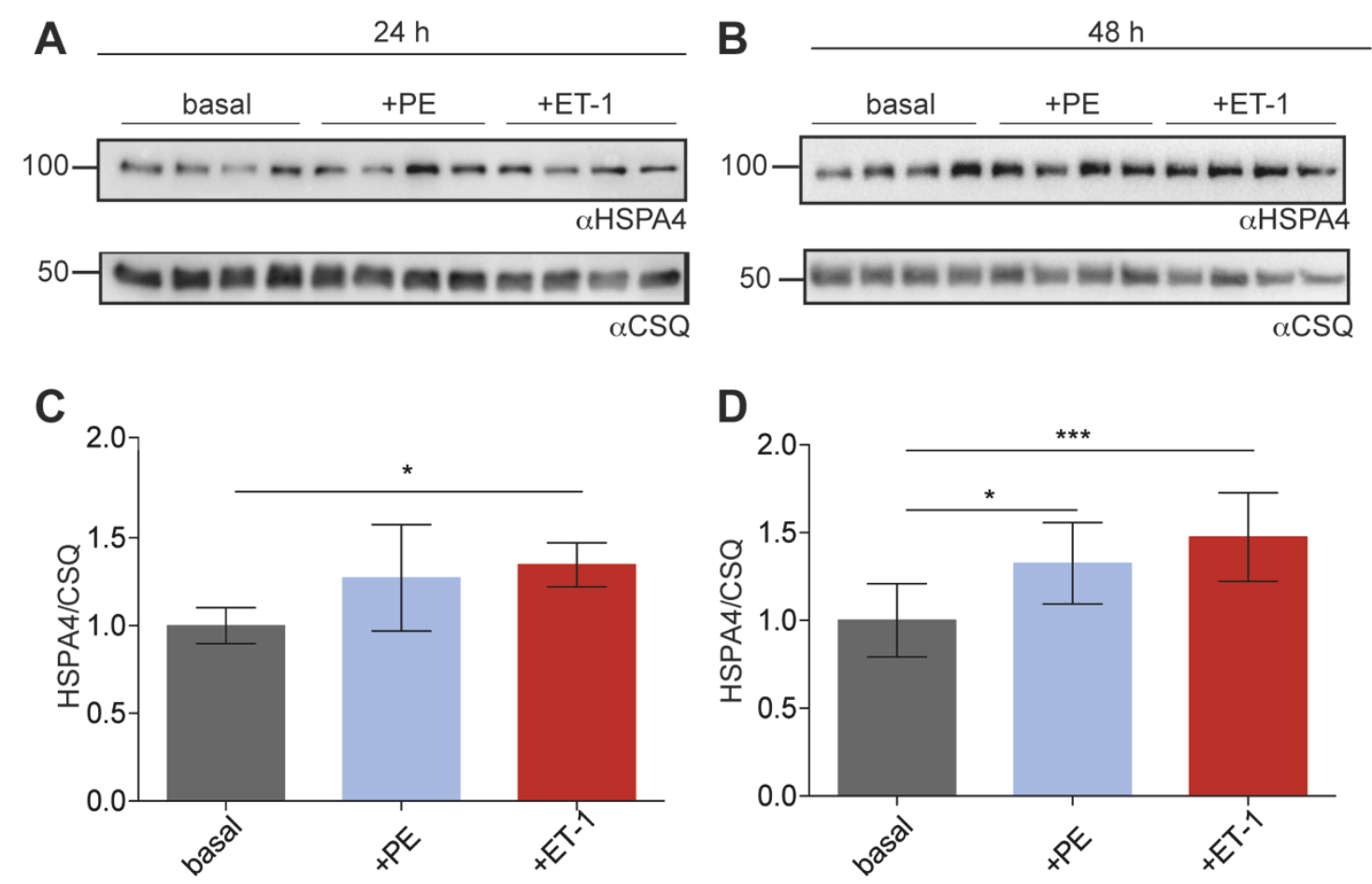

Abb. 9: HSPA4-Expression unter Stimulation mit $10 \mu \mathrm{M}$ PE und $50 \mathrm{nM}$ ET-1 in NRCM.

(A) Repräsentativer Western Blot mit je 4 unabhängigen Proben von Kardiomyozyten, die für $24 \mathrm{~h}$ mit PE bzw. ET-1 stimuliert wurden. Die Membranen inkubierten mit einem Antikörper gegen HSPA4 bzw. zur Ladungskontrolle Calsequestrin (CSQ). (B) Western Blot mit Proben nach $48 \mathrm{~h}$ Stimulation. (C) Densitometrische Auswertung der HSPA4-Expression nach 24 h ( $\mathrm{n}=3$ ). Auf der Ordinate ist das Verhältnis von HSPA4 zu CSQ aufgetragen. (D) Densitometrische Auswertung nach 48 h. (n=3) Test: One-Way-ANOVA mit Bonferroni-Post-Hoc-Test. Die Fehlerbalken zeigen den Standardfehler. ${ }^{*} \mathrm{p}<0.05 * * * \mathrm{p}<0.001$ gegen die Basal-Gruppe.

Neben der rt-PCR wurde die HSPA4-Expression im Western Blot auch auf translationaler Proteinebene untersucht. Proben von Kardiomyozyten, die für 24 Stunden mit PE stimuliert wurden, zeigten keinen signifikanten Unterschied im Expressionsmuster [Kontrolle: $1 \pm$ 0,1 vs + PE: $1,27 \pm 0,11 ;(p=0,106)]$, wohingegen es unter Stimulation mit ET-1 bereits nach 24 
Stunden Inkubation zu einer signifikanten Zunahme von HSPA4 kam (Abb. 9 (A und C)) [Kontrolle: $1 \pm 0,1$ vs + ET-1: $1,34 \pm 0,05 ;(p=0,033)$ ].

In der Western-Blot-Analyse von Zellen nach 48-stündiger Stimulation zeigte sich sowohl unter PE als auch unter ET-1 Behandlung eine kompensatorische, signifikante Hochregulation von HSPA4 um 32\% bzw. 47\% (Abb. 9 (B und D)) [Kontrolle: $1 \pm$ 0,07 vs. +PE: 1,32 \pm 0,08; $(\mathrm{p}=0.016)][($ Kontrolle: $1 \pm 0,07$ vs. + ET-1: $1,47 \pm 0,06 ;(p=0,0002)]$.

\subsection{ET-1 stimuliert nicht die HSPA4-Expression in Fibroblasten}

Eine Stimulation mit PE führte nicht nach 24 Stunden, aber nach 48 Stunden zu einer statistisch signifikanten Zunahme der Expression von HSPA4 in Kardiomyozyten der Ratte (Abb. 9 (A - D)). Dies warf die Frage auf, ob die kompensatorische HSPA4-Hochregulation kardiomyozytenspezifisch ist oder ob eine Stimulation in Fibroblasten ebenfalls die HSPA4Expression beeinflusst. Da Fibroblasten keinen $\alpha_{1}$-Rezeptor exprimieren (Stewart et al. 1994; O’Connell et al. 2001), wurden daher isolierte, ventrikuläre Fibroblasten neonataler Ratten (NRCF) 48 Stunden einzig mit ET-1 und nicht mit dem $\alpha$-Agonisten PE stimuliert.

A

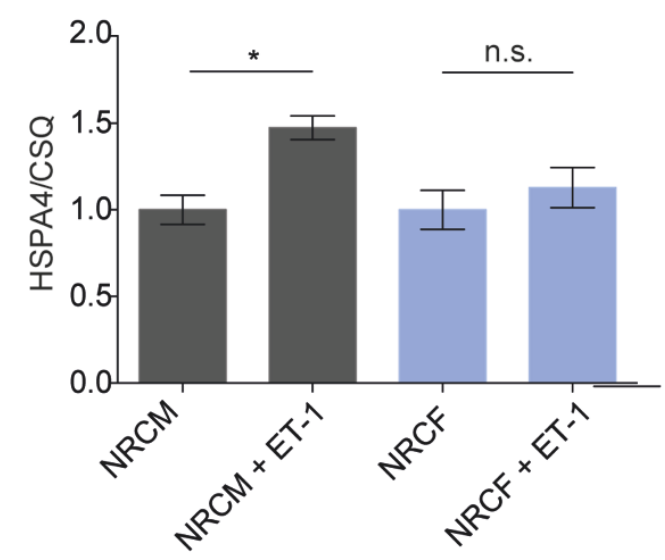

B

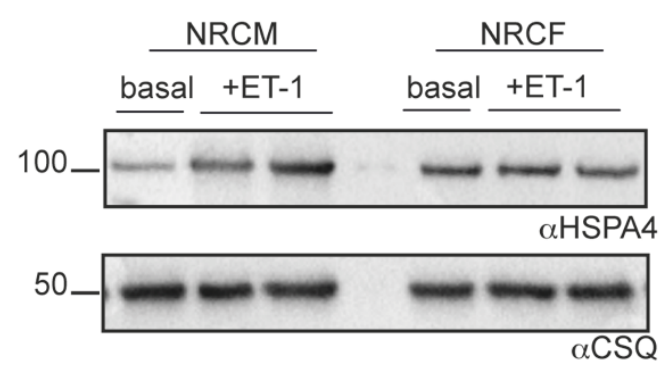

Abb. 10: Western Blot zur Überprüfung der HSPA4-Expression in NRCM und NRCF unter 48-stündiger Inkubation mit ET-1. (A) Densitometrische Auswertung der HSPA4-Expression in beiden Zelltypen. Auf der Y-Achse ist HSPA4 gegen CSQ aufgetragen. (B) Western Blot mit Antikörper gegen HSPA4 und CSQ. $(n=2)$ Test: One-Way-Anova mit Bonferroni-Post-Hoc-Test. Die Fehlerbalken zeigen den Standardfehler. ${ }^{*} \mathrm{p}<0.05$ gegen NRCM.

In der Auswertung konnte keine relevante Änderung der HSPA4-Expression in neonatalen Rattenfibroblasten nachgewiesen werden (Abb. 10) [Kontrolle NRCF: $1 \pm 0,12$ vs. NRCF +ET-1: $1,13 \pm 0,06 ;(\mathrm{p}>0,99)]$. Entgegen der Antwort von NRCM auf eine Stimulation mit 
ET-1, spielt eine kompensatorische HSPA4-Hochregulation in Fibroblasten nach Inkubation mit ET-1 keine Rolle. 


\subsection{Bestimmung der optimalen Ad-HSPA4-Konzentration}

Bevor der Einfluss von HSPA4 auf die Stimulation mit PE oder ET-1 in Kardiomyozyten neonataler Ratten untersucht werden konnte, musste eine Viruskonzentration gefunden werden, die eine optimale HSPA4-Expression bewirkte. Um eine gesteigerte HSPA4-Expression in isolierten, ventrikulären Kardiomyozyten der Ratte zu erzielen, wurde ein Adenovirus genutzt, der im Labor von Frau Prof. Dr. Lutz aufgereinigt und freundlicherweise für diese Arbeit zur Verfügung gestellt wurde. Durch den adenoviralen Gentransfer wurde die HSPA4-DNA in die Kardiomyozyten eingeschleust und eine persistente Transduktion der Ziel-DNA erreicht, ohne dass diese sich in das Genom der Zelle integrierte. Da die MOI (multiplicity of infection) des Virus nicht vorlag, wurden zur Ermittlung der optimalen Viruskonzentration und daraus folgend der optimalen HSPA4-Expression NRCM nach 24 Stunden in serumfreiem Medium mit $1 \mu \mathrm{L}, 3 \mu \mathrm{L}, 10 \mu \mathrm{L}$ und $30 \mu \mathrm{L}$ des Virusstocks versetzt. Als Kontrollvirus diente ein Adenovirus mit einem CMV-Promotor, der lediglich EGFP exprimierte (Ad-CMV-EGFP; SigmaGen Laboratories; PFU Titer: 3.10E+10 PFU/mL). Eine optimale Transduktionseffizienz des Kontrollvirus wurde bei $1 \mu \mathrm{L}$ erreicht. 24 und 48 Stunden nach der Virustransduktion erfolgte eine fluoreszenzmikroskopische Kontrolle, die unter Behandlung mit $10 \mu \mathrm{L}$ und $30 \mu \mathrm{L}$ Viruslösung zytotoxische Granulate und kein EGFP-Signal zeigte. Daher wurden lediglich Zellen mit $1 \mu \mathrm{L}$ und $3 \mu \mathrm{L}$ Virus für die weitere Testung isoliert. Abbildung 11 zeigt ein repräsentatives fluoreszenzmikroskopisches Bild von Kardiomyozyten, die mit $1 \mu \mathrm{L}$ der Viruslösung für $24 \mathrm{~h}$ transduziert wurden.

A
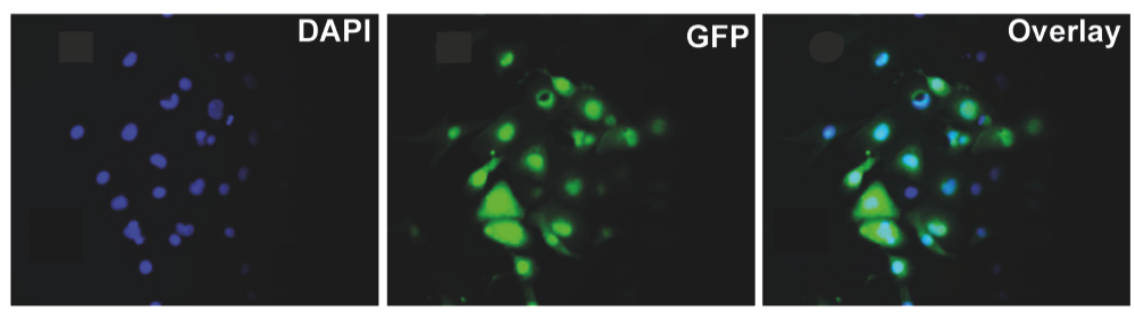

Abb. 11: Fluoreszenzmikroskopisches Bild von Kardiomyozyten nach adenoviraler Transduktion mit $1 \mu \mathrm{L}$ des Ad-HSPA4 nach 24 Stunden. DAPI färbt den Zellkern an. Das EGFPSignal dient als positiver Nachweis der Virusaufnahme.

Um die HSPA4-mRNA-Expression auf Genebene zu messen, wurden neonatale Rattenkardiomyozyten wie oben beschrieben behandelt, RNA isoliert und nach cDNA-Synthese eine rt-PCR durchgeführt. 
In der Analyse der rt-PCR zeigte sich sowohl bei der $1-\mu \mathrm{L}$ - als auch $3-\mu \mathrm{L}$-Viruslösung eine hochsignifikante Überexpression der mRNA-Replikate auf 781\% bzw. 850\% gegenüber der Basal-Gruppe [Kontrolle: $1 \pm 0,08$ vs. $+1 \mu$ L-Ad-HSPA4: 7,81 \pm 0,47; $(\mathrm{p}<0.0001)$ ] [Kontrolle: $1 \pm 0.08$ vs. $+3 \mu$ L-Adeno-HSPA4 $8.5 \pm$ 0,38; (p<0.0001)] (Abb. 12 (A)).

Eine Inkubation über 48 Stunden führte ebenfalls zur Zunahme der mRNA-Replikate sowohl bei $1-\mu \mathrm{L}$ - als auch bei 3- $\mu \mathrm{L}-$ Viruslösung. [Kontrolle: $1 \pm$ 0,06 vs. $1 \mu \mathrm{L}-\mathrm{Ad}-\mathrm{HSPA} 4: 6,88$ \pm 0,57; (p<0.0001)] [Kontrolle: $1 \pm 0,06$ vs. $3 \mu$ L-Ad-HSPA4: 6,1 $\pm 0.4 ;(p<0.0001)]$ (Abb. $12(\mathrm{~B}))$.

A

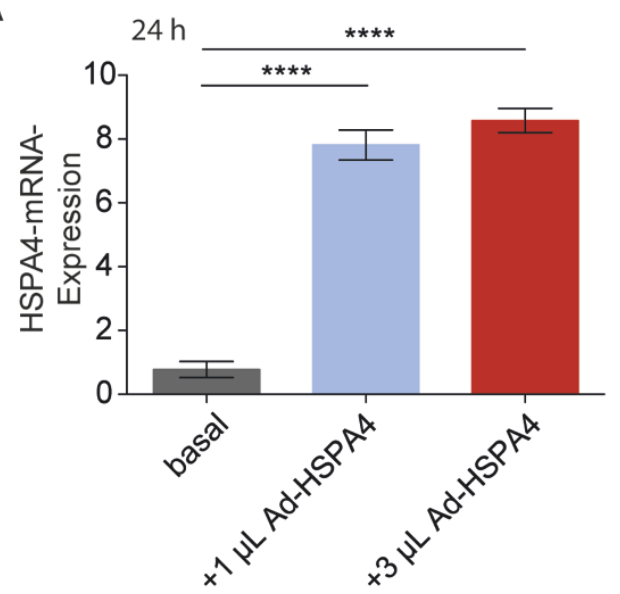

B

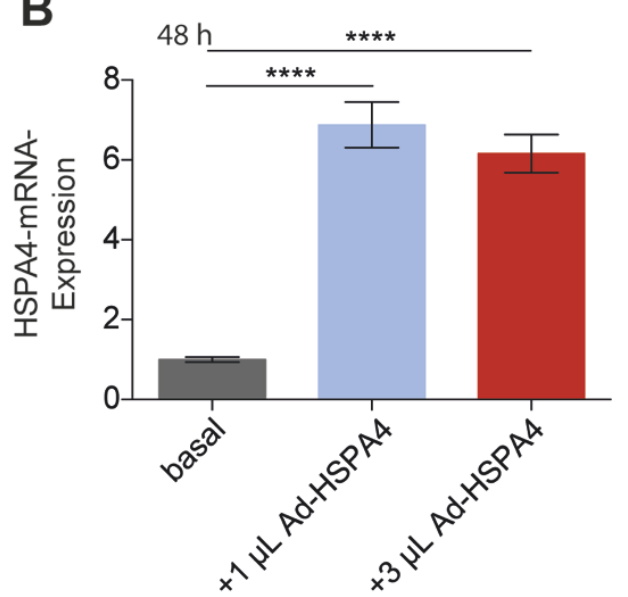

Abb. 12: Quantitative Auswertung der HSPA4-Expression in einer rt-PCR nach adenoviraler Transduktion mit Ad-HSPA4. (A) Graphische Auftragung der HSPA4-mRNA-Expression nach $24 \mathrm{~h}$ adenoviraler Transduktion mit $1 \mu \mathrm{L}$ bzw. $3 \mu \mathrm{L}$ Ad-HSPA4. Auf HPRT normalisiert. (n=2) (B) Der Graph zeigt die HSPA4-mRNA-Expression nach $48 \mathrm{~h}$ Transduktion. Auf HPRT normalisiert. $(\mathrm{n}=2)$ Test: One-Way-ANOVA mit Bonferroni-Post-Hoc-Test. Die Fehlerbalken zeigen den Standardfehler. ${ }^{* * * *} \mathrm{p}<0.0001$

In der Auswertung der HSPA4-Expression auf Proteinebene zeigte sich die höchste Expression bei $1 \mu \mathrm{L}$-Ad-HSPA4 auf 350\% [Kontrolle: $1 \pm 0,05$ vs. $+1 \mu \mathrm{L}$-Ad-HSPA4: 3,55 $\pm 0,28$; $(\mathrm{p}<0,0001)]$. Die Behandlung mit $3 \mu \mathrm{L}$-Viruslösung führte zu einer Überexpression auf fast 200\% [Kontrolle: $1 \pm 0,05$ vs. $+3 \mu \mathrm{L}$-Ad-HSPA4: 1,9 \pm 0,17; $(\mathrm{p}=0,0046$ )] (Abb. 13 (A und C)). Nach 48 Stunden Inkubation wurde eine signifikante Überexpression bei $1 \mu \mathrm{L}$ Viruslösung auf 240\% [Kontrolle: $1 \pm 0,07$ vs. $+1 \mu$ L-Ad-HSPA4: $2,40 \pm 0,49 ;(p=0,0017)]$ gemessen, wohingegen es bei $3 \mu \mathrm{L}$ zu einer deutlichen Abnahme von HSPA4 im Vergleich zum 24- Stunden-Zeitpunkt kam [Kontrolle: $1 \pm 0,08$ vs. $+3 \mu$ L-Adeno-HSPA4: 1,01 \pm 0.08; (p= 0.9991)] (Abb. 13 (B und D)). 
A

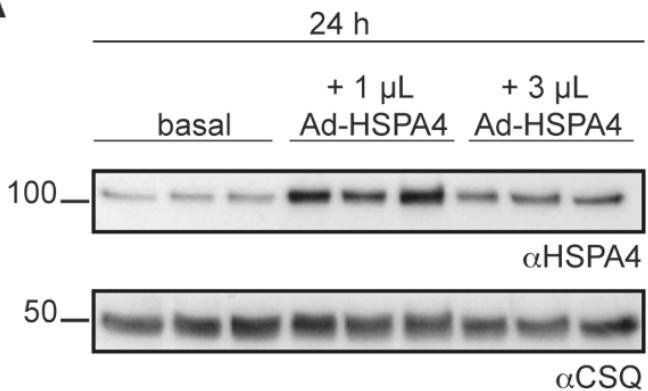

C

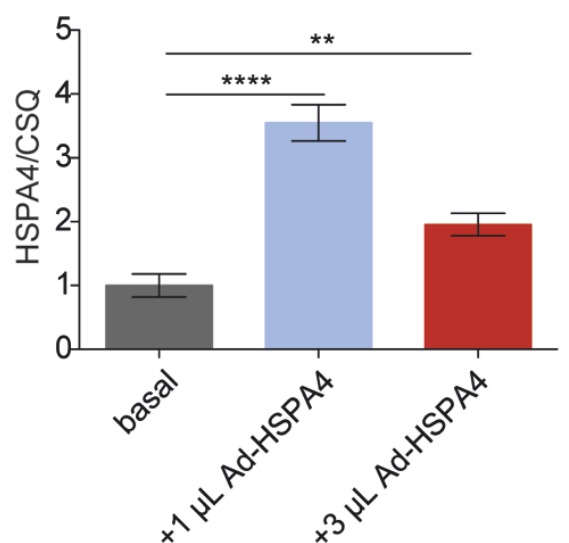

B

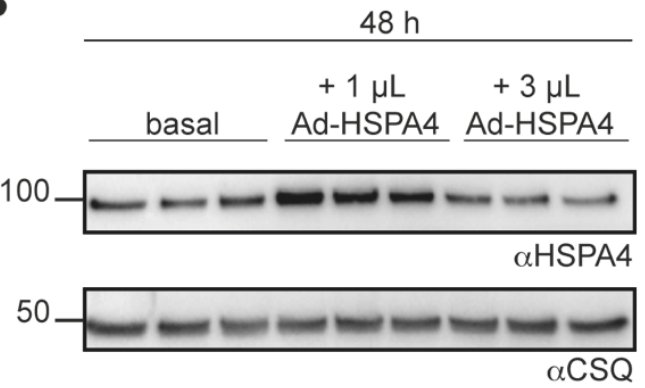

D

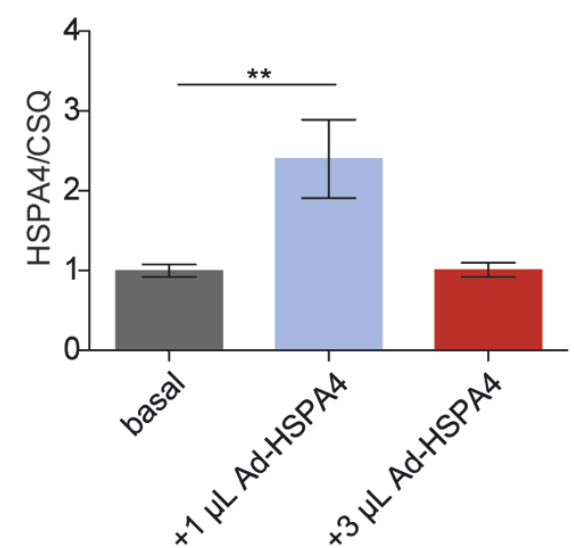

Abb. 13: Western Blot von NRCM nach adenoviraler Transduktion zur Untersuchung der HSPA4-Expression. (A) Der Western Blot zeigt die HSPA4-Expression nach adenoviraler Transduktion von insgesamt $1 \mu \mathrm{L}$ und $3 \mu \mathrm{L}$ Ad-HSPA4 nach $24 \mathrm{~h}$. Als Ladekontrolle diente CSQ. $(n=2)$ (B) Der Western Blot zeigt die HSPA4-Expression nach adenoviraler Transduktion von insgesamt $1 \mu \mathrm{L}$ und $3 \mu \mathrm{L}$ Ad-HSPA4 nach 48 h. Als Ladekontrolle diente CSQ. ( $=2$ ) (C) Quantitative Auswertung der HSPA4-Expression nach 24 h. Gegen CSQ aufgetragen. (D) Quantitative Auswertung der HSPA4-Expression nach 48 h. Gegen CSQ aufgetragen. Test: One-Way-ANOVA mit Bonferroni-Post-Hoc-Test. Die Fehlerbalken zeigen den Standardfehler. ${ }^{* *} \mathrm{p}<0.01 ; * * * \mathrm{p}<0.001$

Aufgrund dieser Ergebnisse wurde $1 \mu \mathrm{L}$ des Virusstocks als optimale Konzentration für die weiterführenden Experimente festgelegt.

\subsection{ANP- und BNP-Level unter PE und ET-1 in HSPA4- überexprimierten Kardiomyozyten}

ANP und BNP dienen als hormonelle Marker hypertrophierender Kardiomyozyten (Yamamoto et al.1996). Zur quantitativen Messung der Hypertrophiemarker ANP und BNP diente die rt-PCR. Neonatale Rattenkardiomyozyten wurden 24 Stunden nach der Transduktion mit dem HSPA4-Virus bzw. einem EGFP-Kontrollvirus für weitere 24 bzw. 48 Stunden mit PE und ET-1 behandelt. Mittels zweifaktorieller Analyse mit darauffolgendem BonferroniPost-Hoc-Test wurden die jeweiligen Gruppen untereinander auf signifikante Unterschiede 
überprüft. Bonferroni-korrigierte Post-Hoc-Tests ergaben, dass eine alleinige Überexpression von HSPA4 in den Kardiomyozyten weder das basale ANP- noch BNP-Level beeinflusste (Abb. 14 (A und B)) [ANP-Ad-EGFP: $1 \pm 0,06$ vs. Ad-HSPA4: 0,78 \pm 0,03; ( $\mathrm{p}>0.9999)$ ] [BNP-Ad-EGFP: $1 \pm$ 0,04 vs. Ad-HSPA4: 0,85 \pm 0,07 ( $\mathrm{p}=0.8687)]$ Die Stimulation mit PE für $24 \mathrm{~h}$ führte zu einer hochsignifikanten ANP-Expression in den Kontrollzellen, während die HSPA4-Überexpression einen solchen Anstieg inhibierte (Abb. 14 (A)) [ANP-Ad-EGFP: $1 \pm 0,06$ vs. Ad-EGFP +PE: $2,56 \pm$ 0,1; ( $<<0.0001)$ ] [ANP-Ad-HSPA4: $0,78 \pm 0,03$ vs. Ad-HSPA4 +PE: $1,14 \pm 0,06 ;(p=0.16)]$.
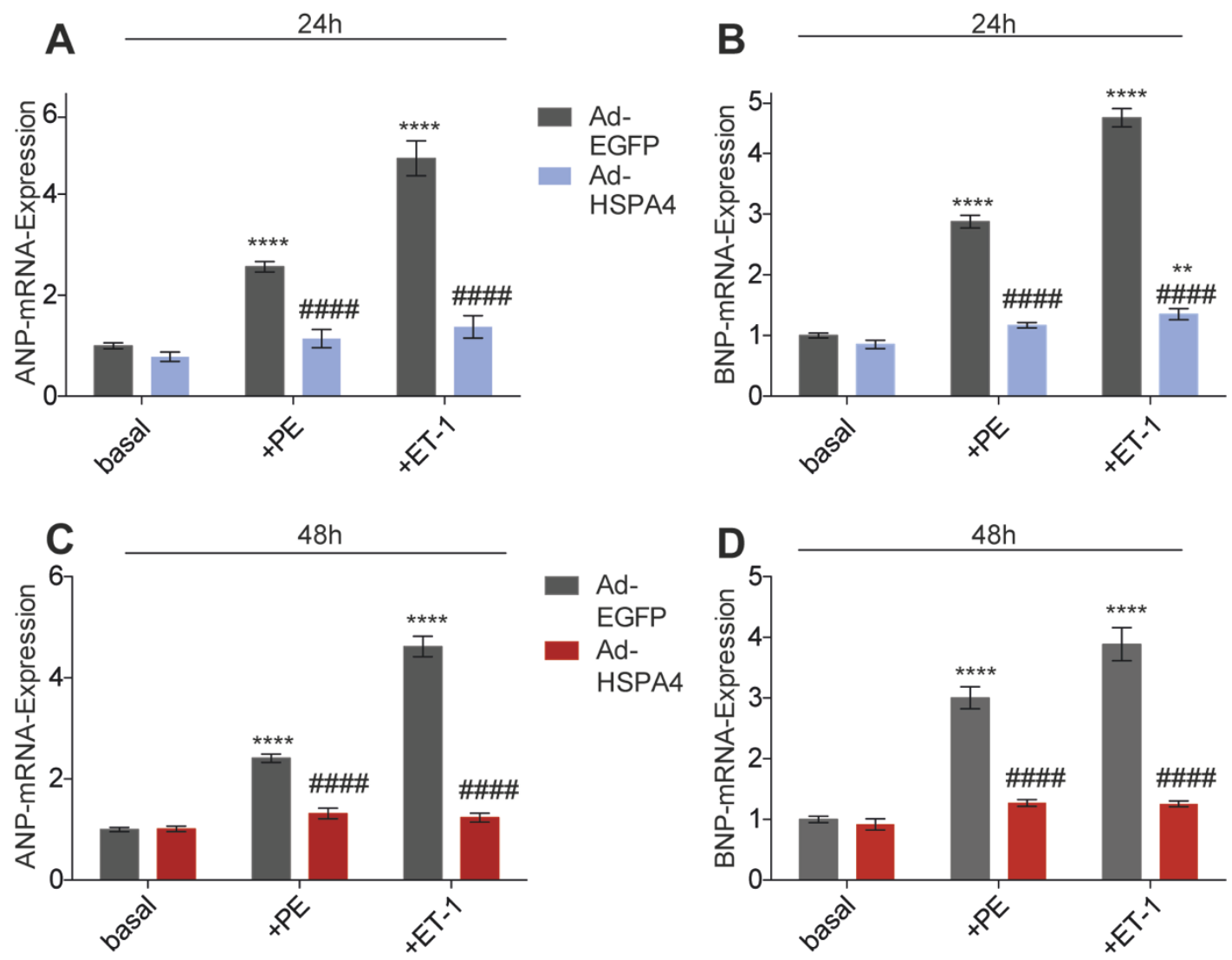

Abb. 14: Quantitative Auswertung der ANP- und BNP-Expression nach adenoviraler Transduktion und Stimulation mit $10 \mu \mathrm{M}$ PE und $50 \mathrm{nM}$ ET-1. (A) Quantitative ANP-mRNA-Level nach 24 h. (B) Quantitative BNP-mRNA-Expression nach 24 h. (C) Quantitative ANP-mRNAExpression (D) BNP-mRNA-Expression nach $48 \mathrm{~h}$. Die Werte wurden auf HPRT normiert. (n=3) Test: Two-Way-ANOVA mit Bonferroni-Post-Hoc-Test. Die Fehlerbalken zeigen den Standardfehler. ${ }^{* *} \mathrm{p}<0.01 ;{ }^{* * * *} \mathrm{p}<0.0001$ gegen korrespondierende Basal-Gruppe; \#\#\#\#p<0.0001 gegen korrespondierende Stimulation mit Ad-EGFP.

Einen noch stärkeren Anstieg der Expression von ANP ließ sich in den Kontrollzellen unter der Stimulation mit ET-1 nachweisen, wohingegen auch hier in den HSPA4überexprimierten Zellen ein deutlich geringerer Anstieg zu verzeichnen war (Abb. 14 (A)) 
[ANP-Ad-EGFP: $1 \pm$ 0,06 vs. Ad-EGFP +ET-1: 4,71 \pm 0,34; (p<0.0001)] [ANP-AdHSPA4: $0,78 \pm 0,03$ vs. Ad-HSPA4 +ET-1: 1,37 \pm 0,07; $(\mathrm{p}=0,14)]$.

Weiterführend ergab die Auswertung der BNP-mRNA-Expression eine Hochregulation unter Behandlung mit PE und ET-1 in den Kontrollzellen auf 280\% bzw. 450\%, wohingegen die BNP-Level in den Ad-HSPA4-transduzierten Kardiomyozyten nach Stimulation nicht signifikant anstiegen (Abb. 14 (B)) [BNP-Ad-EGFP: $1 \pm$ 0,04 vs. Ad-EGFP +PE: 2,87 \pm 0,1; (p<0.0001)] [BNP-Ad-EGFP: $1 \pm 0,04$ vs. Ad-EGFP +ET-1: 4,58 \pm 0,15; $(\mathrm{p}<0.0001)]$ [BNP-Ad-HSPA4: 0,85 \pm 0,07 vs. Ad-HSPA4 +ET-1: 1,35 \pm 0,09; $(\mathrm{p}=0.0052)]$.

Eine HSPA4-Überexpression führte unter Stimulation mit PE und ET-1 folglich zu hochsignifikant geringeren ANP- und BNP-Werten verglichen zu Kontrollzellen.

Auch nach $48 \mathrm{~h}$ hatte die alleine Überexpression von HSPA4 auf die basale ANP- bzw. BNPHöhe keinen Einfluss. Doch nach Stimulation mit PE oder ET-1 stiegen die ANP- und BNP-Werte in den Kontrollzellen signifikant an, in Ad-HSPA4-transduzierten Kardiomyozyten ließ sich keine signifikante Erhöhung messen (Abb. 14 (C und D)) [ANP-Ad-EGFP: $1 \pm 0,04$ vs. Ad-EGFP +PE: 2,41 \pm 0,18; (p<0.0001)] [ANP-Ad-EGFP: $1 \pm$ 0,04 vs. AdEGFP +ET-1: 4,61 \pm 0,2; $(\mathrm{p}<0.0001)]$ [BNP-Ad-EGFP: $1 \pm$ 0,05 vs. Ad-EGFP +PE: 3,0 \pm 0,08; $(\mathrm{p}<0.0001)$ ] [BNP-Ad-EGFP: $1 \pm$ 0,05 vs. Ad-EGFP +ET-1: 3,88 \pm 0,27; $(\mathrm{p}<0.0001)]$. Auch nach $48 \mathrm{~h}$ schützte die HSPA4-Überexpression die Kardiomyozyten vor einer Hochregulation der ANP- bzw. BNP-mRNA. Zusammengefasst supprimierte die adenovirale Überexpression von HSPA4 hochsignifikant die PE- und ET-1-induzierten Hypertrophiemarker ANP und BNP sowohl nach 24 Stunden als auch nach 48 Stunden.

\subsection{HSPA4 verringert die Anzahl ubiquitinierter Proteine}

Das Hitzeschockprotein A4 fungiert als Nukleotidaustauschfaktor für die direkt an der korrekten Faltung von entstehenden Proteinen beteiligten HSP70-Chaperone. Bereits in $\mathrm{HSPA}^{-/-}$-KO-Mäusen konnten eine Akkumulation ubiquitinierter Proteine beobachtet werden. Dies warf die Frage auf, ob eine Überexpression von HSPA4 zu einem vermehrten Abbau ubiquitinierter Proteine führt und in wieweit eine Stimulation mittels PE und ET-1 den Spiegel ubiquitinierter Proteine beeinflusst.

Hierfür wurden NRCM 72 Stunden nach Isolation mit einem HSPA4-spezifischen Adenovirus transduziert, der eine transiente Überexpression des Zielproteins herbeiführte. Weitere 24 Stunden nach der Transduktion erfolgte die Behandlung mit $10 \mu \mathrm{M}$ PE und $50 \mathrm{nM}$ ET-

1. Nach 24-stündiger bzw. 48-stündiger Inkubation erfolgte die Zellisolation, 
Proteinisolation und Western Blot. Die Analyse erfolgte mithilfe der zweifaktoriellen Analyse mit nachfolgendem Bonferroni-Post-Hoc-Test.

A

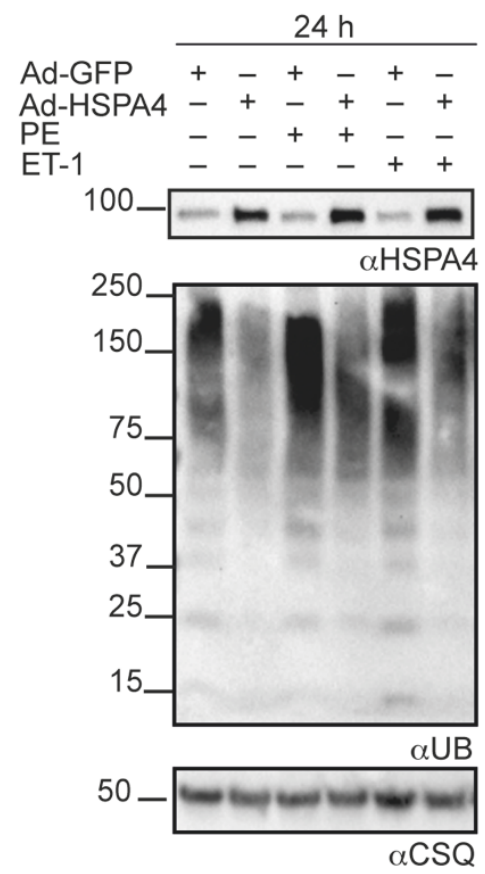

B
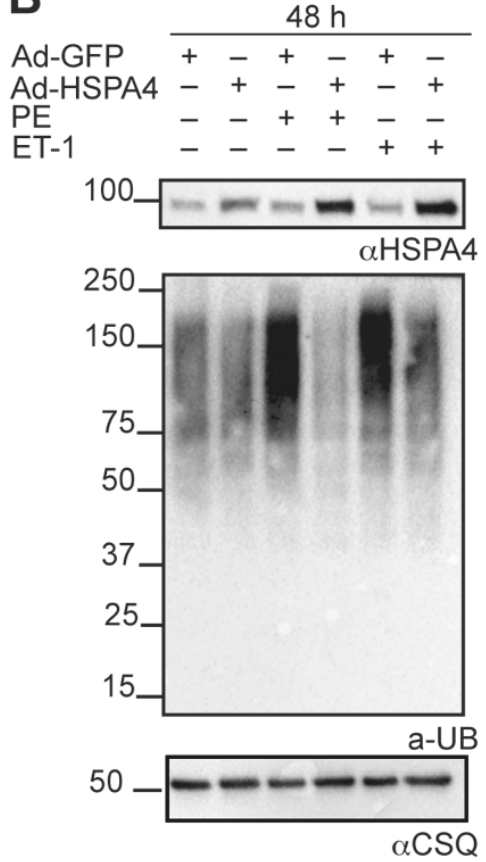

\section{C}
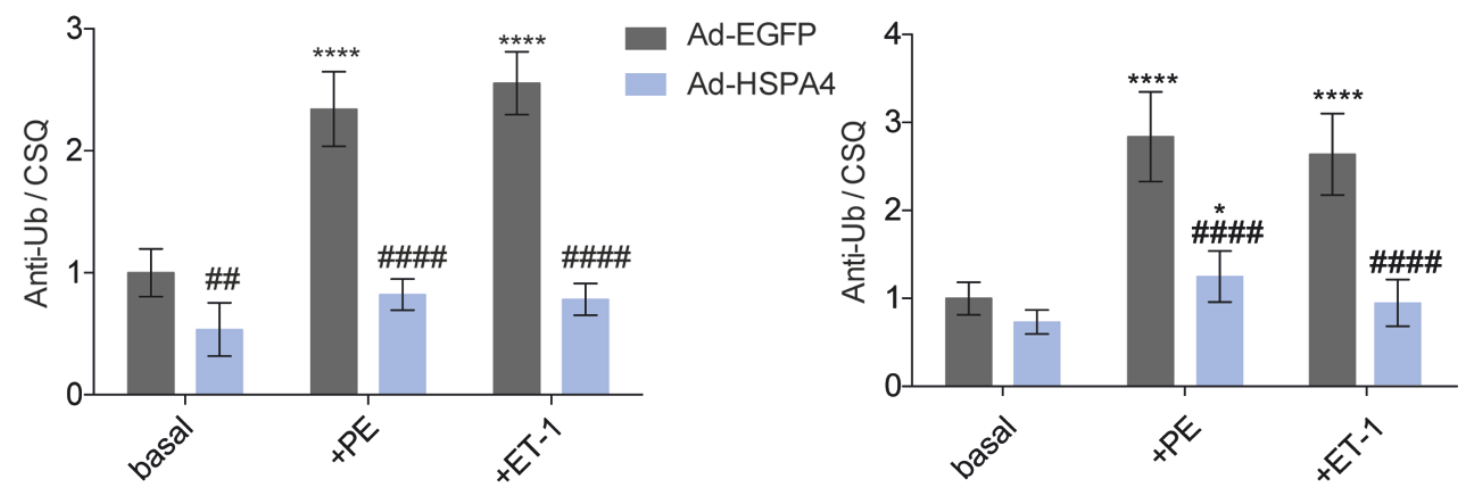

Abb. 15: Nachweis ubiquitinierter Proteine in adenoviral-transduzierten Kardiomyozyten unter Stimulation mit $10 \mu$ M PE bzw. 50 nM ET-1. (A) Western Blot mit Antikörper gegen Ubiquitin und HSPA4 nach 24-stündiger Inkubation mit PE bzw. ET-1. (B) Western Blot mit Antikörper gegen Ubiquitin und HSPA4 nach 48-stündiger Inkubation mit PE bzw. ET-1. Als Ladekontrolle wurde die Membran vom Anti-Ubiquitin-Antikörper gewaschen und mit einem CSQAntikörper inkubiert. (C) Quantitative Auswertung ubiquitinierter Konjugate nach 24 h. Normiert gegen CSQ. (D) Quantitative Auswertung ubiquitinierter Konjugate nach 48 h. Normiert gegen CSQ. $(\mathrm{n}=5)$ Test: Two-Way-ANOVA mit Bonferroni-Post-Hoc-Test. Fehlerbalken zeigen den Standardfehler. ${ }^{*} \mathrm{p}<0.05 ;{ }^{* * * *} \mathrm{p}<0.0001$ gegen korrespondierende Basal-Gruppe; $\# \# \mathrm{p}<0.01 ; \# \# \# \# \mathrm{p}<0.0001$ gegen korrespondierende Behandlung. 
Die alleinige Überexpression von HSPA4 führte, verglichen mit Kontrollzellen, welche alleinig mit einem EGFP-Adenovirus transduziert wurden, zu einer Halbierung von ubiquinitierten Proteinen (Abb. 15 (A und C)) [24h-Ad-EGFP: $1 \pm$ 0,07 vs. Ad-HSPA4: 0,53 \pm 0,08 $(\mathrm{p}=0,0019)]$. Diese Wirkung wurde jedoch 48 Stunden nach Transduktion mit dem Virus nicht mehr beobachtet (Abb. 15 (B und D)) [48h-Ad-EGFP: $1 \pm$ 0,06 vs. Ad-HSPA4: 0,732 \pm 0,04; (p>0,999)].

Während die Stimulation mit PE einen Anstieg ubiquitinierter Proteine auf 230\% bewirkte, mit ET-1 auf 255\%, inhibierte die Überexpression von HSPA4 für beide Stimulanzien hochgradig eine solche Akkumulation (Abb. 15 (A und C)) [24h-Ad-EGFP: $1 \pm$ 0,07 vs. AdEGFP +PE: $2,34 \pm$ 0.1; (p<0.0001)] [24h-Ad-EGFP: $1 \pm$ 0,07 vs. Ad-EGFP +ET-1: 2,55 \pm 0,09; $(\mathrm{p}<0.0001)$ ] [24h-Ad-HSPA4: $0,53 \pm 0,07$ vs. Ad-HSPA4 +PE: 0,82 \pm 0,05; $(\mathrm{p}=0.2395)$ ] [24h-Ad-HSPA4: 0,53 \pm 0,07 vs. Ad-HSPA4 +ET-1: 0,79 \pm 0,05; $(\mathrm{p}=0.4549)]$.

Ferner wurde nach 48 Stunden Inkubation mit PE bzw. ET-1 eine Akkumulation von ubiquitinierten Proteinen beobachtet, welche ebenfalls durch die HSPA4-Hochregulation supprimiert wurde (Abb. 15 (B und D)) [48h-Ad-EGFP: $1 \pm$ 0,06 vs. Ad-EGFP +PE: 2,83 \pm 0,2; $(\mathrm{p}<0.0001)$ [ [48h-Ad-EGFP: $1 \pm 0,07$ vs. Ad-EGFP +ET-1: 2,63 \pm 0,15; (p<0.0001)] [48h-Ad-HSPA4: 0,73 \pm 0,05 vs. Ad-HSPA4 +ET-1: 0,93 \pm 0,09 (p>0.99)] [48h-Ad-HSPA4: $0,93 \pm 0,09$ vs. Ad-HSPA4 +PE: 1,23 $\pm 0,09 ;(p=0,0386)]$.

Im direkten Vergleich ließ sich eine hochsignifikante Reduktion ubiquitinierter Proteine nach Stimulation mit PE bzw. ET-1 zwischen Ad-HSPA4- und Ad-EGFP-transduzierten Kardiomyozyten im Bonferroni-korrigierten-Post-Hoc-Test nachweisen.

Eine adenovirale Überexpression von HSPA4 senkte somit unter basalen Bedingungen signifikant die Menge ubiquitinierter Proteine in Kardiomyozyten und supprimierte deren Akkumulation unter Stimulation mit PE bzw. ET-1.

\subsection{HSPA4-Überexpression reduziert die PE- und ET-1-induzierte Hypertrophie}

Die PE- und ET-1-induzierte Hypertrophie in isolierten, ventrikulären Kardiomyozyten neonataler Ratten ist fundiert beschrieben worden (Bupha-Intr et al. 2012; Peter et al. 2016). Um den Einfluss von HSPA4 auf das Zellwachstum in NRCM nach Stimulation mit PE und ET-1 zu evaluieren, wurden diese 72 Stunden nach der Isolation mit $1 \mu \mathrm{L}$-Viruslösung des Ad-HSPA4 transduziert. Zum Ausgleich der Viruslast wurden Kontrollzellen mit einem EGFP-Adenovirus transduziert. Um eine Hypertrophie zu erzielen, wurden 24 Stunden nach der Transduktion Zellen für 24 und 48 Stunden mit $10 \mu \mathrm{M}$ PE bzw. 50 nM ET-1 inkubiert. 
Die Zellen wurden unter 40-facher Vergrößerung fotografiert und die Zellengröße mit dem Programm ImageJ vermessen. Die graphische Darstellung erfolgte relativ auf die durchschnittliche Oberfläche der EGFP-Adenovirus-behandelten Zellen bezogen. In den AdEGFP transduzierten Zellen induzierte die Inkubation mit PE eine Hypertrophie von 45\%, mit ET-1 von 46\% (Abb. 16 (A und B)) [Ad-EGFP: $1 \pm$ 0,02 vs. Ad-EGFP +PE: 1,45 \pm 0,07; (p<0.0001)] [Ad-EGFP: $1 \pm 0,02$ vs. Ad-EGFP +ET-1: 1,46 \pm 0,03; $(\mathrm{p}<0.0001)]$.

Während eine reine Überexpression von HSPA4, verglichen mit Kontrollzellen, zu keiner Änderung der Zellgröße führte, inhibierte die adenovirale Hochregulation von HSPA4 signifikant das hypertrophe Wachstum unter PE nach 24 Stunden, jedoch nicht unter ET-1 (Abb. 16 (A und B)) [Ad-EGFP: $1 \pm 0,02$ vs. Ad-HSPA4: $0.80 \pm 0.06$; ( $p=0.1195)$ ] [AdHSPA4: 0,80 \pm 0,06 vs. Ad-HSPA4 +PE: 0,99 \pm 0,05; $(\mathrm{p}=0.1510)$ ] [Ad-HSPA4: 0,80 \pm 0,06 vs. Ad-HSPA4 +ET-1: 1,05 \pm 0,05; $(\mathrm{p}=0.0192)]$.

Im direkten Vergleich reduzierte die HSPA4-Überexpression signifikant die PE- bzw. ET-1induzierte Hypertrophie nach 24 Stunden .

Nach 48 h wurde eine Zellgrößenzunahme unter PE von 61\%, unter ET-1 von 59\% gemessen (Abb. 16 (A und C)) [Ad-EGFP: $1 \pm 0,03$ vs. Ad-EGFP +PE: 1,59 \pm 0,08; $(\mathrm{p}<0.0001)]$ [Ad-EGFP: $1 \pm 0,03$ vs. Ad-EGFP +ET-1: 1,59 \pm 0,05; $(\mathrm{p}<0.0001)]$.

Auch hier reduzierte die Überexpression von HSPA4 eine Hypertrophieentwicklung (Abb. 16 (A und B)) [Ad-HSPA4: 0,86 \pm 0,04 vs. Ad-HSPA4 +PE: 1,11 \pm 0,05; (p =0.078)] [AdHSPA4: 0,86 \pm 0,04 vs. Ad-HSPA4 + ET-1: 1,16 \pm 0,08; $(\mathrm{p}=0.016)]$.

In diesem Versuch ließ sich mit PE und ET-1 jeweils eine signifikante Hypertrophie in AdEGFP-transduzierten NRCM induzieren. Durch Überexpression von HSPA4 mittels adenoviraler Transduktion konnte dieser Wachstumseffekt signifikant inhibiert werden. 
A
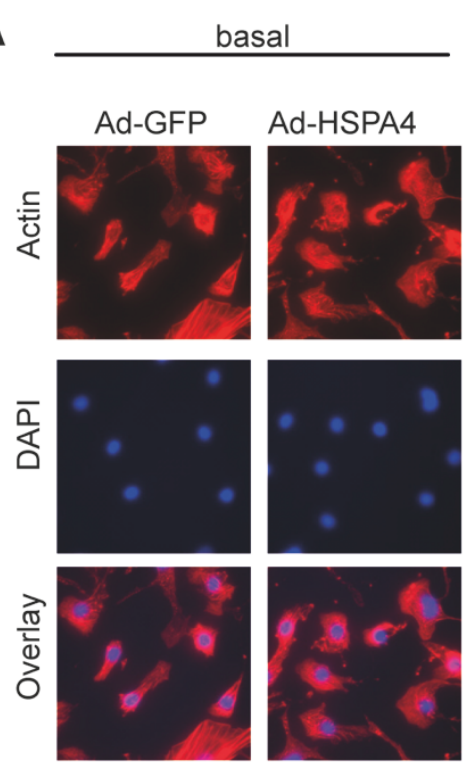

B
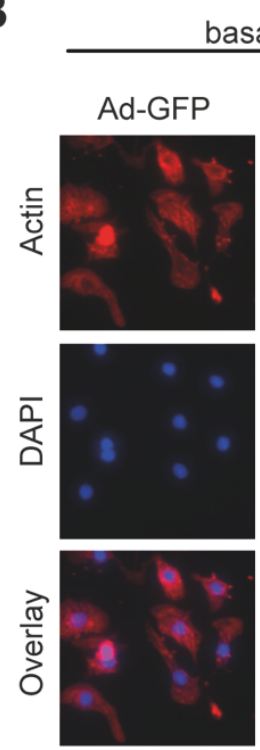

C
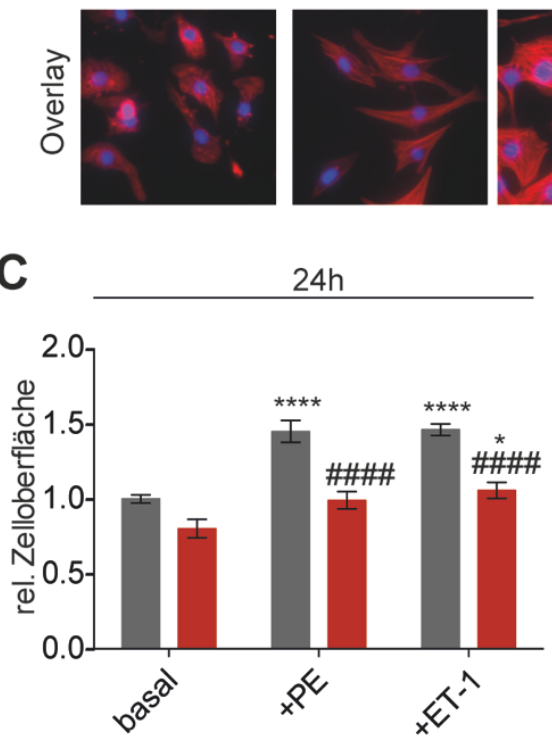

Phenylephrin
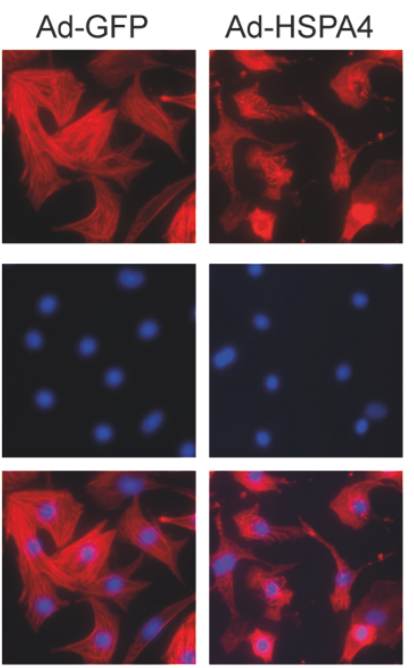

Phenylephrin
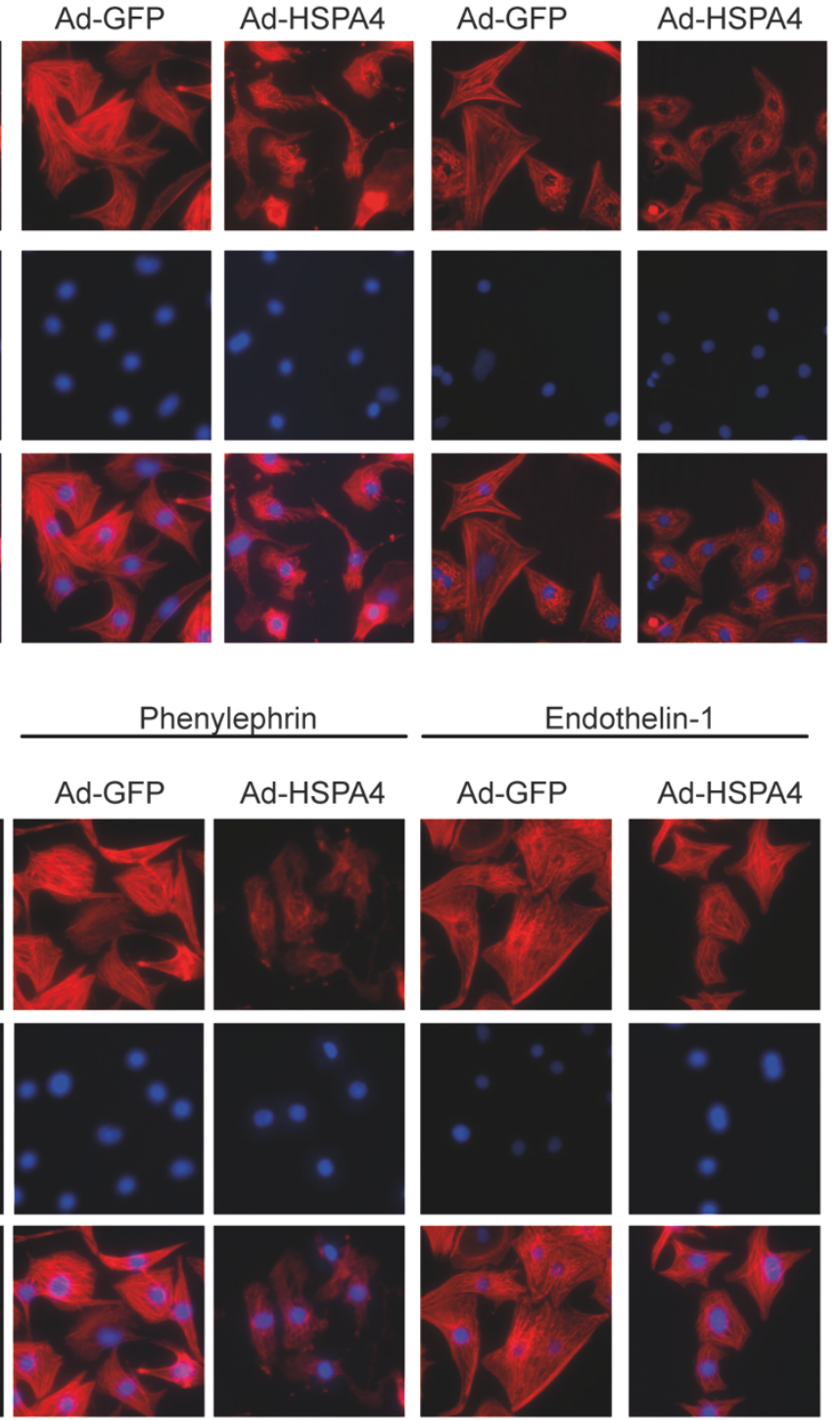

$24 \mathrm{~h}$

Endothelin-1

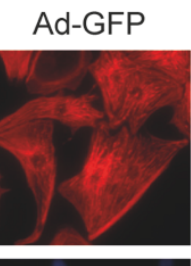

Ad-HSPA4
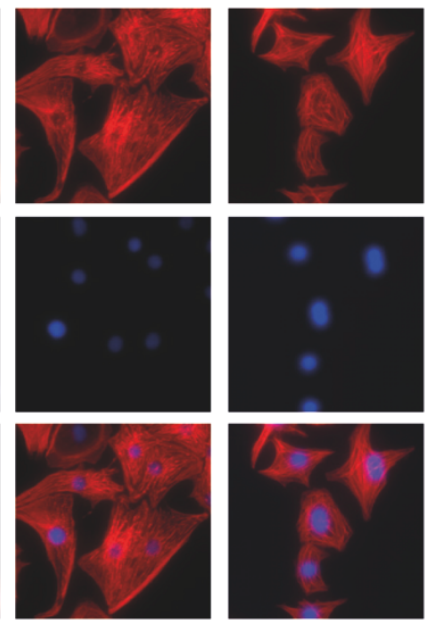

$48 \mathrm{~h}$
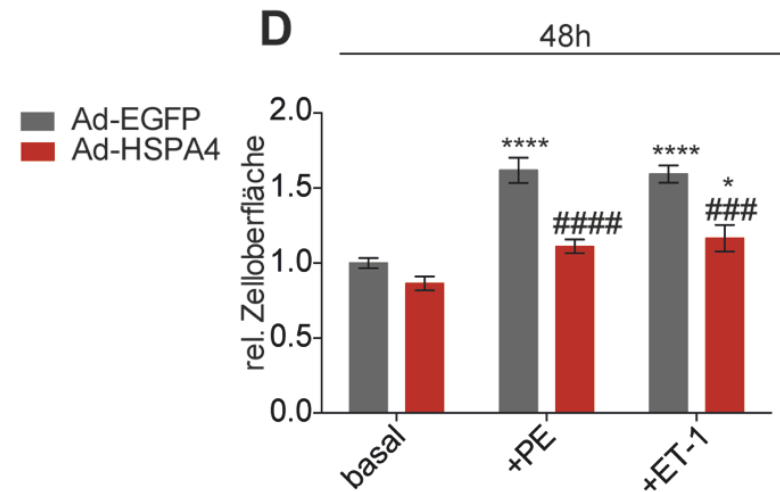

Abb. 16: Graphische Auswertung der Zelloberfläche nach adenoviraler Transduktion zur Überexpression und Stimulation mit $10 \mu \mathrm{M}$ PE und 50 nM ET-1. (A) Repräsentative Immunfluoreszenzbilder mit Phalloidin und DAPI von NRCM nach 24-stündiger Stimulation. (B) Repräsentative Immunfluoreszenzbilder mit Phalloidin und DAPI von NRCM nach 48-stündiger 
Stimulation. (C) Graphische Darstellung der Zellgrößen nach 24 h Stimulation. (D) Graphische Darstellung der Zellgrößen nach 48 h Stimulation. Pro Bedingung und pro Experiment wurden mindestens 40 Zellen ausgewertet. Die Werte wurden relativ zum Mittelwert der basal Ad-EGFPtransduzierten Zellen aufgetragen. Die Fehlerbalken stellen den Standardfehler dar. ( $n=3)$ Test: TwoWay-ANOVA mit Bonferroni-Post-Hoc-Test. Fehlerbalken zeigen den Standardfehler. ${ }^{*} \mathrm{p}<0,05$ ge-

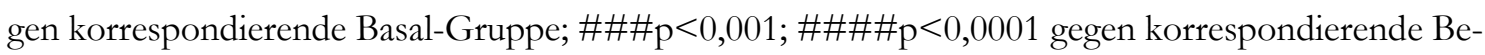
handlung.

\subsection{Relative Fluoreszenzintensität unter Stimulation mit PE und ET-1}

Die Höhe der Signalintensität von adenoviral-transduzierten Zellen korreliert mit der EGFPSynthese und der Höhe an EGFP in der Zelle. Dieses wiederum korreliert mit der Gesamtproteinsynthese und der Genexpression in der Zelle, wenn die Fluoreszenz mittels Durchflusszytometrie gemessen wird (Soboleski et al. 2005; Vettel et al. 2012). Zur Messung der Fluoreszenzintensität in isolierten, ventrikulären Kardiomyozyten neonataler Ratten wurden Kardiomyozyten mit einem EGFP-Adenovirus und einem HSPA4-kodierenden Adenovirus, der zusätzlich noch für EGFP kodiert, adenoviral transduziert und für 24 und 48 Stunden jeweils mit PE bzw. ET-1 stimuliert.

Danach wurden unter standardisierten Bedingungen (Ausschalten externer Lichtquellen, gleiche Belichtungszeit und gleiche Vergrößerung etc.) drei repräsentative Bilder mit einem Fluoreszenzmikroskop aufgenommen und die Signalintensität der Bilder mit dem Programm Image J gemessen.

So führte die Behandlung mit PE in den Kontrollzellen nach 24 Stunden zu einem 237\% stärkerem Signal im Vergleich zu unstimulierten, Ad-EGFP-transduzierten Zellen, wohingegen in HSPA4-überexprimierten Kardiomyozyten lediglich ein 193\% stärkeres Signal gemessen wurde (Abb. 17 (A und B)) [Ad-EGFP +PE: 2,37 \pm 0,1 vs. Ad-HSPA4 +PE: 1,54 \pm 0,08; $(\mathrm{p}<0.0001)]$. In der Analyse der Inkubation mit ET-1 nach 24h konnte in den Kontrollzellen ein Anstieg der Fluoreszenz um 96\% ermittelt werden, in den HSPA4-Zellen lediglich ein Anstieg um 68\% (Abb. 17 (A und B)) [Ad-EGFP +ET-1: 1,96 \pm 0,06 vs. AdHSPA4 +ET-1: $1,35 \pm 0,06(\mathrm{p}<0.0001)]$. 
A

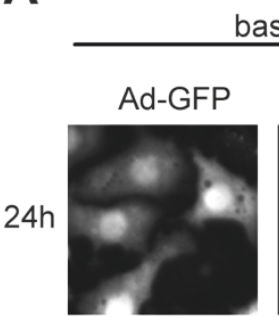

basal

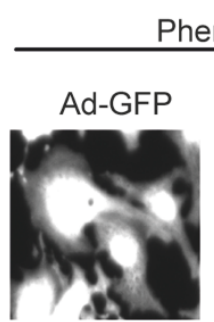

Phenylephrin Endothelin-1

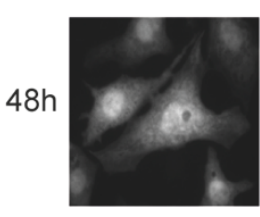

B

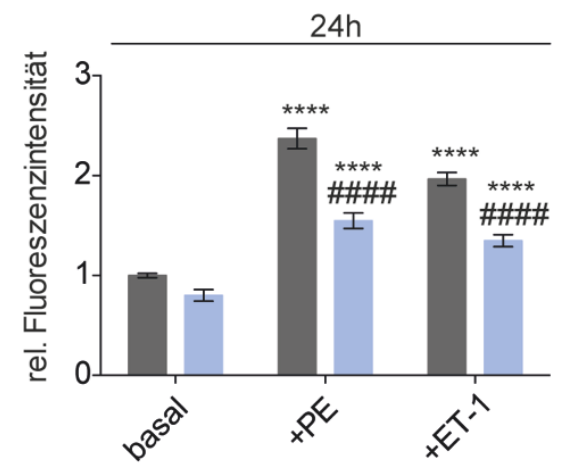

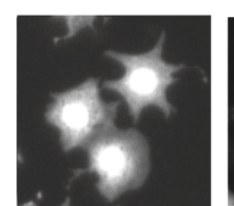

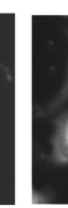

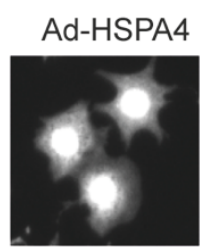

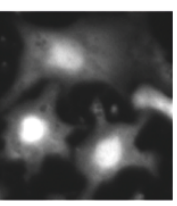

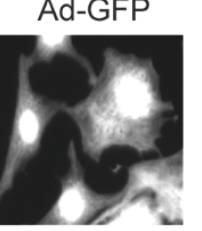

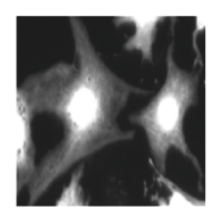

C

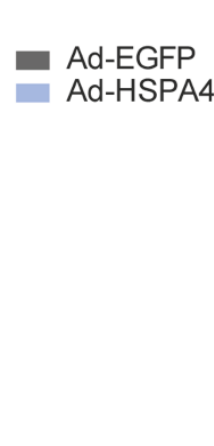

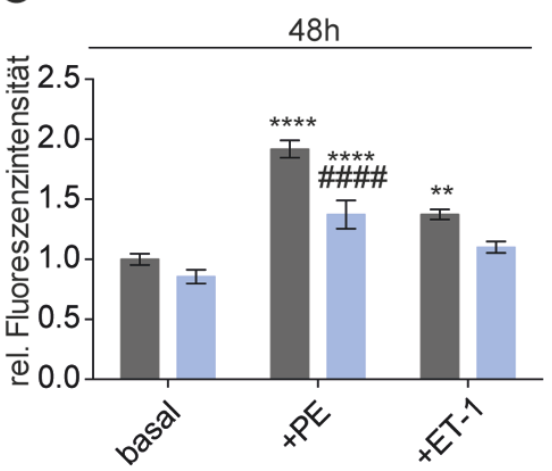

Abb. 17: Graphische Auswertung der Fluoreszenzintensität nach adenoviraler Transduktion zur Überexpression von HSPA4 und Stimulation mit $10 \mu \mathrm{M}$ PE und 50 nM ET-1. (A) Repräsentative Immunfluoreszenzbilder von ventrikulären Kardiomyozyten. (B) Graphische Darstellung der Fluoreszenzintensität nach 24 h. (C) Graphische Darstellung der Fluoreszenzintensität nach 48 h. Pro Bedingung und pro Experiment wurden mindestens 40 Zellen ausgewertet. Die Werte wurden relativ zum Mittelwert der basal Ad-EGFP-transduzierten Zellen aufgetragen. Die Fehlerbalken stellen den Standardfehler dar. ( $\mathrm{n}=3$ ) Test: Two-Way-ANOVA mit Bonferroni-Post-Hoc-Test. Fehlerbalken zeigen den Standardfehler. ${ }^{* *} \mathrm{p}<0.01 ;{ }^{* * * *} \mathrm{p}<0.0001$ gegen korrespondierende Basal-Gruppe; $\# \# \#$ $<<0.0001$ gegen korrespondierende Stimulation.

Nach 48 Stunden konnte in den Kontrollzellen, welche mit PE kultiviert wurden, ein 191\% höheres Signal detektiert werden, in HSPA4-überexprimierten Kardiomyozyten hingegen lediglich um 160\%(Abb. 17 (A und C)) [Ad-EGFP +PE: 1,91 \pm 0,07 vs. Ad-HSPA4 +PE: $1,37 \pm 0,11 ;(p<0.0001)]$. Zwar wurde in Ad-EGFP +ET-1 verglichen mit den basalen Werten der Ad-EGFP-Zellen, eine signifikant höhere Fluoreszenzintensität gemessen $(p=0,0053)$, jedoch ergab der Bonferroni-Post-Hoc-Test keinen statistischen Unterschied zwischen Ad-EGFP +ET-1- und Ad-HSPA4 +ET-1-Zellen ( $\mathrm{p}=0,1078$ ) (Abb. 17 (A und C)). 
Wenn die hier angewandte Messmethode auf die von Soboleski et al. beschriebene Korrelation von Signalintensität auf Gesamtproteinsynthese der Zelle übertragbar ist, führte die HSPA4-Überexpression verglichen mit Ad-EGFP transduzierten Zellen unter Stimulation mit PE oder ET-1 nach 24 und 48 Stunden zu einer signifikant geringeren Proteinsynthese in ventrikulären Kardiomyozyten neonataler Ratten.

\subsection{HSPA4-spezifische Herunterregulation mittels siRNA}

Bevor der Einfluss von PE und ET-1 in HSPA4-herunterregulierten NRCM untersucht werden konnte, wurde zunächst die Effizienz mehrerer HSPA4-spezifischer siRNAs getestet, die nur Bindung an HSPA4-mRNA-Replikate das Ablesen und die Proteintranslation inhibieren.

A

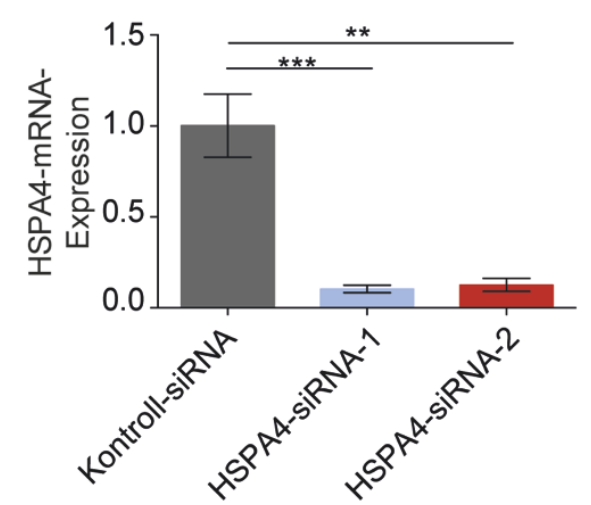

B

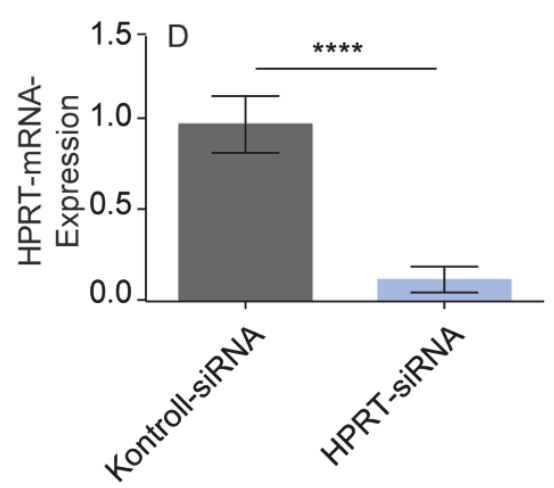

Abb. 18: Überprüfung der HSPA-Herunterregulation mittels rt-PCR. (A) Quantitative Auswertung der rt-PCR von HSPA4-mRNA nach 24-stündiger Inkubation mit HSPA4-siRNA. Normalisiert auf HPRT. (n=2) (B) Positiv-Kontrolle mit HPRT-spezifischer siRNA. Quantitative Auswertung der HPRT-spezifischen Herunterregulation. Normalisiert auf GAPDH. Test: One-WayANOVA mit Bonferroni-Post-Hoc-Test bzw. ungepaarter Student's T-Test Die Fehlerbalken zeigen den Standardfehler. ${ }^{* *} \mathrm{p}<0,01 ;{ }^{* * *} \mathrm{p}<0.001 ;{ }^{* * * *} \mathrm{p}<0.0001$

Hierzu wurden Zellen in Antibiotika-freiem, 2\%-FCS-haltigem Medium für 24 Stunden und 48 Stunden mit einer HSPA4-spezifischen siRNA inkubiert.

Es konnte zusätzlich mittels Western Blots für beide getesteten HSPA4-spezifischen siRNAs auf Proteinebene eine signifikante Herunterregulation auf 26\% für HSPA4-siRNA-2 bzw. 34\% für HSPA4-sirRNA-1 erzielt werden. [Kontroll-siRNA: $1 \pm$ 0,07 vs. HSPA4-siRNA-1: 0,34 \pm 0,01; $(\mathrm{p}<0.0001)]$ [Kontroll-siRNA: $1 \pm 0.07$ vs. HSPA4-siRNA-2: 0,26 \pm 0,03; $(\mathrm{p}<0.0001)]$ (Abb. 19 (A und B)). 
A

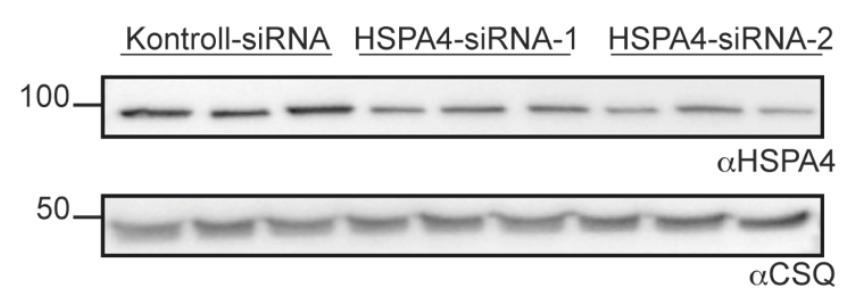

B

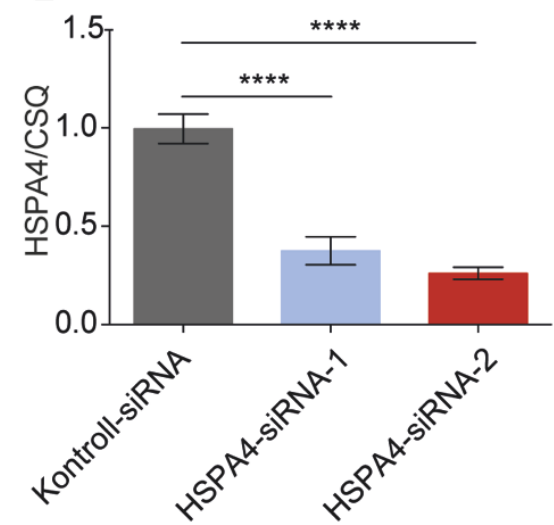

Abb. 19: Überprüfung der HSPA-Herunterregulation mittels Western Blot und rt-PCR.

(A) Western Blot mit Antikörper gegen HSPA4 und CSQ nach 24 h Inkubation mit zwei HSPA4spezifischen-siRNAs. Die Ladekontrolle erfolgte mittels CSQ. (B) Quantitative Auftragung der HSPA4-Herunterregulation. Das Verhältnis von HSPA4 gegen CSQ ist aufgetragen. ( $n=2)$ (C) Quantitative Auswertung der rt-PCR von HSPA4-mRNA nach 24-stündiger Inkubation mit HSPA4siRNA. Normalisiert auf HPRT. ( $\mathrm{n}=2$ ) (D) Positiv-Kontrolle mit HPRT-spezifischer siRNA. Quantitative Auswertung der HPRT-spezifischen Herunterregulation. Normalisiert auf GAPDH. Test: One-Way-ANOVA mit Bonferroni-Post-Hoc-Test bzw. ungepaarter student's T-Test Die Fehlerbalken zeigen den Standardfehler. ${ }^{* * *} \mathrm{p}<0.001 ;{ }^{* * * *} \mathrm{p}<0.0001$

Neonatale Rattenkardiomyozyten, die für 48 Stunden mit siRNA inkubiert wurden, zeigten hingegen weder auf Proteinebene noch auf mRNA-Ebene eine relevante Herunterregulation von HSPA4 bzw. HSPA4-mRNA (nicht gezeigt). Daher wurde für Experimente mit siRNA lediglich das 24 Stundenintervall genutzt. 


\subsection{ANP- und BNP-Level unter PE und ET-1 in HSPA4-}

\section{herunterregulierten Kardiomyozyten}

Zur Untersuchung der kardialen Hormone ANP und BNP auf Genebene wurde eine rt-PCR mit Lysaten von isolierten, ventrikulären Rattenkardiomyozyten durchgeführt.

Diese wurden 72 Stunden nach der Isolation mit einer HSPA4-spezifischen siRNA kultiviert. Kontrollzellen wurden mit einer unspezifischen siRNA kultiviert. Parallel wurden Zellen zusätzlich mit PE (PE: $10 \mu \mathrm{M})$ und ET-1 (ET-1: $50 \mathrm{nM}$ ) behandelt und für 24 Stunden inkubiert.

A

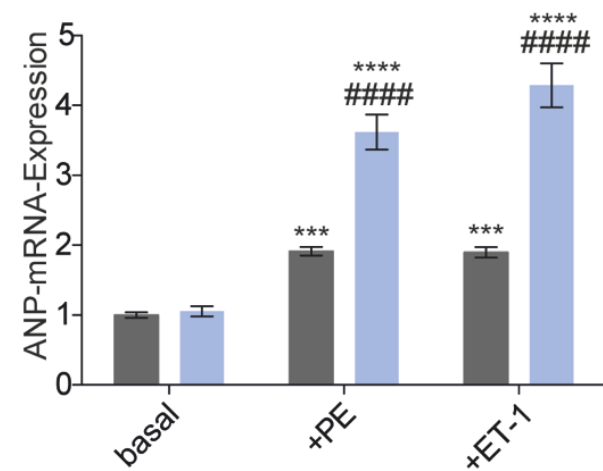

B

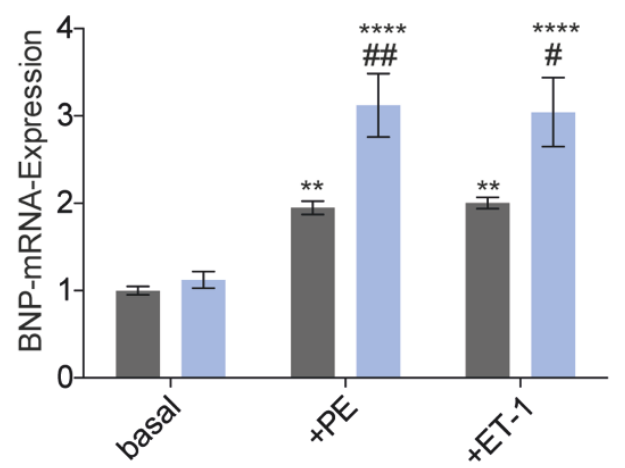

Abb. 20: Quantitative Auswertung der ANP-mRNA- und BNP-mRNA-Expression nach siRNA-vermittelter HSPA4-Herunterregulation und Stimulation mit $10 \mu \mathrm{M}$ PE und $50 \mathrm{nM}$ ET-1. (A) Quantitative Auswertung der ANP-mRNA-Expression nach 24 h. (B) BNP-mRNAExpression nach 24 h. Die Werte wurden auf HPRT normalisiert. (n=3) Test: Two-Way-ANOVA mit Bonferroni-Post-Hoc-Test. Die Fehlerbalken zeigen den Standardfehler. ${ }^{* *} \mathrm{p}<0.01 ;{ }^{* *} \mathrm{p}<0.001$; ${ }^{* * * *} \mathrm{p}<0.0001$ gegen korrespondiere Basal-Gruppe; $\# \mathrm{p}<0.05 ; \# \# \mathrm{p}<0.01 ; \# \# \# \# \mathrm{p}<0.0001$ gegen korrespondierende Stimulation.

Die Kultivierung von HSPA4-siRNA-Kardiomyozyten mit PE führte zu einem signifikanten Anstieg der ANP-mRNA auf 361\%, die BNP-mRNA-Expression auf 300\% (Abb. 20 (A und B)) [ANP HSPA4-siRNA: 1,05 \pm 0,07 vs. HSPA4-siRNA + PE: 3,61 $\pm 0,24 ;(\mathrm{p}<0.0001)]$ [BNP: HSPA4-siRNA: 1,1 \pm 0,1 vs. HSPA4-siRNA + PE: 3,12 $\pm 0,36 ;(p<0.0001)]$. Ebenso führte ET-1 zu einer Erhöhung von ANP auf über das 4-Fache, von BNP auf das 3-Fache in den HSPA4-herunterregulierten Kardiomyozyten [ANP HSPA4-siRNA: 1,05 \pm 0,07 vs. HSPA4-siRNA + ET-1: 4,28 \pm 0,31; $(\mathrm{p}<0,0001)]$ [(BNP: HSPA4-siRNA: 1,1 \pm 0,1 vs. HSPA4-siRNA +ET-1: 3,04 \pm 0,39; $(\mathrm{p}<0,0001)]$. 
Doch auch in den Kontroll-siRNA-Zellen verursachte die Stimulation eine statistisch signifikante Erhöhung beider ANP- bzw. BNP-Level, die allerdings im direkten Vergleich zu den HSPA4-herunterregulierten Kardiomyozyten signifikant geringer ausfiel [ANP HSPA4siRNA +PE: 3,61 \pm 0,24 vs. Kontroll-siRNA+ PE : 1,91 \pm 0,06 (p<0.0001)] [ANP: HSPA4siRNA + ET-1: 4,28 \pm 0,31 vs. Kontroll-siRNA + ET-1: 1,89 $\pm 0,07(\mathrm{p}<0.0001)][B N P$ HSPA4-siRNA + PE: 3,12 \pm 0,36 vs. Kontroll-siRNA+ PE : 1,94 $\pm 0,07(p<0.0001)]$ [BNP: HSPA4-siRNA + ET-1: 3,04 \pm 0,39 vs. Kontroll-siRNA + ET-1: 2,0 \pm 0,06 $(\mathrm{p}<0.0001)]$.

Zusammengefasst führte eine HSPA4-Herunterregulation unter Stimulation mit PE oder ET-1 nach 24 h zu einer signifikant höheren ANP- und BNP-Expression als in Kontrollzellen.

\subsection{HSPA4-Herunterregulation fördert die Akkumulation ubiquitinierter Proteine}

Um den Einfluss des Hitzeschockproteins A4 in HSPA4-herunterregulierten Kardiomyozyten auf die Menge von ubiquitinierten Proteinen zu untersuchen, wurden isolierte, ventrikuläre Kardiomyozyten neonataler Ratten 72 Stunden nach der Isolation mit einer HSPA4spezifischen siRNA inkubiert, wohingegen Kontrollzellen mit einer siRNA behandelt wurden, deren Basenabfolge keine in Ratten komplementäre HSPA4-mRNA bindet. Zeitgleich erfolgte die Inkubation mit PE und ET-1. Durch die Herunterregulation von HSPA4 konnte ein Anstieg ubiquitinierter Proteine auf 340\% beobachtet werden. [Kontroll-siRNA: $1 \pm$ 0,1 vs. HSPA4-siRNA: 3,4 \pm 0,1; $(\mathrm{p}<0,0001)]$. Während in den Kontroll-siRNA-Zellen durch die Kultivierung mit PE bzw. ET-1 ein Anstieg um 79\% bzw. 240\% gezeigt werden konnte, blieb die Menge ubiquitinierter Proteine in den HSPA4-siRNA-Kardiomyozyten annährend auf einem Niveau (Abb. 21 (A und B)) [Kontroll-siRNA: $1 \pm 0,1$ vs. Kontroll-siRNA +PE: $1,79 \pm 0,22 ;(\mathrm{p}=0,0468)$ ] [Kontroll-siRNA: $1 \pm 0,1$ vs. Kontroll-siRNA +ET-1: 2,47 \pm 0.23; $(p<0,0001)$ ] [HSPA4-siRNA: 3,44 \pm 0,15 vs. HSPA4-siRNA +PE: 3,14 $\pm 0,15 ;(p>0,9999)$ ] [HSPA4-siRNA: 3,44 \pm 0,15 vs. HSPA4-siRNA +ET-1: $3.66 \pm$ 0.19; ( $>$ >0,9999)].

In der Auswertung der korrespondierenden PE-Zellen ließ sich ein statistisch signifikanter Unterschied aufzeigen $(\mathrm{p}=0,0002)$, ebenso in den korrespondierenden ET-1-Zellen $(p=0,0009)$. Die Herunterregulation von HSPA4 führte zur signifikanten Akkumulation ubiquitinierter Proteine, die zwar unter Stimulation nicht weiteranstiegen, dennoch signifikant höher lagen als den stimulierten Kontrollzellen. 
A

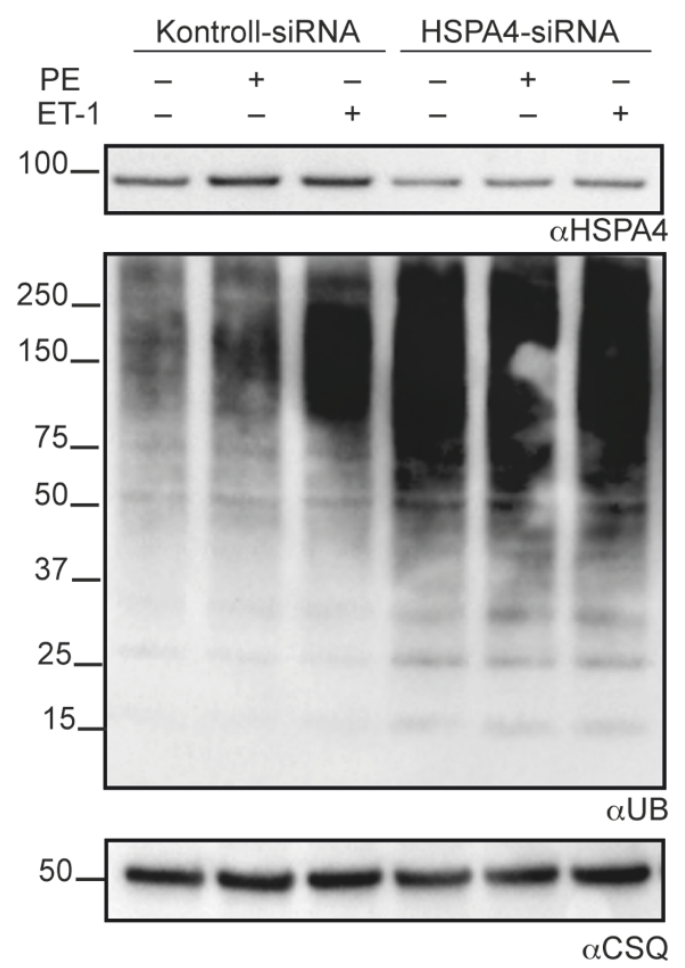

B

Kontroll-siRNA

HSPA4-siRNA

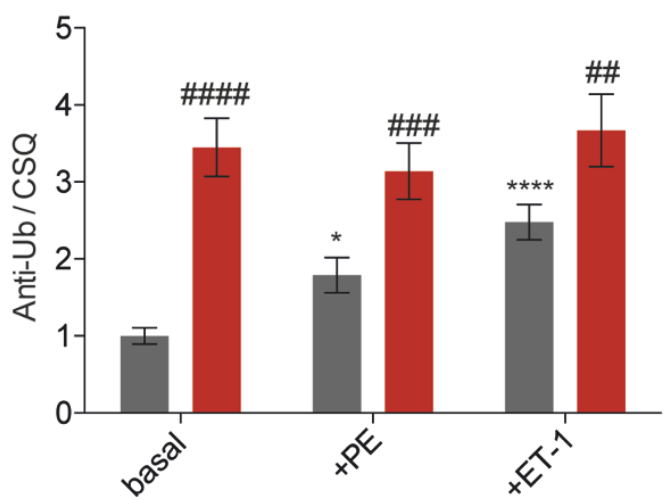

Abb. 21: Nachweis ubiquitinierter Proteine in HSPA4-herunterregulierten Kardiomyozyten unter Stimulation mit $10 \mu$ M PE bzw. 50 nM ET-1. (A) Western Blot mit Antikörper gegen Ubiquitin und HSPA4 nach 24-stündiger Inkubation mit PE bzw. ET-1. Als Ladekontrolle wurde die Membran vom Anti-Ubiquitin-Antikörper gewaschen und mit CSQ-Antikörper inkubiert. (B) Quantitative Auswertung ubiquitinierter Konjugate nach 24 h. Normiert gegen CSQ. ( $n=5)$ Test: Two-Way-ANOVA mit Bonferroni-Post-Hoc-Test. Fehlerbalken zeigen den Standardfehler. ${ }^{*} \mathrm{p}<0.05 ; \quad{ }^{* * * *} \mathrm{p}<0.0001 \quad$ gegen korrespondierende Basal-Gruppe; $\# \mathrm{p}<0.05 ; \quad \# \# \# \mathrm{p}<0.01 ;$ $\# \# \#$ $<<0.0001$ gegen korrespondierende Behandlung 


\subsection{HSPA4-Herunterregulation begünstigt PE- und ET-1-induzierte}

\section{Hypertrophie}

Um das Zellwachstumsverhalten von isolierten, ventrikulären Kardiomyozyten neonataler Ratten zu messen, in denen HSPA4 mittels einer spezifischen HSPA4-siRNA herunterreguliert wurde, wurden Zellen 72 Stunden nach Isolation mit einer HSPA4-spezifischen siRNA kultiviert.

A
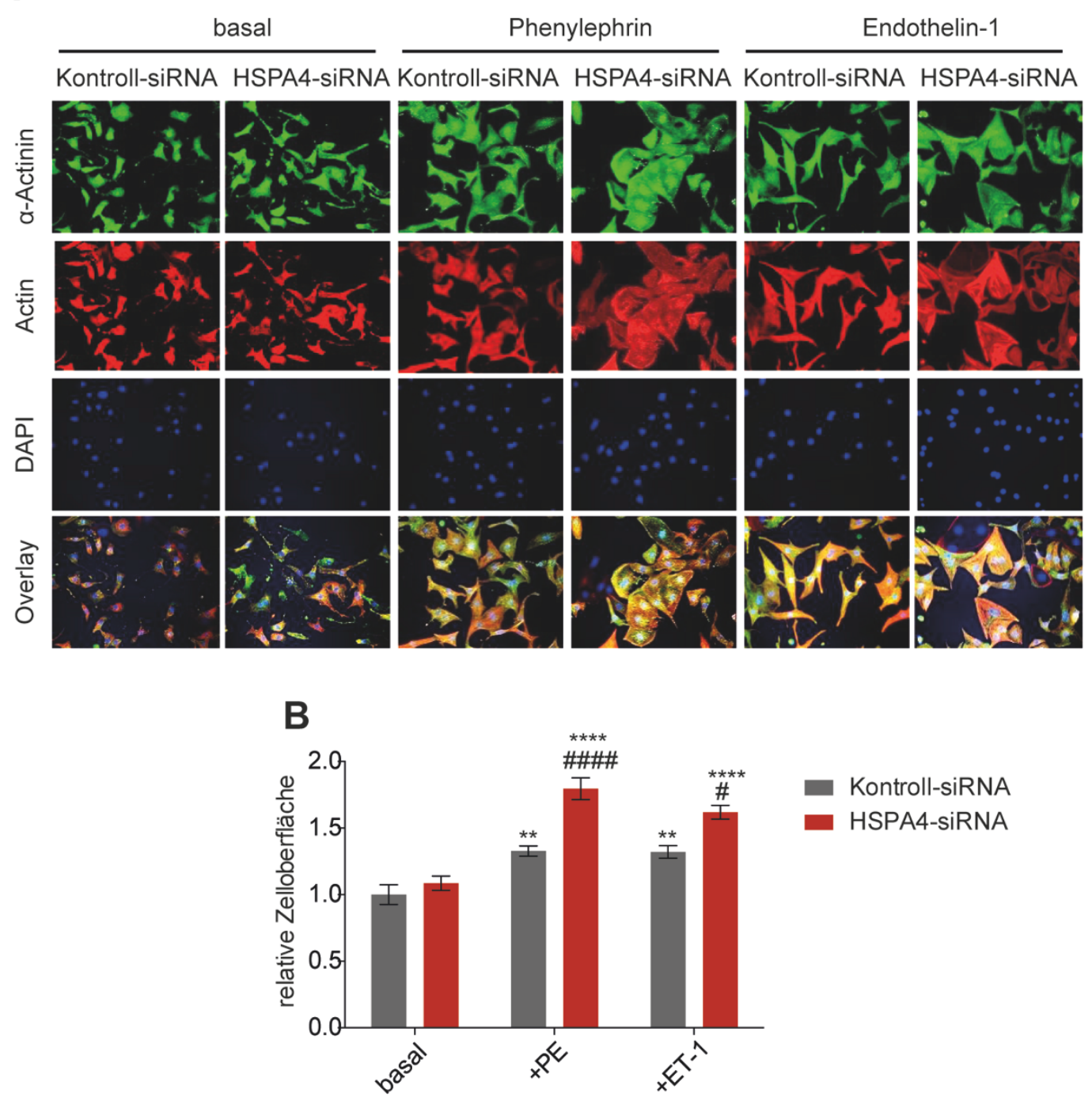

Abb. 22: Graphische Auswertung der Zelloberfläche nach Herunterregulation von HSPA4 und Stimulation mit $10 \mu \mathrm{M}$ PE und $50 \mathrm{nM}$ ET-1. (A) Repräsentative Immunfluoreszenzbilder mit $\alpha$-Actinin, Phalloidin und DAPI von NRCM. (B) Graphische Darstellung der Zellgrößen nach 24 Stunden. Pro Bedingung und pro Experiment wurden mindestens 70 Zellen ausgewertet. Die Werte wurden relativ zum Mittelwert der basalen Kontroll-siRNA-transfizierten Zellen aufgetragen. Die Fehlerbalken stellen den Standardfehler dar. ( $\mathrm{n}=3)$ Test: Two-Way-ANOVA mit Bonferroni-PostHoc-Test. Fehlerbalken zeigen den Standardfehler. ${ }^{*} \mathrm{p}<0.01 ;{ }^{* * * *} \mathrm{p}<0.0001$ gegen korrespondierende Basal-Gruppe; $\# \mathrm{p}<0.05 ; \# \# \# \# \mathrm{p}<0.0001$ gegen korrespondierende Stimulation. 
Während in den Kontrollzellen unter PE bzw. ET-1 eine Hypertrophie von jeweils 32\% gemessen wurde, resultierte aus der HSPA4-Herunterregulation eine Zellgrößenzunahme von 79\% unter PE und 61\% unter ET-1 (Abb. 22 (A und B)). [Kontroll-siRNA: $1 \pm$ 0,07 vs. Kontroll-siRNA +PE: 1,32 \pm 0,04; $(p=0,0048)$ ] [Kontroll-siRNA: $1 \pm$ 0,07 vs. KontrollsiRNA +ET-1: 1,32 \pm 0,05; $(\mathrm{p}=0,0063)$ ] [HSPA4-siRNA: $1,08 \pm 0,05$ vs. HSPA4-siRNA +PE: 1,79 \pm 0,08; $(\mathrm{p}<0.0001)$ ] [HSPA4-siRNA: 1,08 \pm 0,05 vs. HSPA4-siRNA +ET-1: 1,61 $\pm 0,04 ;(\mathrm{p}<0.0001)]$.

Die Herunterregulation von HSPA4 begünstigte und steigerte somit das PE- und ET-1induzierte Zellwachstum signifikant im Vergleich zu Kontrollzellen nach 24 Stunden. 


\section{Diskussion}

\section{1 Überblick über die Ergebnisse}

Herzerkrankungen wie die chronisch ischämische Herzkrankheit, der akute Myokardinfarkt und die Herzinsuffizienz stellen in Deutschland die drei häufigsten Todesursachen dar (Statistisches Bundesamt 2015). Alle Erkrankungen gehen mit einer vermehrten Akkumulation ubiquitinierter Proteine in Zellen des Herzens einher (Willis und Patterson 2013). Die PQC bestehend aus Chaperonen, dem Ubiquitin-Proteasom-System und der Autophagie nimmt eine wichtige Stellung in der Erhaltung der zellulären Homöostase ein. Ein Zellkulturmodell mit isolierten, ventrikulären Kardiomyozyten neonataler Ratten bietet geeignete Voraussetzungen, die Wirkung an der PQC-beteiligter Proteine durch Modulation der Expressionshöhe zu charakterisieren und unter Stimulation mit PE bzw. ET-1 zu untersuchen. In dieser Arbeit konnte gezeigt werden, dass in NRCM eine Stimulation mit PE oder ET-1 eine kompensatorische Hochregulation von HSPA4 induzierte. Dies wurde sowohl im Western Blot auf Proteinebene als auch mittels rt-PCR auf Transkriptionsebene nachgewiesen. Mithilfe eines adenoviralen HSPA4-Konstrukts konnte eine signifikante Überexpression von HSPA4 erzielt werden, wohingegen mit einer HSPA4-spezifischen siRNA eine verlässliche Herunterregulation von HSPA4 erreicht wurde. In der planimetrischen Auswertung führte eine adenovirale HSPA4-Überexpression zu einer signifikanten Inhibition der PE- oder ET1-induzierten Hypertrophie. Mittels rt-PCR wurde die Höhe der Hypertrophiemarker ANP und BNP bestimmt. HSPA4-überexprimierende Kardiomyozyten zeigten unter Stimulation mit PE oder ET-1 keine steigenden ANP- oder BNP-Werte, wohingegen in Kontrollkardiomyozyten ein deutlicher Anstieg beobachtet werden konnte. Damit einhergehend zeigten HSPA4-überexprimierende Kardiomyozyten eine signifikante Reduktion ubiquitinierter Proteine auf, deren Menge auch unter Stimulation von PE oder ET-1 nicht anstieg. Im Kontrast dazu aggravierte in der planimetrischen Auswertung die durch PE- oder ET-1ausgelöste Hypertrophie in HSPA4-herunterregulierten Kardiomyozyten. In diesem Zusammenhang zeigten HSPA4-herunterregulierte Kardiomyozyten auch vermehrte Hypertrophiemarker wie ANP und BNP. Durch die siRNA-vermittelte HSPA4-Herunterregulation akkumulierten ubiquitinierte Proteine. Es kam in diesen Zellen unter Stimulation mit PE oder ET-1 zu keinem weiteren signifikanten Anstieg ubiquitinierter Proteine. 


\subsection{Validität des Versuchsmodells}

Mohamed et al. fanden 2012 heraus, dass die HSPA4-Expression kompensatorisch in einem TAC-Mausmodell und in humanen Proben von Patienten mit Aortenklappenstenose erhöht ist. Damit identifizierten sie mit der Nachlasterhöhung einen wichtigen Induktor für die HSPA4-Expression im Herzen. Im Gegensatz dazu führte eine Vorlasterhöhung zu keiner relevanten Zunahme von HSPA4. Weiterhin akkumulierten in HSPA4 ${ }^{-/-}-\mathrm{KO}-\mathrm{Mäusen}$ ubiquitinierte Proteine, wie sie auch in mehreren kardiovaskulären Erkrankungen gefunden werden (Pattison et al. 2008; Tannous et al. 2008). Basierend auf diesen Vorstudien sollte mittels einer adenoviralen Transduktion und mittels einer siRNA-vermittelten Herunterregulation der Einfluss von HSPA4 auf die Stimulation mit PE und ET-1 untersucht werden. In Abschnitt 3.1 wurden NRCM $72 \mathrm{~h}$ nach Isolation mit $10 \mu \mathrm{M}$ PE (Gan et al. 2005)und 50 nM ET-1 (Sakai et al. 2012) für 24 und 48 h inkubiert und die HSPA4-Expression im Western Blot überprüft. Während Mohamed et al. in humanen und murinen Proben eine um das 2,5Fache erhöhte HSPA4-Expression ermittelte, lag diese auf Proteinebene in Zellkultur-bedingungen deutlich niedriger. Es zeigte sich, dass nach 24-stündiger Inkubation ET-1 eine signifikante HSPA4-Hochregulation bewirkte, wohingegen nach $48 \mathrm{~h}$ sowohl durch PE als auch durch ET-1 beide Stimulanzien eine HSPA4-Überexpression induzierten. Auf Transkriptionsebene zeigte sich, dass die HSPA4-mRNA um das 3-Fache als Zeichen vermehrter Expression anstieg. Damit ist auch das Zellkulturmodell mit NRCM geeignet, mittels beider Stimulanzien PE und ET-1 eine HSPA4-Expression zu bewirken, wenn auch in geringerem Maße. Da unter anderem die Infektion mit Viren einen Trigger für die vermehrte Expression von Hitzeschockproteinen darstellt, wurden Kontrollzellen mit einem EGFP-kodierenden Adenovirus transduziert, um auszuschließen, dass eine adenovirale Transduktion eine HSPA4-Expression bewirkt und um somit vergleichbare Versuchsbedingungen herzustellen (Collins und Hightower 1982; La Thangue und Latchman 1988; Aparicio et al. 2005).

\subsection{Der Einfluss von HSPA4 auf die Expression von ANP und BNP}

Ein wesentliches Merkmal der kardialen Hypertrophie ist neben der Zunahme der Zellgröße und einer erhöhten Proteinsynthese die Aktivierung fetaler Gene (Cox und Marsh 2014). Diese umfassen unter anderem das atriale natriuretische Peptid (ANP) und das natriuretische Peptid Typ B (BNP) (Thum et al. 2007; Barry et al. 2008).

Da neben PE auch ET-1 in Kardiomyozyten eine pathologische Hypertrophie induzieren kann, dient auf transkriptioneller Ebene die Höhe der ANP- und BNP-Replikate als Marker 
für hypertrophierende Kardiomyozyten (Hanford et al. 1994; Magga et al. 1994; Nakagawa et al. 1995).

Unter basalen Bedingungen führte eine reine Überexpression von HSPA4 zu keiner statistisch signifikanten Verminderung der ANP- und BNP-Werte. Auch in HSPA4herunterregulierten Kardiomyozyten ergab sich unter basalen Bedingungen im Gegensatz zu den Ergebnissen von Mohamed et al. 2012 kein statistisch signifikanter Anstieg. Dieser ermittelte im Vergleich zu Wildtypmäusen in 12-Wochen-alten HSPA4 ${ }^{-/-}$-KO-Mäusen vor TAC -Operation einen Anstieg von ANP um das 7-Fache und von BNP um das 4-Fache. In diesem Experiment wurde jedoch eine Maus mit globalem Knockout von HSPA4 verwendet. Daher konnte nicht endgültig bewiesen werden, ob der Anstieg von ANP und BNP auf den kardiomyozyten-spezifischen Knockout von HSPA4 zurückzuführen war oder auf einer systemischen Ursache fußte (Mohamed et al. 2012). Im Gegenzug dazu bewirkte die Transfektion mit HSPA4-spezifischer siRNA in dieser Arbeit eine Herunterregulation auf translationaler Ebene auf durchschnittlich 26\% (siehe Abschnitt 3.4). Es ist daher möglich, dass unter basalen Bedingungen die verbleibende Höhe an HSPA4 ausreichend war einen Anstieg der beiden kardialen Hormone zu verhindern.

PE und ET-1 sind beides potente Stimulanzien auf deren Inkubation NRCM mit einer reaktiven ANP- und BNP-Sekretion reagieren (Schiebinger und Gomez-Sanchez 1990; Sei und Glembotski 1990; Bogoyevitch et al. 1993). Eine HSPA4-Überexpression supprimierte unter Stimulation von PE und ET-1 hochsignifikant einen Anstieg von ANP und BNP. Im Gegensatz dazu stiegen die Werte unter identischen Bedingungen von ANP in den Kontrollzellen unter PE nach 24-stündiger Inkubation auf über 250\% bzw. unter ET-1 auf 470\%. Eine ähnliche Entwicklung zeigte sich auch bei BNP, das unter PE auf 280\% und unter ET-1 auf $450 \%$ anstieg. Im Gegenzug dazu führte die HSPA4-Herunterregulation unter Inkubation mit PE bzw. ET-1 zu einer signifikanten Zunahme der kardialen Hormone ANP und BNP. Diesen Anstieg fand auch Mohamed et al. in HSPA4 $4^{-/}-$KO-Mäusen, der damit auf der kardiomyozytenspezifischen Herunterregulation zu beruhen scheint.

Auf transkriptioneller Ebene konnte mit der Bestimmung der kardialen Stresshormone ANP und BNP unter Stimulation mit PE bzw. ET-1 damit die kardioprotektive Wirkung von HSPA4 aufgezeigt werden. 


\subsection{Der Einfluss von HSPA4 auf die Entwicklung der Zellgröße}

Isolierte ventrikuläre Kardiomyozyten neonataler Ratten sind ein gut etabliertes Versuchsmodell, um den Einfluss spezifischer Proteine auf die Entwicklung einer durch PE- oder ET-1-induzierten pathologischen Hypertrophie zu untersuchen. In mehreren Versuchsmodellen konnte für PE (Zobel et al. 2002; Huang et al. 2015; Nakaoka et al. 2015) ebenso wie für ET-1 (Yamazaki et al. 1996; Menaouar et al. 2014; Archer et al. 2017) eine Aktivierung mehrerer pro-hypertropher Signalwege mit Induktion einer Zellgrößenzunahme nachgewiesen werden.

Je nach gewählter Konzentration und Dauer der Inkubation können NRCM nach PEStimulation um 150\% hypertrophieren (Grebe et al. 2011; Peter et al. 2016). Weitere Studien zeigen sogar eine Verdopplung der Zellgröße unter 24-stündiger Stimulation mit $100 \mu \mathrm{M}$ PE (Shen et al. 2016) und eine fast Verdreifachung der Zellgröße unter 48-stündiger ET-1Stimulation mit einer Konzentration von $100 \mathrm{nM}$ (Jen et al. 2017). In dieser Arbeit wurde eine Konzentration von $10 \mu \mathrm{M}$ PE und 50 nM ET-1 verwendet, unter denen nach 24-stündiger Inkubation Kardiomyozyten eine Hypertrophie um 45\% (PE) bzw. 46\% (ET-1) aufwiesen. Nach 48-stündiger Inkubation ließ sich ein weiterer Anstieg unter PE um insgesamt 61\% messen, unter ET-1 um 59\%. Dagegen supprimierte eine Überexpression von HSPA4 sowohl nach 24-stündiger als auch nach 48-stündiger Inkubation im direkten Vergleich signifikant die PE- und ET-1-induzierte Hypertrophie. Eine Überexpression von HSPA4 erhöhte die Kapazität der PQC und vermindert durch noch nicht verstandene Mechanismen die hypertrophe Antwort. Diese Ergebnisse werden untermauert von einer Studie um Kim et al. 2006, die zeigen konnten, dass ein Knockout von HSP70 in einem Mausmodell zu einer Beeinträchtigung der PQC führt und eine Inhibierung von hypertrophen Signalwegen aufhebt, darunter p38-MAPKs und die Raf-1-vermittelte Hypertrophie.

Neben einer Nachlasterhöhung in einem TAC-Mausmodell (Tannous et al. 2008), sind PE (Zobel et al. 2002) und ET-1 (Yamazaki et al. 1996) in einem Zellkulturmodell mit NRCM ebenfalls geeignet eine pathologische Hypertrophie zu induzieren. Diese wird von einer erhöhten Proteinsynthese begleitet (Neyses et al. 1991; Mel'nikova et al. 2004; Rolfe et al. 2005). Diese Studien nutzen ferner radioaktiv markierte Aminosäuren, um einen vermehrten Einbau in neuentstehende Proteine zu detektieren (Sun et al. 2013). Da eine erhöhte Proteinsynthese auch das transgene Protein EGFP umfasst, kann über die Messung der 
Fluoreszenzintensität mittels Durchflusszytometrie oder Fluoreszenzdektor auf die Höhe der Proteinsynthese in Zellen geschlossen werden (Richards et al. 2003; Soboleski et al. 2005; Uemura et al. 2008). In dieser Doktorarbeit wurde dies zusätzlich durch Messung des Fluoreszenzsignals im Rahmen der Zellgrößenbestimmung ermittelt. Es konnte einhergehend mit vorigen Studien eine deutlich erhöhte Fluoreszenzintensität unter Stimulation mit PE und ET-1 gemessen werden. Das stärkere EGFP-Signal in PE-stimulierten Kardiomyozyten im direkten Vergleich zu ET-1-stimulierten Zellen resultiert aus der Aktivierung des CMVPromoters durch PE (Maass et al. 2003). In beiden eingesetzten Adenoviren wurde das EGFP-Gen von einem CMV-Promoter kontrolliert, so dass die Fluoreszenzintensität beider Adenoviren vergleichbar ist. Zwar war in HSPA4-überexprimierenden Kardiomyozyten auch ein signifikanter Anstieg der Fluoreszenz zu verzeichnen, jedoch war dieser hochsignifikant im direkten Vergleich zu EGFP-transduzierten Kardiomyozyten kleiner. Eine erhöhte Proteinsynthese als Zeichen einer Hypertrophie konnte durch Überexpression von HSPA4 signifikant reduziert werden.

Entgegen der Studie von Mohamed et al. bewirkte in dieser Arbeit eine reine Herunterregulation von HSPA4 keine Zellgrößenzunahme. Auch die entgegengesetzte Überexpression führte in diesem Zellkulturmodell zu keiner Reduktion der Zellgröße. Unter Stimulation hingegen hypertrophierten die HSPA4-herunterregulierten Kardiomyozyten um 79\% unter PE und um 61\% unter ET-1 signifikant, wodurch die kardiomyozytenspezifische Wirkung auf die Hypertrophieentwicklung von HSPA4 von Mohamed et al. bestätigt wird. Daher waren PE und ET-1 in dieser Doktorarbeit geeignete Stimulanzien um den Einfluss von HSPA4 auf die PE- bzw. ET-1-induzierte Hypertrophie in NRCM zu untersuchen.

PE und ET-1 wirken an den $\mathrm{ET}_{\mathrm{A}^{-}}$und $\alpha_{1}$-Rezeptoren, die zu den G-gekoppelten Rezeptoren gehören und die unter anderem mit G- ${ }_{\alpha q / 11}$ (Snabaitis et al. 2005), $G_{\alpha s}$ (Eguchi et al. 1993; Yamazaki et al. 1996) sowie $G_{\alpha 12}$ interagieren und mittels Phospholipase $C_{\beta}$ die Hydrolyse von Phosphatidyl-Inositol-4,5-bisphosphat ( $\mathrm{PIP}_{2}$ ) aktiveren (Wu et al. 1992; Clerk und Sugden 1997). Die Hydrolyse von $\mathrm{PIP}_{2}$ führt zu Inositol-1,4,5-Triphosphat (IP 3 ) und Diacylglycerin (DAG). Während DAG die Proteinkinase C (PKC) aktiviert (Huang 1989), führt die Bindung von $\mathrm{IP}_{3}$ an $\mathrm{IP}_{3}$-Rezeptoren, die unter anderem auch nukleär lokalisiert sind (Bare et al. 2005; Wu et al. 2006) zur Freisetzung von $\mathrm{Ca}^{2+}$ aus intrazellulären Speichern (Shubeita et al. 1990; Simonson und Dunn 1990). Intrazelluläres $\mathrm{Ca}^{2+}$ aktiviert unter anderem die Calmodulin-regulierte Serin/Threonin-Phosphatase Calcineurin (Iwai-Kanai und Hasegawa 2004), welche das zytosolisch gelegene NFAT dephosphoryliert. Dephosphoryliertes NFAT 
transloziert in den Kern und interagiert dort mit GATA4 (Molkentin et al. 1998), das als Transkriptionsfaktor in Kardiomyozyten eine Schlüsselrolle bei der Initiierung von der Transkription prohypertropher Gene einnimmt, darunter das atriale natriuretische Peptid (ANP), natriuretische Peptid Typ B (BNP), $\alpha$-Actinin und $\beta$-Myosin (Molkentin 2004; Tang et al. 2010; Liu et al. 2012).

Auch ein $\mathrm{HSPA}^{-/-}{ }^{-K}$ Kock-out bewirkte einen aktivierten Calcineurin-NFAT-Signalweg (Mohamed et al. 2012), ebenso wie ein HSPB5 ${ }^{-/-}$-Knock-out (Kumarapeli et al. 2008). Während unter basalen Bedingungen NFAT hauptsächlich zytoplasmatisch lokalisiert ist, transloziert es unter PE-Stimulation in den Kern (Hunton et al. 2002; Dai et al. 2005). Kumarapeli et. al. überexprimierten in ihrer Studie 2008 HSPB5 und zeigen, dass die protektive Wirkung von HSPB5 in NRCM auf einer unterdrückten NFAT-Translokation beruht. Möglicherweise interagiert HSPB5 direkt mit NFAT und unterdrückt die Translokation. Einen ähnlichen Mechanismus finden Dai et al. 2005. Mrj, ein Mitglied der HSP40-Familie, interagiert direkt mit NFAT. Mrj blockiert jedoch nicht die Translokation von NFAT, sondern die transkriptionelle Aktivität im Kern. Einerseits konnte durch Temperaturerhöhung ein Stimulus identifiziert werden durch den Mrj vermehrt mit NFAT in den Kern transloziert und dieses dort supprimiert, andererseits interagiert Mrj zudem noch direkt mit mehreren Klasse-II-HistonDeacetylasen (HDACs) (Dai et al. 2005). Diese liegen dadurch vermehrt nukleär vor und supprimieren die pro-hypertrophe Transkriptionsaktivität des myocyte-enhancer-factor-2 (Mef2) (Miska et al. 1999; Lu et al. 2000a) oder von GATA2 (Ozawa et al. 2001) durch spezifische Bindung an die Transkriptionsfaktoren.

Neben dem oben erwähnten Calcineurin-NFAT-Signalweg konnte auch eine erhöhte Aktivität der $\mathrm{Ca}^{2+} /$ Calmodulin-abhängigen-Protein-Kinase II (CaMKII) in $\mathrm{HSPA}^{-/-}-\mathrm{KO}-$ Mäusen gemessen werden (Mohamed et al. 2012). Diese wird ebenfalls durch PE und ET-1 über die Erhöhung von intrazellulärem $\mathrm{Ca}^{2+}$, das wiederum an Calmodulin bindet (CaMKII), aktiviert (Fern et al. 1995). Eine vermehrte Bindungsfrequenz zwischen $\mathrm{Ca}^{2+} / \mathrm{Calmodulin}$ und der CaMKII führt zur Autophosphorylierung (Koninck und Schulman 1998). Diese bedingt einerseits über eine erhöhte Affinität von Calmodulin an die CaMKII eine konstante Enzymaktivität trotz absinkender intrazellulärer $\mathrm{Ca}^{2+}-$ Konzentrationen (Anderson et al. 2011). Andererseits verleiht die Autophosphorylierung der CaMKII eine erhöhte autonome Aktivität auch nach $\mathrm{Ca}^{2+} /$ Calmodulin-Dissoziation (Meyer et al. 1992). O-Uchi et al. zeigten 2005, dass aktivierte CaMKII in Rattenkardiomyozyten vor einer $\alpha_{1}$-Stimulation nur an der Zellmembran lokalisiert ist. Nach Stimulation am $\alpha_{1}$-Rezeptor lässt sich aktivierte CaMKII 
an den transversen Tubuli nachweisen, wo die höchste Dichte an L-Typ $\mathrm{Ca}^{2+}$-Kanälen zu finden ist. Die Autoren schlussfolgern daraus, dass CaMKII durch $\alpha_{1}$-Stimulation phosphoryliert wird und den $\mathrm{Ca}^{2+}$-Einstrom steigert (O-Uchi et al. 2005).

Auch andere Hitzeschockproteine beeinflussen hypertrophe Signalwege.

In diesem Zusammenhang vermittelt HSP20 einen maladaptiven Prozess. HSP20 wird ubiquitär exprimiert, am höchsten unter anderem in Kardiomyozyten (Martin et al. 2014). Die Cam-Kinase-Familie umfasst als Untergruppe auch die Proteinkinase D1 aus der Familie der Proteinkinasen D (Manning et al. 2002; Rykx et al. 2003). PKD1 wirkt ebenfalls als Serin/Threonin-Kinase (Valverde et al. 1994). Einen Stimulus für eine erhöhte PKD1Aktivierung stellt die unter anderem eine erhöhte Nachlast (Harrison et al. 2006) oder eine $\alpha$-Stimulation mittels PE (Haworth et al. 2000) dar, die einen Trigger für eine vermehrte PKC-Konzentration darstellt (Gu und Bishop 1994). PKD1 wird durch die PKC phosphoryliert und durch Bindung an DAG aktiviert (Oancea et al. 2003; De Arcangelis et al. 2009). Um die Translokation aus dem Zytosol in den Nukleus zu vermitteln, muss HSP20 zwingend an der katalytischen Untereinheit von PKD1 binden (Sin et al. 2015). Sin et al. fanden 2015, dass durch Disruption des HSP20-PKD1-Komplexes die PKD1-vermittelte Hypertrophie und Entwicklung einer Fibrose unterdrückt wird. HSP20 agiert daher als obligatorisches nukleäres Import-Chaperon für PKD1. Im Kern phosphoryliert PKD1 unter anderem Klasse II-HDAC5 und fördert den Export von HDAC5 aus dem Kern in das Zytoplasma (Harrison et al. 2006). Hierdurch hebt PKD1 indirekt die Unterdrückung von pro-hypertrophen Transkriptionsfaktoren, wie Mef2, auf und fördert dadurch pathologisches Remodeling (Fielitz et al. 2008).

Demgegenüber gestellt kann HSP20 jedoch auch eine kardioprotektive Rolle einnehmen. Eine Nachlasterhöhung (Teiger et al. 1996) oder eine Ischämie (Krijnen et al. 2002) gehen mit einer erhöhten Apoptoserate von Kardiomyozyten einher. Fan et al. identifizierten 2005, dass in HSP20 $0^{+/}$-transgenen Mäusen nach einer induzierten Ischämie HSP20 das antiapoptotische Protein Bcl-2 und apoptoseeinleitende Protein Bcl-2-assoziiertes-X-Protein (Bax) stabilisiert. HSP20 bildet einen Komplex mit Bax und verhindert so in diesem I/P-Mausmodell die Translokation von Bax in die Mitochondrien (Fan et al. 2005). Dadurch wird die Freisetzung von Cytochrom c aus den Mitochondrien gehemmt und die Aktivierung von der Procaspase 3 zur aktiven Caspase 3 verhindert (Guttenplan et al. 2001; Fan et al. 2005). Hierdurch hemmt HSP20 die Einleitung der Apoptose. 
Neben der negativen Beeinflussung prohypertropher Signalwege, modulieren HSP20 und HSP27 positiv die Kontraktilität in Kardiomyozyten. Tucker und Shelden zeigen 2009 in einem Zebrafischmodell, dass unter Hitzeeinwirkung HSP27 aus dem Zytoplasma an eine Untereinheit der Titinfilamente des kontraktilen Apparates transloziert. Diese werden dadurch stabilisiert und vor Aggregation geschützt (Tucker und Shelden 2009). Zudem fördern ischämische Bedingungen einen sauren $\mathrm{pH}$, der die Aggregation von Titin und damit eine Versteifung von Myozyten bedingt. Durch Assoziation von Titin mit HSP27 wird die Aggregation und die nachfolgende Versteifung verhindert, schlussfolgern Kötter et al. (Kötter et al. 2014).

HSP20 beeinflusst zudem die Kontraktilität über einen regulatorischen Effekt auf die sarkoplasmatisch gelegene Calcium-ATPase (SERCA) positiv (Pipkin et al. 2003; Li et al. 2017). Unter basalen Bedingungen interagiert und desphosphoryliert die Proteinphosphatase 1 (PP1) Phospholamban (PLN). Phospholamban selbst moduliert die SERCA negativ. Unter B-adrenergem Stress phosphoryliert die PKA HSP20, welches die Dissoziation zwischen PP1 und PLN fördert und PP1 hochaffin an HSP20 bindet (Chu et al. 2004). Hierdurch wird PP1 inhibiert und PLN vermehrt phosphoryliert. Phosphoryliertes PLN vermindert die Inhibition auf die SERCA, die daraufhin stimuliert wird und die Aufnahme von Calcium in das sarkoplasmatische Retikulum steigert (Qian et al. 2011; Vafiadaki et al. 2013). Eine erhöhte Calciumaufnahme steht mit verbesserter kardialer Kontraktilität und Relaxation in Zusammenhang (Wang et al. 2009)

Zusammengefasst aktiviert die Stimulation von ET-1 und PE in vielfältiger Weise mehrere zur Entwicklung der kardialen Hypertrophie-beitragende Signalwege, die ebenfalls in $\mathrm{HSPA}^{-/-}$-KO-Mäusen aktiviert waren. Eine direkte Übertragbarkeit der an der Hypertrophie-beteiligten $\alpha$-Rezeptoren von NRCM auf den Menschen erscheint schwierig, da die $\alpha_{1-}$ Rezeptorendichte in der Ratte um das zehnfache höher liegt als in humanen Kardiomyozyten (Steinfath et al. 1992; Michel et al. 1994; Noguchi et al. 1995).

Mit einer adenoviralen Überexpression von HSPA4 konnte in diesem Zellkulturmodell eine PE- und ET-1-induzierte Hypertrophie supprimiert werden. Es sind Folgestudien nötig, um die Rolle der erwähnten pro-hypertrophen Signalwege in HSPA4-überexprimierenden Kardiomyozyten zu untersuchen. Dies könnte durch die möglicherweise selektive HSPA4vermittelte Depletion an den Signalwegen beteiligter Enzyme vermittelt werden. Alternativ 
könnte HSPA4 mechanistisch den protektiven Effekt auch über einen ähnlich der HSP20und HSP27-vermittelten Protektion bewirken. 


\subsection{Der Einfluss von HSPA4 auf ubiquitinkonjugierte Proteine}

Eine optimale Kardiomyozyten-Funktion beruht auf dem feinjustierten Gleichgewicht aus Proteinsynthese, korrekter Proteinfaltung und Proteindegradation (Li et al. 2010; Willis und Patterson 2013). Zudem fördert zellulärer Stress die Fehlfaltung von neuentstehenden Proteinen (Whitley et al. 1999; Bucciantini et al. 2002; Tannous et al. 2008).

Pathologische Hypertrophie zeigt sich in ventrikulärem Remodeling, das die Herzfunktion und den Energieverbauch beeinträchtigt (Deschamps und Spinale 2006). Um der erhöhten Fehlfaltung zu begegnen, werden vermehrt kleine HSPs, die spezifisch mit Proteinen des kontraktilen Apparats in Verbindung stehen, exprimiert (Stangl et al. 2002; Verschuure et al. 2002). So interagiert $\alpha$-Crystallin B (HSPB5) mit Desmin und verhindert dessen Fehlfaltung und Aggregation (Wang et al. 2003). Das Chaperon UNC-45 nimmt durch seine regulatorische Rolle in der Myosinfaltung und im Verhindern von dessen Aggregation eine bedeutende Rolle für die Funktion der Kardiomyozyten ein (Barral et al. 2002; Willis und Patterson 2013). Auch HSPA4 gehört zu der Gruppe von Chaperonen, die durch erhöhte Nachlast in Kardiomyozyten vermehrt exprimiert werden (Mohamed et al. 2012).

Eine reine Herunterregulation von HSPA4 führte in dieser Doktorarbeit zu einer signifikanten Akkumulation unlöslicher ubiquitinkonjugierter Proteine um mehr als das 3-Fache. Auch in der Arbeit von Mohamed et al. im Jahr 2012 zeigen globale HSPA4 ${ }^{-1-}$-KO-Mäuse eine erhöhte Anzahl löslicher und unlöslicher Proteinaggregate. Diese Ergebnisse belegen, dass die Herunterregulation von HSPA4 eine Störung der PQC bewirkt und in der Folge eine Akkumulation ubiquitinierter Proteine fördert. Zudem scheint dieser Effekt nicht auf systemischen Ursachen zu beruhen, sondern scheint kardiomyozytenspezifisch zu sein.

Weiterführend konnte gezeigt werden, dass ein Knock-out von an der PQC beteiligten Proteinen, wie der $\mathrm{NAP}^{+}$-abhängigen Deacetylase Sirt1, eine Beeinträchtigung der $\mathrm{PQC}$ zur Folge hat und zu einer Akkumulation ubiquitinierter Proteine führt (Gregersen et al. 2006; Tomita et al. 2015).

Damit einhergehend konnten in PE- und ET-1-stimulierten Kardiomyozyten erhöhte Mengen ubiquitinkonjugierter Proteine gemessen werden (Tannous et al. 2008; Jenie et al. 2013; Sun et al. 2013). Allerdings konnte in HSPA4-herunterregulierten Kardiomyozyten keine signifikante Zunahme von Ubiquitinkonjugaten unter Stimulation mit PE oder ET-1 beobachtet werden. Im Gegenzug dazu war eine Überexpression von HSPA4 geeignet eine Reduktion ubiquitinierter Proteine in Kardiomyozyten nach 24 h, aber nicht nach 48 h zu bewirken. 
Möglicherweise lag das an der abnehmenden HSPA4-Expression des Adenovirus nach $48 \mathrm{~h}$ (siehe Abschnitt 3.3). Während in den Kontrollzellen unter Stimulation mit PE bzw. ET-1 ein signifikanter Anstieg ubiquitinierter Proteine um das 2,5-Fache beobachtetet werden konnte, supprimierte eine Überexpression von HSPA4 im direkten Vergleich sowohl nach $24 \mathrm{~h}$ als auch nach $48 \mathrm{~h}$ hochsignifikant den Anstieg unlöslicher Proteinaggregate.

Damit ist HSPA4 ein geeigneter Kandidat, um durch Erhöhung der PQC-Kapazität im Rahmen einer PE- bzw. ET-1-induzierten erhöhten Proteinsynthese die Höhe fehlgefalteter ubiquitinierter Proteine zu senken.

Auch eine Überexpression von HSP70, einem zentralen Chaperon in der PQC, reduzierte ubiquitinierte Proteine (Howarth et al. 2009) und wirkte in einem I/P-Mausmodell kardioprotektiv hinsichtlich der Infarktgröße und der Funktionalität nach Reperfusion (Marber et al. 1993; Plumier et al. 1995). In der Langzeitbeobachtung einer weiterführenden Maus-Studie schützte allerdings die Überexpression von HSP70 nicht vor einer sich entwickelnden Herzinsuffizienz und dem Auftreten von Vorhofflimmern (Bernardo et al. 2015).

Ein Hauptweg der Proteindegradation ist das Ubiquitin-Proteasom-System (Wang und Maldonado 2006). In Herzen von Patienten mit fortgeschrittener Herzinsuffizienz ließen sich nicht nur eine erhöhte Menge ubiquitinierter Proteine messen, sondern zudem eine eingeschränkte Proteasomaktivität feststellen (Tsukamoto et al. 2006; Predmore et al. 2010; Day 2013). Depre et al. (2006) wiesen hingegen bei chronischer Nachlast eine erhöhte Proteasomaktivtität nach. Die Proteasomfunktion wird unter anderem von kleinen, löslichen Proteinaggregaten beeinträchtigt (Bence et al. 2001; Bennett et al. 2005; Kristiansen et al. 2007; Goldberg 2009; Thibaudeau et al. 2018). Dies führt in der Folge zu einer Beeinflussung prohypertropher Signalwege. Dahingehende auf HSPA4${ }^{-/}-\mathrm{KO}-\mathrm{Mäuse}$ bezogene Experimente ergaben jedoch, dass die Proteasomaktivität nicht eingeschränkt war und typische proteasomale Substrate wie p53 nicht akkumulierten. Die Anzahl unlöslicher Proteinaggregate lag zudem über der löslichen Fraktion (Mohamed et al. 2012). In jüngeren Studien konnte gezeigt werden, dass die Autophagie im Ischämie-Perfusionsmodell (I/P) und in TACMausmodellen aktiviert wird (Xie et al. 2011; Li et al. 2016; Wu et al. 2017). Da unlösliche Proteinaggregate einen intrazellulären Trigger für den Autophagie-Lysosomen-Weg darstellen und hauptsächlich über diesen abgebaut werden, sollten künftige Studien auf die Aktivität der Autophagie in HSPA4-überexprimierenden Kardiomyozyten und die Interaktion mit HSPA4 fokussieren (Tannous et al. 2008). 


\subsection{Potenzielle Mechanismen der HSPA4-vermittelten Kardioprotektion}

Es erscheint eher unwahrscheinlich, dass die gefundenen Ergebnisse dieser Doktorarbeit vollumfänglich darin begründet liegen, dass HSPA4 selbst an denaturierte Proteine bindet und unter ATP-Hydrolyse diese in die korrekte Konformation überführt.

HSPA4 enthält eine zu HSP70 hochgradig homologe substratbindende Domäne (Raviol et al. 2006; Liu und Hendrickson 2007; Schuermann et al. 2008). Mattoo et al. konnten 2013 zeigen, dass HSPA4 selbst mit HSP40 interagiert und unter energiefreisetzender Hydrolyse von ATP fehlgefaltete Polypeptide bindet und in ihre native Struktur überführen kann. Allerdings war der proteinfaltende Effekt in Anwesenheit von HSP70 deutlich stärker ausgeprägt (Mattoo et al. 2013). Zu ähnlichen Ergebnissen kommen auch die Autoren um Rampelt et al. und Garcia et al., die der nukleotidaustauschenden Funktion von HSPA4 in Kooperation mit HSP70 eine wesentlich höhere Bedeutsamkeit einräumen als der proteinfaltenden Komponente (Rampelt et al. 2012; Garcia et al. 2017).

Weiterführend wurde widerlegt, dass ein vermehrtes zytosolisches Vorliegen von HSPA4 im Sinne einer Hochregulation, wie in dieser Doktorarbeit durchgeführt, einen direkten stimulierenden Einfluss auf die Geschwindigkeit der Proteinfaltung im HSP70-HSP110-HSP40Komplex nimmt (Cabrera et al. 2019). Cabrera et al. berichten 2019, dass HSPA4 ein zweiphasiges Verhalten annimmt. Während HSPA4 in niedrigeren Konzentrationen den ATPaseZyklus von HSP70 und damit die Bindung von Chaperon zu Proteinaggregat und die Faltungsaktivität fördert, inhibiert es in höheren Konzentrationen diese Prozesse. Eine höhere Konzentration von HSPA4 führt eher zu einer verfrühten Dissoziation zwischen ATP und HSP70 und damit zu einer fehlenden Hydrolyse und zu keiner korrekten Proteinfaltung mittels HSP70 (Cabrera et al. 2019).

Weiterführende Forschung in der Arbeitsgruppe von Prof. Toischer weisen in HSPA $4^{-{ }_{-}}$ KO-Mäusen auf eine Beeinträchtigung der Autophagie hin. So akkumulierten, verglichen zu Wildtypmäusen, in HSPA4 ${ }^{-/-}$-KO-Mäusen Autophagosome, einhergehend mit einer erhöhten Expression von LC3-II und p62. Diese Konstellation spricht für eine beeinträchtigte Fusion von Autophagosomen mit Lysosomen in der späten Phase der Autophagie. Ein beeinträchtigter Autophagie-Abbauweg korreliert mit Störungen im Energiemetabolismus (Li und Lerman 2012) und mit vermehrter maladaptiver kardialer Hyptertrophie (Bhuiyan et al. 2013; Li et al. 2016; Wang und Cui 2017). Diese überschießende maladaptive Aktivierung 
der Autophagie wird unter anderem über phosphorylierte Histon-Deacytelasen wie HDAC1 und HDAC2 (Cao et al. 2011; Yoon et al. 2018) vermittelt (Oh et al. 2008; El-Khoury et al. 2014).

Hier könnte HSPA4 eine mögliche protektive Wirkung vermitteln. Zum einen könnte HSPA4 direkt mit HDAC2 interagieren und durch Bildung eines HSPA4-HDAC2Komplexes als HDAC-Inhibitor fungieren. Eine solche Wirkung wird unterstützt von Forschungsarbeiten, die zeigen konnten, dass durch Zugabe von HDAC-Inhibitoren wie Trichostatin A (TSA) die Autophagie-Aktivierung auf ein adaptives Niveau gesenkt werden und pathologisches Remodeling rückgängig gemacht werden konnte (Cao et al. 2011; Wang et al. 2018). Während eine myokardiale Ischämie in einem Mausmodell eine verstärkte Expression von p62, LC3-II und eine Akkumulation von Autophagosomen induzierte, reversierte die TSA-Gabe diesen Effekt (Wang et al. 2018).

Ebenso könnte HSPA4 indirekt die Aktivität von HDACs durch posttranslationale Modifikationen im Sinne einer Phosphorylation oder Dephosphorylation beeinflussen (Sengupta und Seto 2004; Habibian und Ferguson 2018). So könnte die Bildung eines HSPA4-HDACKomplexes einen Trigger für eine verstärkte Bindung an eine Proteinphosphatase wie Proteinphosphatase 2A darstellen, die zu einer vermehrten Dephosphorylierung von HDACs führt und somit deren Aktivität senkt (Eom et al. 2011; Eom und Kook 2015). Ein entgegengesetzter Mechanismus ist für HSP70-HDAC2 beschrieben (Kee Hae Jin et al. 2008; Yoon et al. 2018). Eine Überexpression von HSP70 steigerte durch Phosphorylation die Aktivität von HDAC2 und die Bindungsstärke an HSP70, was wiederrum die Bindung an die aktivitätshemmende Proteinphosphatase 2A abschwächte.

Durch einen solchen Komplex könnte als dritte Möglichkeit HSPA4 damit auch die subzelluläre Lokalisation beeinflussen (Sengupta und Seto 2004; Ling Shukuan et al. 2012). So induzieren Phosphorylierungen von HDAC4 und HDAC5 den nukleären Export und heben die Repression von Mef2 auf (Miska et al. 1999; Wang et al. 1999; McKinsey et al. 2000). Mittels des oben genannten Mechanismus würden nukleär vermehrt HDACs vorliegen und hierdurch die prohypertrophe Akitvität von Mef2 (Lu et al. 2000b) durch eine selektive Deacetylierung inhibieren (Zhao et al. 2005). Sowohl der auch in HSPA4 ${ }^{-/-}$KO-Mäusen aktivierte Calcineurin-Signalweg (Mao und Wiedmann 1999; Wu et al. 2001) als auch die aktivierte Calmodulin/CaM-Kinase (Blaeser et al. 2000; Passier et al. 2000) steuern unter anderem ihre hypertrophe Signalantwort über Mef2. Unterstützt werden diese hypothetischen Mechanismen einerseits durch Zhang et. al, der in transgenen CaMKII-Kinase ${ }^{+/+}$ Mäusen zeigen konnte, dass die kardiale Hypertrophie über Mef2 durch die Dissoziation von 
phosphorylierten Klasse-II-HDACs bewirkt wird (Zhang et al. 2007). Abschließend zeigte sich in HSPA4 ${ }^{-/}-$KO-Mäusen eine erhöhte HDAC7a Expression, die vermuten lässt, dass die CaMKII ihre hypertrophe Wirkung in den KO-Mäusen über diesen Mechanismus vermittelt (Barakat 2010).

\section{A Hypothese 1 : HSPA4 inhibiert HDAC-Aktivität durch Komplexbildung}

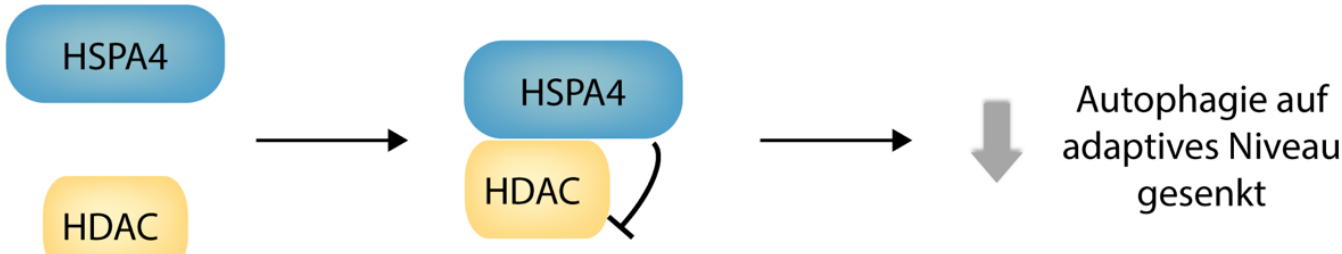

B Hypothese 2 : HSPA4 aktiviert HDAC durch PP2-vermittelte Dephosphorylierung und dadurch vermehrte nukleäre Lokalisation und Herunterregulation von mef2
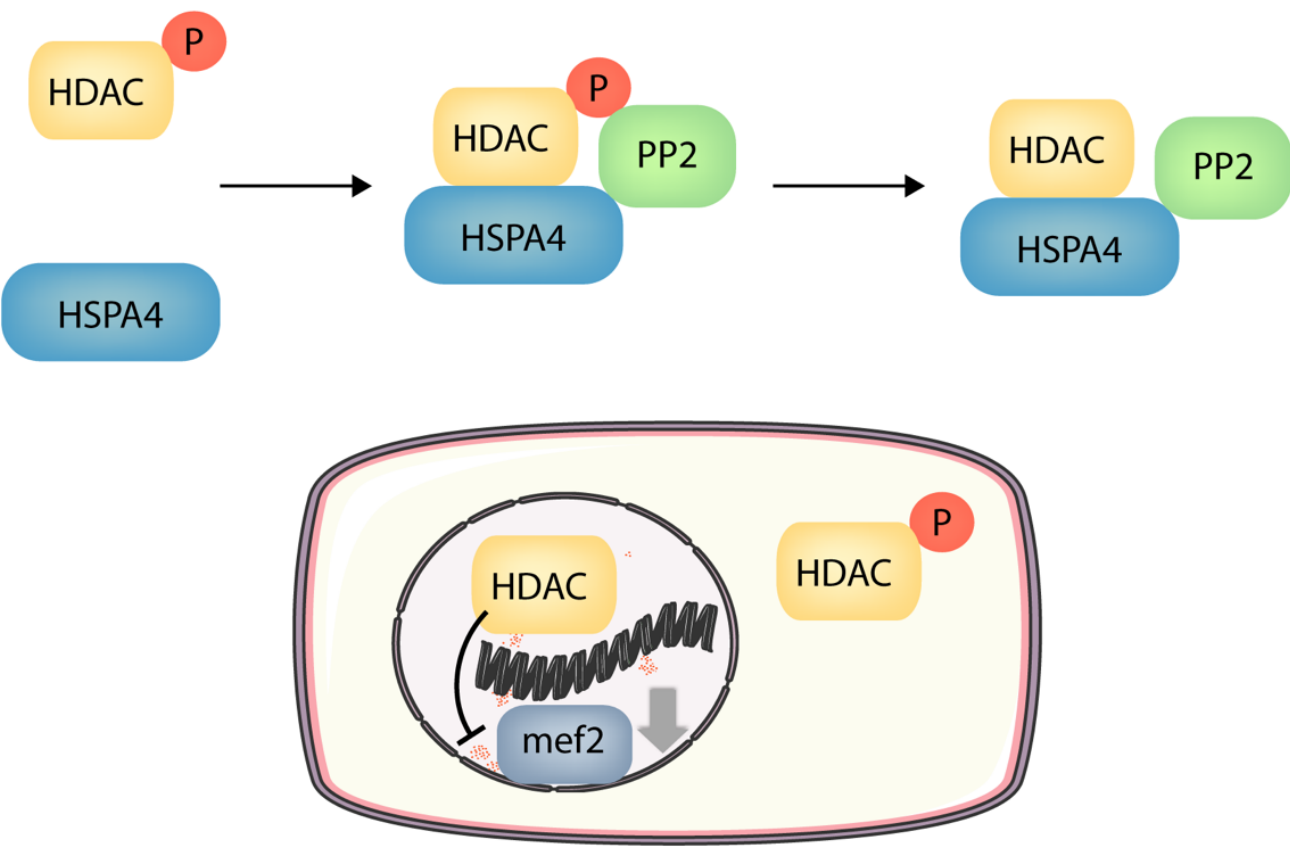

Abb. 23: Graphische Darstellung der HSPA4-vermittelten Kardioprotektion. Mit freundlicher Genehmigung von Sevier Medical Art.

Ein weiterer kardioprotektiver Ansatzpunkt von HSPA4 könnte direkt an der Fusion zwischen Autophagosomen und Lysosomen liegen. Beclin-1, ein zentrales Protein sowohl in der Autophagsomen-Bildung als auch der Fusion mit Lysosomen, nimmt eine steuernde Funktion ein (Kang et al. 2011; Mony et al. 2016; Wang und Cui 2017). Durch Interaktion von Beclin-1, im Komplex mit mehreren Proteinen (beclin-1:VPS34:p150) (Funderburk. et al. 
2010), mit dem UV-irridiation-resistance-associated-gene (UVRAG), wird die AutophagosomenLysosomen-Fusion und damit die Degradation befördert (Liang et al. 2008). Bindet jedoch die RUN domain and cysteine-rich domain containing, beclin-1-interacting protein (Rubicon) an den beclin-1:VPS34:p150-UVRAG-Komplex, wird der Autophagie-Fluss vor allem beim Fusionsschritt inhibiert (Matsunaga et al. 2009; Zhong et al. 2009).

Wenn in diesem Zusammenhang HSPA4 mit Rubicon interagierte, hierdurch die Bindung an Beclin-1 verhinderte und damit die inhibitorische Wirkung Rubicons aufheben würde, förderte dies die Fusion der Autophagsomen mit den Lysosomen und bedingt einen gesteigerten Abbau zu degradierender Proteine.

Ein therapeutischer Ansatzpunkt, um die mögliche kardioprotektive Wirkung HSPA4s in Kardiomyozyten klinisch nutzbar zu machen, liegt zum einen in der Identifikation spezifischer kardialer Rezeptoren, die durch Bindung eines spezfischen Liganden eine Erhöhung des intrazellulären HSPA4s bewirken. Zum anderen könnten Antikörper als AntikörperWirkstoff-Konjugat mit HSPA4 gekoppelt werden, deren Bindung an einen bereits bekannten kardialen Rezeptor zur Internalisierung von HSPA4 und damit auch zur intrazellulären Erhöhung HSPA4s führt. Ferner könnten Kleinmolekül-Wirkstoffkandidaten identifiziert werden, die zu einer Erhöhung von HSPA4 und damit einer kardioprotektiven Wirkung führen würden.

\subsection{Chancen, Limitationen und Ausblick}

In dieser Doktorarbeit wurde die Wirkung von HSPA4 auf isolierte, ventrikuläre Kardiomyozyten neonataler Ratten untersucht. Ein Vorteil dieses Versuchsmodells war die gute Zugänglichkeit und die regelmäßige Isolation der Zellen. Weiterhin sind die adenovirale Transduktion und siRNA-vermittelte Herunterregulation gut beschriebene Methoden die Proteinhöhe zu modulieren. Die hier durchgeführten Experimente sollten die Frage klären, ob HSPA4 ein geeigneter Modulator der PQC ist eine Reduktion von ubiquitinierten Proteinaggregaten in NRCM zu erzielen. Zudem wurden mittels Bestimmung kardialer Hormone und der Zellgrößenzunahme Parameter einer pathologischen Hypertrophie untersucht.

Das Zellkulturmodell war mechanistisch geeignet diese Fragen zu klären. Allerdings ist es als „2D-Modell“ nicht geeignet die Interaktion verschiedener Zelltypen (Kardiomyozyten, Fibroblasten, Endothelzellen, Immunzellen) untereinander zu beleuchten.

Einschränkend muss ebenfalls darauf hingewiesen werden, dass diese Experimente nicht die kardiale Funktion einer Überexpression von HSPA4 betrachten. In-Vivo-Studien sind 
notwendig, um diesen funktionellen Aspekt im Rahmen einer Nachlasterhöhung im TACMausmodell bewerten zu können. Da die Proteasomaktivität in HSPA4 ${ }^{-/}-\mathrm{KO}-\mathrm{Mäusen}$ nicht beeinträchtigt war (Mohamed et al. 2012), sollte die Aktivität und Rolle der Autophagie in einer transgenen Mauslinie näher adressiert werden. Darauf bezugnehmend kann durch Gabe von Doxorubicin die Autophagie in einer transgenen Mauslinie inhibiert werden. Zudem sollte überprüft werden, ob der beobachtete Phänotyp in HSPA4 ${ }^{-1-}-\mathrm{KO}-\mathrm{Mäusen} \mathrm{durch}$ Injektion eines kardiomyozytenspezifischen Virus (AAV9-HSPA4), der HSPA4 überexprimiert, verbessert wird.

Entsprechende Fragestellungen werden derzeit in der Arbeitsgruppe von Herrn Prof. Toischer bearbeitet. 


\section{Zusammenfassung}

Die PQC nimmt eine bedeutende Rolle in der Zellhomöostase ein. Ein Akkumulieren fehlgefalteter Proteine kann zum Funktionsverlust von Kardiomyozyten führen und zur Entwicklung einer Herzinsuffizienz beitragen. Chaperone als Teil der PQC vermitteln die Faltung von Proteinen in die korrekte Konformation und können ebenfalls deren Abbau initiieren. HSPA4, ein Co-Chaperon, wurde als Nukleotidaustauschfaktor für HSP70 identifiziert. Eine frühere Studie zeigte ein maldaptives kardiales Remodeling in $\mathrm{HSPA}^{-/-}-\mathrm{KO}-$ Mäusen.

Ziel dieser Arbeit war, die Auswirkung einer HSPA4-Überexpression bzw. HSPA4Herunterregulation in NRCM auf eine Stimulation mit PE bzw. ET-1, beides potente Induktoren einer kardialen Hypertrophie, hin zu untersuchen. Dazu wurden NRCM isoliert und mittels siRNA-vermittelter Transfektion und adenoviraler Transduktion die HSPA4Expression beeinflusst.
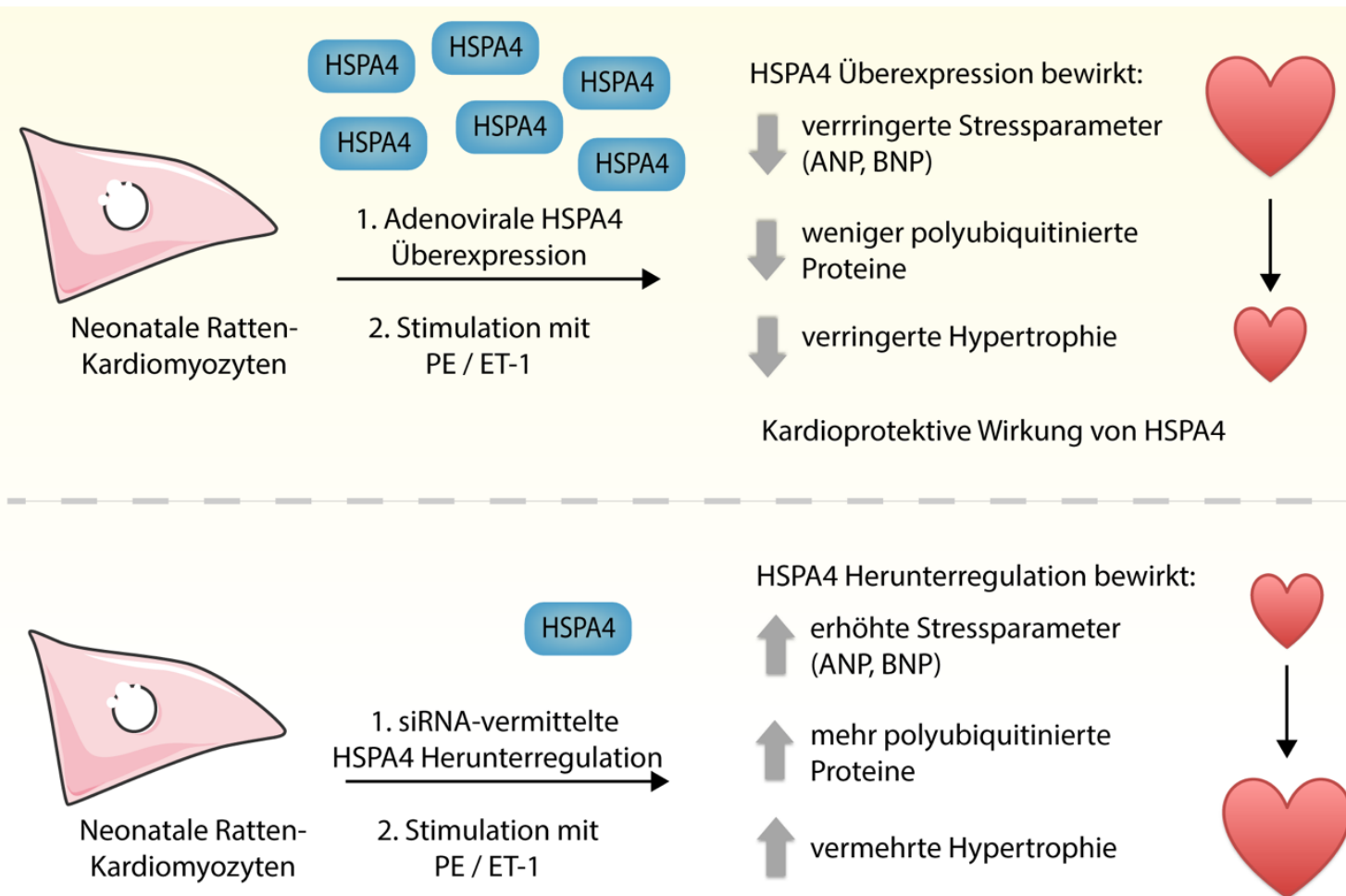

HSPA4 Herunterregulation bewirkt:

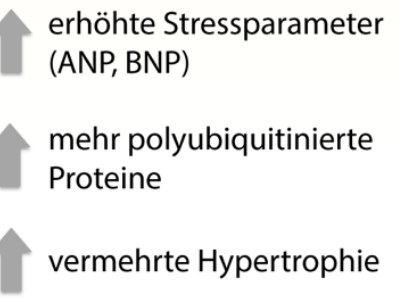

Kardiodestruktive Wirkung von HSPA4

Abb. 24: Graphische Übersicht der Ergebnisse. Mit freundlicher Genehmigung von Sevier Medical Art. 
Eine Überexpression von HSPA4 war geeignet, die Kapazität der PQC zu steigern, und reduzierte signifikant ubiquitinierte Proteine im Western Blot. Unter Stimulation mit PE bzw. ET-1 supprimierte es die Hypertrophieentwicklung in der planimetrischen Auswertung der Kardiomyozyten. Damit einhergehend supprimierte HSPA4 auch den Anstieg der kardialen Hormone ANP und BNP in der qPCR. Damit konnte der kardioprotektive Effekt einer HSPA4-Überexpression festgestellt werden.

Im Gegensatz dazu verstärkte die Herunterregulation von HSPA4 die Hypertrophie in der Planimetrie und förderte die Akkumulation ubiquitinierter Proteine. In einer früheren Studie konnte in HSPA4 ${ }^{-/}-\mathrm{KO}-\mathrm{Mäusen}$ kein Unterschied der Proteasomaktivität gemessen werden, weswegen künftige Studien die Rolle der HSPA4-vermittelten Autophagie näher untersuchen sollten.

Für die Entwicklung zielgerichteter Therapeutika ist ein tiefgreifendes Verständnis der molekularen Grundlagen von großer Bedeutung. Die hier dargestellten Ergebnisse unterstützen die Entwicklung neuer Behandlungsstrategien in der Herzinsuffizienz. 


\section{Literaturverzeichnis}

Adachi T, Sakurai T, Kashida H, Mine H, Hagiwara S, Matsui S, Yoshida K, Nishida N, Watanabe T, Itoh K, et al. (2015): Involvement of Heat Shock Protein A4/Apg-2 in Refractory Inflammatory Bowel Disease. Inflamm Bowel Dis 21, 31-39

Agarraberes FA, Terlecky SR, Dice JF (1997): An Intralysosomal hsp70 Is Required for a Selective Pathway of Lysosomal Protein Degradation. J Cell Biol 137, 825-834

Anderson ME, Brown JH, Bers DM (2011): CaMKII in myocardial hypertrophy and heart failure. J Mol Cell Cardiol $\underline{51}, 468-473$

Andréasson C, Fiaux J, Rampelt H, Druffel-Augustin S, Bukau B (2008): Insights into the structural dynamics of the Hsp110-Hsp70 interaction reveal the mechanism for nucleotide exchange activity. Proc Natl Acad Sci U S A 105, 16519-16524

Aparicio F, Thomas CL, Lederer C, Niu Y, Wang D, Maule AJ (2005): Virus Induction of Heat Shock Protein 70 Reflects a General Response to Protein Accumulation in the Plant Cytosol. Plant Physiol $\underline{138}, 529-536$

Archer CR, Robinson EL, Drawnel FM, Roderick HL (2017): Endothelin-1 promotes hypertrophic remodelling of cardiac myocytes by activating sustained signalling and transcription downstream of endothelin type A receptors. Cell Signal $\underline{36}, 240-254$

Atlas SA, Maack T (1987): Effects of atrial natriuretic factor on the kidney and the renin-angiotensinaldosterone system. Endocrinol Metab Clin North Am 16, 107-143

Ayyadevara S, Mercanti F, Wang X, Mackintosh SG, Tackett AJ, Prayaga SVS, Romeo F, Shmookler Reis RJ, Mehta JL (2016): Age- and hypertension-associated protein aggregates in mouse heart have similar proteomic profiles. Hypertension $\underline{67}, 1006-1013$

Bandyopadhyay U, Kaushik S, Varticovski L, Cuervo AM (2008): The Chaperone-Mediated Autophagy Receptor Organizes in Dynamic Protein Complexes at the Lysosomal Membrane. Mol Cell Biol 28, 5747-5763 
Bare DJ, Kettlun CS, Liang M, Bers DM, Mignery GA (2005): Cardiac Type 2 Inositol 1,4,5-Trisphosphate Receptor Interaction and Modulation by Calcium/Calmodulin-Depent Protein KinaseII. J Biol Chem 280, 15912-15920

Bar-Nun S, Glickman MH (2012): Proteasomal AAA-ATPases: Structure and function. Biochim Biophys Acta BBA $1823,67-82$

Barral JM, Hutagalung AH, Brinker A, Hartl FU, Epstein HF (2002): Role of the Myosin Assembly Protein UNC-45 as a Molecular Chaperone for Myosin. Science 295, 669-671

Barry SP, Davidson SM, Townsend PA (2008): Molecular regulation of cardiac hypertrophy. Int J Biochem Cell Biol 무, 2023-2039

Bence NF, Sampat RM, Kopito RR (2001): Impairment of the Ubiquitin-Proteasome System by Protein Aggregation. Science 292, 1552-1555

Bennett EJ, Bence NF, Jayakumar R, Kopito RR (2005): Global Impairment of the Ubiquitin-Proteasome System by Nuclear or Cytoplasmic Protein Aggregates Precedes Inclusion Body Formation. Mol Cell $\underline{17}, 351-365$

Bergmann O, Bhardwaj RD, Bernard S, Zdunek S, Barnabé-Heider F, Walsh S, Zupicich J, Alkass K, Buchholz BA, Druid H, et al. (2009): Evidence for cardiomyocyte renewal in humans. Science $\underline{324}, 98-102$

Bernardo BC, Sapra G, Patterson NL, Cemerlang N, Kiriazis H, Ueyama T, Febbraio MA, McMullen JR (2015): Long-Term Overexpression of Hsp70 Does Not Protect against Cardiac Dysfunction and Adverse Remodeling in a MURC Transgenic Mouse Model with Chronic Heart Failure and Atrial Fibrillation. PLOS ONE $\underline{10}$, e0145173

Bhuiyan MdS, Pattison JS, Osinska H, James J, Gulick J, McLendon PM, Hill JA, Sadoshima J, Robbins J (2013): Enhanced autophagy ameliorates cardiac proteinopathy. J Clin Invest $\underline{123}$, 5284-5297

Bjørkøy G, Lamark T, Brech A, Outzen H, Perander M, Øvervatn A, Stenmark H, Johansen T (2005): p62/SQSTM1 forms protein aggregates degraded by autophagy and has a protective effect on huntingtin-induced cell death. J Cell Biol 171, 603-614 
Blaeser F, Ho N, Prywes R, Chatila TA (2000): Ca2+-dependent Gene Expression Mediated by MEF2 Transcription Factors. J Biol Chem $\underline{275}$, 197-209

Bogoyevitch MA, Glennon PE, Sugden PH (1993): Endothelin-1, phorbol esters and phenylephrine stimulate MAP kinase activities in ventricular cardiomyocytes. FEBS Lett $\underline{317}, 271-275$

Borges JC, Ramos CHI (2005): Protein folding assisted by chaperones. Protein Pept Lett 12, 257261

Brehme M, Voisine C (2016): Model systems of protein-misfolding diseases reveal chaperone modifiers of proteotoxicity. Dis Model Mech $\underline{9}, 823-838$

Bucciantini M, Giannoni E, Chiti F, Baroni F, Formigli L, Zurdo J, Taddei N, Ramponi G, Dobson CM, Stefani M (2002): Inherent toxicity of aggregates implies a common mechanism for protein misfolding diseases. Nature $\underline{416}, 507-511$

Bupha-Intr T, Haizlip KM, Janssen PML (2012): Role of Endothelin in the Induction of Cardiac Hypertrophy In Vitro. PLOS ONE 7, e43179

Cabrera Y, Dublang L, Fernández-Higuero JA, Albesa-Jové D, Lucas M, Viguera AR, Guerin ME, Vilar JMG, Muga A, Moro F (2019): Regulation of Human Hsc70 ATPase and Chaperone Activities by Apg2: Role of the Acidic Subdomain. J Mol Biol 431, 444-461

Cao DJ, Wang ZV, Battiprolu PK, Jiang N, Morales CR, Kong Y, Rothermel BA, Gillette TG, Hill JA (2011): Histone deacetylase (HDAC) inhibitors attenuate cardiac hypertrophy by suppressing autophagy. Proc Natl Acad Sci U S A 108, 4123-4128

Carrell RW, Lomas DA (1997): Conformational disease. Lancet 350, 134-138

Chiang HL, Terlecky SR, Plant CP, Dice JF (1989): A role for a 70-kilodalton heat shock protein in lysosomal degradation of intracellular proteins. Science $\underline{246}, 382-385$

Chu G, Egnaczyk GF, Zhao W, Jo S-H, Fan G-C, Maggio JE, Xiao R-P, Kranias EG (2004): Phosphoproteome analysis of cardiomyocytes subjected to beta-adrenergic stimulation: identification and characterization of a cardiac heat shock protein p20. Circ Res 94, 184-193 
Ciechanover A, Kwon YT (2015): Degradation of misfolded proteins in neurodegenerative diseases: therapeutic targets and strategies. Exp Mol Med 47, e147

Clerk A, Sugden PH (1997): Regulation of phospholipases C and D in rat ventricular myocytes: stimulation by endothelin-1, bradykinin and phenylephrine. J Mol Cell Cardiol 29, 1593-1604

Collins PL, Hightower LE (1982): Newcastle disease virus stimulates the cellular accumulation of stress (heat shock) mRNAs and proteins. J Virol 44, 703-707

Cox EJ, Marsh SA (2014): A Systematic Review of Fetal Genes as Biomarkers of Cardiac Hypertrophy in Rodent Models of Diabetes. PLOS ONE $\underline{9}$, e92903

Crawford KC, Flores MV, Oehlers SH, Hall CJ, Crosier KE, Crosier PS (2011): Zebrafish heat shock protein a4 genes in the intestinal epithelium are up-regulated during inflammation. Genesis $\underline{49}, 905$ 911

Cuervo AM, Dice JF (1996): A receptor for the selective uptake and degradation of proteins by lysosomes. Science $\underline{273}, 501-503$

Cuervo AM, Wong E (2014): Chaperone-mediated autophagy: roles in disease and aging. Cell Res $\underline{24}$, $92-104$

Czepluch FS, Wollnik B, Hasenfuß G (2018): Genetic determinants of heart failure: facts and numbers. ESC Heart Fail $\underline{5}, 211-217$

Dai Y-S, Xu J, Molkentin JD (2005): The DnaJ-Related Factor Mrj Interacts with Nuclear Factor of Activated T Cells c3 and Mediates Transcriptional Repression through Class II Histone Deacetylase Recruitment. Mol Cell Biol 25, 9936-9948

Dantuma NP, Lindsten K (2010): Stressing the ubiquitin-proteasome system. Cardiovasc Res $\underline{85}$, $263-271$

Day SM (2013): The ubiquitin proteasome system in human cardiomyopathies and heart failure. Am J Physiol 304, H1283-H1293

De Arcangelis V, Liu R, Soto D, Xiang Y (2009): Differential Association of Phosphodiesterase 4D Isoforms with $\beta 2$-Adrenoceptor in Cardiac Myocytes. J Biol Chem 284, 33824-33832 
Deschamps AM, Spinale FG (2006): Pathways of matrix metalloproteinase induction in heart failure: Bioactive molecules and transcriptional regulation. Cardiovasc Res $\underline{69}$, 666-676

Dice JF (1990): Peptide sequences that target cytosolic proteins for lysosomal proteolysis. Trends Biochem Sci 15, 305-309

Dragovic Z, Broadley SA, Shomura Y, Bracher A, Hartl FU (2006): Molecular chaperones of the Hsp110 family act as nucleotide exchange factors of Hsp70s. EMBO J 25, 2519-2528

Drews O, Taegtmeyer H (2014): Targeting the Ubiquitin-Proteasome System in Heart Disease: The Basis for New Therapeutic Strategies. Antioxid Redox Signal 21, 2322-2343

Drews O, Wildgruber R, Zong C, Sukop U, Nissum M, Weber G, Gomes AV, Ping P (2007): Mammalian Proteasome Subpopulations with Distinct Molecular Compositions and Proteolytic Activities. Mol Cell Proteomics $\underline{6}$, 2021-2031

Easton DP, Kaneko Y, Subjeck JR (2000): The Hsp110 and Grp170 stress proteins: newly recognized relatives of the Hsp70s. Cell Stress Chaperones $\underline{5}$, 276-290

Efthymiou CA, Mocanu MM, de Belleroche J, Wells DJ, Latchmann DS, Yellon DM (2004): Heat shock protein 27 protects the heart against myocardial infarction. Basic Res Cardiol 99, 392-394

Eguchi S, Hirata Y, Imai T, Marumo F (1993): Endothelin receptor subtypes are coupled to adenylate cyclase via different guanyl nucleotide-binding proteins in vasculature. Endocrinology 132, 524-529

El-Khoury V, Pierson S, Szwarcbart E, Brons NHC, Roland O, Cherrier-De Wilde S, Plawny L, Van Dyck E, Berchem G (2014): Disruption of autophagy by the histone deacetylase inhibitor MGCD0103 and its therapeutic implication in B-cell chronic lymphocytic leukemia. Leukemia $\underline{28}$, 1636-1646

Ellis RJ, van der Vies SM (1991): Molecular Chaperones. Annu Rev Biochem 60, 321-347

Eom GH, Kook H (2015): Role of histone deacetylase 2 and its posttranslational modifications in cardiac hypertrophy. BMB Rep 48, 131-138

Eom GH, Cho YK, Ko J-H, Shin S, Choe N, Kim Y, Joung H, Kim H-S, Nam K-I, Kee HJ, Kook H (2011): Casein kinase-2 $\alpha 1$ induces hypertrophic response by phosphorylation of histone deacetylase 2 S394 and its activation in the heart. Circulation $\underline{123}$, 2392-2403 
Eroglu B, Moskophidis D, Mivechi NF (2010): Loss of Hsp110 leads to age-dependent tau hyperphosphorylation and early accumulation of insoluble amyloid beta. Mol Cell Biol $\underline{30}$, 4626-4643

Eskelinen E-L, Saftig P (2009): Autophagy: A lysosomal degradation pathway with a central role in health and disease. Biochim Biophys Acta 1793, 664-673

Fan G-C, Ren X, Qian J, Yuan Q, Nicolaou P, Wang Y, Jones WK, Chu G, Kranias EG (2005): Novel cardioprotective role of a small heat-shock protein, Hsp20, against ischemia/reperfusion injury. Circulation $\underline{111}$, 1792-1799

Fern RJ, Hahm MS, Lu HK, Liu LP, Gorelick FS, Barrett PQ (1995): Ca2+/calmodulin-dependent protein kinase II activation and regulation of adrenal glomerulosa Ca2+ signaling. Am J Physiol-Ren Physiol 269, F751-F760

Fielitz J, Kim M-S, Shelton JM, Latif S, Spencer JA, Glass DJ, Richardson JA, Bassel-Duby R, Olson EN (2007): Myosin accumulation and striated muscle myopathy result from the loss of muscle RING finger 1 and 3. J Clin Invest 117, 2486-2495

Fielitz J, Kim M-S, Shelton JM, Qi X, Hill JA, Richardson JA, Bassel-Duby R, Olson EN (2008): Requirement of protein kinase D1 for pathological cardiac remodeling. Proc Natl Acad Sci U S A $\underline{105}, 3059-3063$

Finley D (2009): Recognition and Processing of Ubiquitin-Protein Conjugates by the Proteasome. Annu Rev Biochem 78, 477-513

Frydman J (2001): Folding of Newly Translated Proteins In Vivo: The Role of Molecular Chaperones. Annu Rev Biochem 70, 603-647

Funderburk. SF, Wang QJ, Yue Z (2010): Beclin 1-VPS34 complex - At the Crossroads of Autophagy and Beyond. Trends Cell Biol 20, 355-362

Gan XT, Rajapurohitam V, Haist JV, Chidiac P, Cook MA, Karmazyn M (2005): Inhibition of Phenylephrine-Induced Cardiomyocyte Hypertrophy by Activation of Multiple Adenosine Receptor Subtypes. J Pharmacol Exp Ther 312, 27-34 
Garcia VM, Nillegoda NB, Bukau B, Morano KA (2017): Substrate binding by the yeast Hsp110 nucleotide exchange factor and molecular chaperone Sse1 is not obligate for its biological activities. Mol Biol Cell 28, 2066-2075

Goedert M, Spillantini MG, Tredici KD, Braak H (2013): 100 years of Lewy pathology. Nat Rev Neurol $\underline{9}, 13-24$

Goldstein G, Scheid M, Hammerling U, Schlesinger DH, Niall HD, Boyse EA (1975): Isolation of a polypeptide that has lymphocyte-differentiating properties and is probably represented universally in living cells. Proc Natl Acad Sci U S A $\underline{72}, 11-15$

Gomes AV, Zong C, Edmondson RD, Li X, Stefani E, Zhang J, Jones RC, Thyparambil S, Wang GW, Qiao X, et al. (2006): Mapping the murine cardiac 26S proteasome complexes. Circ Res $\underline{99}$, 362 371

Gomes AV, Young GW, Wang Y, Zong C, Eghbali M, Drews O, Lu H, Stefani E, Ping P (2009): Contrasting Proteome Biology and Functional Heterogeneity of the $20 \mathrm{~S}$ Proteasome Complexes in Mammalian Tissues. Mol Cell Proteomics MCP $\underline{8}, 302-315$

Grebe C, Klingebiel T-M, Grau SP, Toischer K, Didié M, Jacobshagen C, Dullin C, Hasenfuss G, Seidler T (2011): Enhanced expression of DYRK1A in cardiomyocytes inhibits acute NFAT activation but does not prevent hypertrophy in vivo. Cardiovasc Res $\underline{90}, 521-528$

Gregersen N, Bross P, Vang S, Christensen JH (2006): Protein Misfolding and Human Disease. Annu Rev Genomics Hum Genet 7, 103-124

Groll M, Ditzel L, Löwe J, Stock D, Bochtler M, Bartunik HD, Huber R (1997): Structure of 20S proteasome from yeast at $2.4 \AA$ resolution. Nature $\underline{386}, 463-471$

Gu X, Bishop SP (1994): Increased protein kinase C and isozyme redistribution in pressure-overload cardiac hypertrophy in the rat. Circ Res $\underline{75}, 926-931$

Guttenplan N, Lee C, Frishman WH (2001): Inhibition of myocardial apoptosis as a therapeutic target in cardiovascular disease prevention: focus on caspase inhibition. Heart Dis $\underline{3}, 313-318$

Habibian J, Ferguson BS (2018): The Crosstalk between Acetylation and Phosphorylation: Emerging New Roles for HDAC Inhibitors in the Heart. Int J Mol Sci 20, 30597863 
Hammerer-Lercher A, Mair J, Bonatti J, Watzka SBC, Puschendorf B, Dirnhofer S (2001): Hypoxia induces heat shock protein expression in human coronary artery bypass grafts. Cardiovasc Res $\underline{50}$, $115-124$

Hanford DS, Thuerauf DJ, Murray SF, Glembotski CC (1994): Brain natriuretic peptide is induced by alpha 1-adrenergic agonists as a primary response gene in cultured rat cardiac myocytes. J Biol Chem 269, 26227-26233

Hanna J, Meides A, Zhang DP, Finley D (2007): A Ubiquitin Stress Response Induces Altered Proteasome Composition. Cell $\underline{129}, 747-759$

Harrison BC, Kim M-S, van Rooij E, Plato CF, Papst PJ, Vega RB, McAnally JA, Richardson JA, Bassel-Duby R, Olson EN, McKinsey TA (2006): Regulation of Cardiac Stress Signaling by Protein Kinase D1. Mol Cell Biol 26, 3875-3888

Haworth RS, Goss MW, Rozengurt E, Avkiran M (2000): Expression and activity of protein kinase $\mathrm{D} /$ protein kinase $\mathrm{C}$ mu in myocardium: evidence for alpha1-adrenergic receptor- and protein kinase C-mediated regulation. J Mol Cell Cardiol 32, 1013-1023

Held T, Paprotta I, Khulan J, Hemmerlein B, Binder L, Wolf S, Schubert S, Meinhardt A, Engel W, Adham IM (2006): Hspa4l-Deficient Mice Display Increased Incidence of Male Infertility and Hydronephrosis Development. Mol Cell Biol 26, 8099-8108

Held T, Barakat AZ, Mohamed BA, Paprotta I, Meinhardt A, Engel W, Adham IM (2011): Heatshock protein HSPA4 is required for progression of spermatogenesis. Reproduction 142, 133-144

Henning RH, Brundel BJJM (2017): Proteostasis in cardiac health and disease. Nat Rev Cardiol $\underline{14}$, $637-653$

Hershko A, Ciechanover A (1998): The Ubiquitin System. Annu Rev Biochem 67, 425-479 Holtwick R, van Eickels M, Skryabin BV, Baba HA, Bubikat A, Begrow F, Schneider MD, Garbers DL, Kuhn M (2003): Pressure-independent cardiac hypertrophy in mice with cardiomyocyte-restricted inactivation of the atrial natriuretic peptide receptor guanylyl cyclase-A. J Clin Invest 111, 1399 1407

Howarth JL, Glover CPJ, Uney JB (2009): HSP70 interacting protein prevents the accumulation of inclusions in polyglutamine disease1. J Neurochem $\underline{108}, 945-951$ 
Huang KP (1989): The mechanism of protein kinase C activation. Trends Neurosci 12, 425-432

Huang Q, Huang J, Zeng Z, Luo J, Liu P, Chen S, Liu B, Pan X, Zang L, Zhou S (2015): Effects of ERK1/2/PPAR $\alpha / S C A D$ signal pathways on cardiomyocyte hypertrophy induced by insulin-like growth factor 1 and phenylephrine. Life Sci $\underline{124}, 41-49$

Hunton DL, Lucchesi PA, Pang Y, Cheng X, Dell'Italia LJ, Marchase RB (2002): Capacitative Calcium Entry Contributes to Nuclear Factor of Activated T-cells Nuclear Translocation and Hypertrophy in Cardiomyocytes. J Biol Chem $\underline{277}, 14266-14273$

Iwai-Kanai E, Hasegawa K (2004): Intracellular signaling pathways for norepinephrine- and endothelin-1-mediated regulation of myocardial cell apoptosis. Mol Cell Biochem 259, 163-168

Jee H (2016): Size dependent classification of heat shock proteins: a mini-review. J Exerc Rehabil 12 , 255-259

Jen H-L, Yin W-H, Chen J-W, Lin S-J (2017): Endothelin-1-Induced Cell Hypertrophy in Cardiomyocytes is Improved by Fenofibrate: Possible Roles of Adiponectin. J Atheroscler Thromb $\underline{24}, 508$ 517

Jenie RI, Nishimura M, Fujino M, Nakaya M, Mizuno N, Tago K, Kurose H, Itoh H (2013): Increased ubiquitination and the crosstalk of $\mathrm{G}$ protein signaling in cardiac myocytes: involvement of Ric- $8 \mathrm{~B}$ in Gs suppression by Gq signal. Genes Cells $\underline{18}, 1095-1106$

Jensen KT, Carstens J, Pedersen EB (1998): Effect of BNP on renal hemodynamics, tubular function and vasoactive hormones in humans. Am J Physiol 274, F63-72

Jucker M, Walker LC (2013): Self-propagation of pathogenic protein aggregates in neurodegenerative diseases. Nature $\underline{501}, 45-51$

Kaneko Y, Nishiyama H, Nonoguchi K, Higashitsuji H, Kishishita M, Fujita J (1997a): A Novel hsp110-related Gene, apg-1, That Is Abundantly Expressed in the Testis Responds to a Low Temperature Heat Shock Rather than the Traditional Elevated Temperatures. J Biol Chem 272, 26402645

Kaneko Y, Kimura T, Kishishita M, Noda Y, Fujita J (1997b): Cloning of apg-2 encoding a novel member of heat shock protein 110 family. Gene $\underline{189}, 19-24$ 
Kang C-M, Park K-P, Cho C-K, Seo J-S, Park W-Y, Lee S-J, Lee Y-S (2002): Hspa4 (HSP70) is involved in the radioadaptive response: results from mouse splenocytes. Radiat Res $\underline{157}$, 650-655

Kang R, Zeh HJ, Lotze MT, Tang D (2011): The Beclin 1 network regulates autophagy and apoptosis. Cell Death Differ $\underline{18}, 571-580$

Kedar V, McDonough H, Arya R, Li H-H, Rockman HA, Patterson C (2004): Muscle-specific RING finger 1 is a bona fide ubiquitin ligase that degrades cardiac troponin I. Proc Natl Acad Sci U S A 101, 18135-18140

Kee Hae Jin, Eom Gwang Hyeon, Joung Hosouk, Shin Sera, Kim Ju-Ryoung, Cho Young Kuk, Choe Nakwon, Sim Bo-Woong, Jo Daewoong, Jeong Myung Ho, et al. (2008): Activation of Histone Deacetylase 2 by Inducible Heat Shock Protein 70 in Cardiac Hypertrophy. Circ Res 103, 1259-1269

Kim H, Huh PW, Kim C, Kim Y-J, Park E-M, Park Y-M (2001): Cerebral activation and distribution of inducible hsp110 and hsp70 mRNAs following focal ischemia in rat. Toxicology 167, 135-144

Koegl M, Hoppe T, Schlenker S, Ulrich HD, Mayer TU, Jentsch S (1999): A Novel Ubiquitination Factor, E4, Is Involved in Multiubiquitin Chain Assembly. Cell $\underline{96}$, 635-644

Koh HS, Moon IS, Lee YH, Shong M, Kwon OY (2000): Expression of an HSP110 family, ischemiaresponsive protein (irp94), in the rat brain after transient forebrain ischemia. J Biosci $\underline{55}$, 449-454

Koninck PD, Schulman H (1998): Sensitivity of CaM Kinase II to the Frequency of Ca2+ Oscillations. Science $\underline{279}, 227-230$

Kostin S (2003): Myocytes Die by Multiple Mechanisms in Failing Human Hearts. Circ Res $\underline{92}$, 715724

Kötter S, Unger A, Hamdani N, Lang P, Vorgerd M, Nagel-Steger L, Linke WA (2014): Human myocytes are protected from titin aggregation-induced stiffening by small heat shock proteins. J Cell Biol 204, 187-202

Kraft C, Peter M, Hofmann K (2010): Selective autophagy: ubiquitin-mediated recognition and beyond. Nat Cell Biol 12, 836-841 
Krijnen PAJ, Nijmeijer R, Meijer CJLM, Visser CA, Hack CE, Niessen HWM (2002): Apoptosis in myocardial ischaemia and infarction. J Clin Pathol $\underline{55}, 801-811$

Kristiansen M, Deriziotis P, Dimcheff DE, Jackson GS, Ovaa H, Naumann H, Clarke AR, Leeuwen FWB van, Menéndez-Benito V, Dantuma NP, et al. (2007): Disease-Associated Prion Protein Oligomers Inhibit the 26S Proteasome. Mol Cell $\underline{26}, 175-188$

Kumarapeli ARK, Su H, Huang W, Tang M, Zheng H, Horak KM, Li M, Wang X (2008): $\alpha$ B-Crystallin Suppresses Pressure Overload Cardiac Hypertrophy. Circ Res 103, 1473-1482

La Thangue NB, Latchman DS (1988): A cellular protein related to heat-shock protein 90 accumulates during herpes simplex virus infection and is overexpressed in transformed cells. Exp Cell Res 178, 169-179

Labbadia J, Morimoto RI (2015): The Biology of Proteostasis in Aging and Disease. Annu Rev Biochem $\underline{84}, 435-464$

Lee M-Y, Choi Y-S, Choi J-S, Min DS, Chun M-H, Kim ON, Lee SB, Kim SY (2002): An immunohistochemical study of APG-2 protein in the rat hippocampus after transient forebrain ischemia. Brain Res $\underline{924}$, 237-241

Li C, Liu D, Yuan Y, Huang S, Shi M, Tao K, Feng W (2010): Overexpression of Apg-2 increases cell proliferation and protects from oxidative damage in BaF3-BCR/ABL cells. Int J Oncol $\underline{36}$, 899_ 904

Li F, Xiao H, Zhou F, Hu Z, Yang B (2017): Study of HSPB6: Insights into the Properties of the Multifunctional Protective Agent. Cell Physiol Biochem 44, 314-332

Li GC (1983): Induction of thermotolerance and enhanced heat shock protein synthesis in chinese hamster fibroblasts by sodium arsenite and by ethanol. J Cell Physiol 115, 116-122

Li GC, Laszlo A (1985): Amino acid analogs while inducing heat shock proteins sensitize CHO cells to thermal damage. J Cell Physiol 122, 91-97

Li J, Horak KM, Su H, Sanbe A, Robbins J, Wang X (2011): Enhancement of proteasomal function protects against cardiac proteinopathy and ischemia/reperfusion injury in mice. J Clin Invest $\underline{121}$, 3689-3700 
Li L, Xu J, He L, Peng L, Zhong Q, Chen L, Jiang Z (2016): The role of autophagy in cardiac hypertrophy. Acta Biochim Biophys Sin $\underline{48}, 491-500$

Li Z-L, Lerman LO (2012): Impaired myocardial autophagy linked to energy metabolism disorders. Autophagy $\underline{8}, 992-994$

Liang C, Lee J, Inn K-S, Gack MU, Li Q, Roberts EA, Vergne I, Deretic V, Feng P, Akazawa C, Jung JU (2008): Beclin1-binding UVRAG targets the class C Vps complex to coordinate autophagosome maturation and endocytic trafficking. Nat Cell Biol $\underline{10}, 776-787$

Ling S, Sun Q, Li Y, Zhang L, Zhang P, Wang X, Tian C, Li Qi, Song J, Liu H, et al. (2012): CKIP1 Inhibits Cardiac Hypertrophy by Regulating Class II Histone Deacetylase Phosphorylation Through Recruiting PP2A. Circulation 126, 3028-3040

Liu C-W, Li X, Thompson D, Wooding K, Chang T, Tang Z, Yu H, Thomas PJ, DeMartino GN (2006): ATP Binding and ATP Hydrolysis Play Distinct Roles in the Function of $26 S$ Proteasome. Mol Cell 24, 39-50

Liu Q, Hendrickson WA (2007): Insights into Hsp70 Chaperone Activity from a Crystal Structure of the Yeast Hsp110 Sse1. Cell 131, 106-120

Liu Q, Chen Y, Auger-Messier M, Molkentin JD (2012): Interaction between NFxB and NFAT Coordinates Cardiac Hypertrophy and Pathological Remodeling. Circ Res $\underline{110}, 1077-1086$

Lorenzon A, Beffagna G, Bauce B, De Bortoli M, Li Mura IEA, Calore M, Dazzo E, Basso C, Nava A, Thiene G, Rampazzo A (2013): Desmin mutations and arrhythmogenic right ventricular cardiomyopathy. Am J Cardiol 111, 400-405

Lowe J, Stock D, Jap B, Zwickl P, Baumeister W, Huber R (1995): Crystal structure of the 20S proteasome from the archaeon T. acidophilum at 3.4 A resolution. Science 268, 533-539

Lu J, McKinsey TA, Zhang C-L, Olson EN (2000a): Regulation of Skeletal Myogenesis by Association of the MEF2 Transcription Factor with Class II Histone Deacetylases. Mol Cell $\underline{6}$, 233-244

Lu J, McKinsey TA, Nicol RL, Olson EN (2000b): Signal-dependent activation of the MEF2 transcription factor by dissociation from histone deacetylases. Proc Natl Acad Sci U S A $\underline{97}, 4070$ 4075 
Lüders J, Demand J, Höhfeld J (2000): The ubiquitin-related BAG-1 provides a link between the molecular chaperones Hsc70/Hsp70 and the proteasome. J Biol Chem 275, 4613-4617

Luheshi LM, Crowther DC, Dobson CM (2008): Protein misfolding and disease: from the test tube to the organism. Curr Opin Chem Biol 12, 25-31

Maass A, Langer SJ, Oberdorf-Maass S, Bauer S, Neyses L, Leinwand LA (2003): Rational promoter selection for gene transfer into cardiac cells. J Mol Cell Cardiol 35, 823-831

Magga J, Marttila M, Mäntymaa P, Vuolteenaho O, Ruskoaho H (1994): Brain natriuretic peptide in plasma, atria, and ventricles of vasopressin- and phenylephrine-infused conscious rats. Endocrino$\log \underline{134}, 2505-2515$

Manning G, Whyte DB, Martinez R, Hunter T, Sudarsanam S (2002): The Protein Kinase Complement of the Human Genome. Science 298, 1912-1934

Mao Z, Wiedmann M (1999): Calcineurin enhances MEF2 DNA binding activity in calcium-dependent survival of cerebellar granule neurons. J Biol Chem $\underline{274}$, 31102-31107

Marber MS, Latchman DS, Walker JM, Yellon DM (1993): Cardiac stress protein elevation 24 hours after brief ischemia or heat stress is associated with resistance to myocardial infarction. Circulation $\underline{88}, 1264-1272$

Maron BJ, Towbin JA, Thiene G, Antzelevitch C, Corrado D, Arnett D, Moss AJ, Seidman CE, Young JB, American Heart Association, et al. (2006): Contemporary definitions and classification of the cardiomyopathies: an American Heart Association Scientific Statement from the Council on Clinical Cardiology, Heart Failure and Transplantation Committee; Quality of Care and Outcomes Research and Functional Genomics and Translational Biology Interdisciplinary Working Groups; and Council on Epidemiology and Prevention. Circulation 113, 1807-1816

Martin TP, Currie S, Baillie GS (2014): The cardioprotective role of small heat-shock protein 20. Biochem Soc Trans $\underline{42}, 270-273$

Mathew A, Morimoto RI (1998): Role of the heat-shock response in the life and death of proteins. Ann N Y Acad Sci 851, 99-111 
Matsunaga K, Saitoh T, Tabata K, Omori H, Satoh T, Kurotori N, Maejima I, Shirahama-Noda K, Ichimura T, Isobe T, et al. (2009): Two Beclin 1-binding proteins, Atg14L and Rubicon, reciprocally regulate autophagy at different stages. Nat Cell Biol $\underline{11}, 385-396$

Mattoo RUH, Sharma SK, Priya S, Finka A, Goloubinoff P (2013): Hsp110 Is a Bona Fide Chaperone Using ATP to Unfold Stable Misfolded Polypeptides and Reciprocally Collaborate with Hsp70 to Solubilize Protein Aggregates. J Biol Chem 288, 21399

Mayer MP, Bukau B (2005): Hsp70 chaperones: Cellular functions and molecular mechanism. Cell Mol Life Sci $\underline{62}, 670-684$

McDonough H, Patterson C (2003): CHIP: a link between the chaperone and proteasome systems. Cell Stress Chaperones $\underline{8}, 303-308$

McKinsey TA, Zhang C-L, Lu J, Olson EN (2000): Signal-dependent nuclear export of a histone deacetylase regulates muscle differentiation. Nature $\underline{408}, 106-111$

McLendon PM, Robbins J (2015): Proteotoxicity and Cardiac Dysfunction. Circ Res 116, 1863-1882

Melkani GC, Bodmer R, Ocorr K, Bernstein SI (2011): The UNC-45 Chaperone Is Critical for Establishing Myosin-Based Myofibrillar Organization and Cardiac Contractility in the Drosophila Heart Model. PLOS ONE $\underline{6}$, e22579

Mel'nikova NP, Timoshin SS, Pelliniemi LJ, Jokinen E, Abdelwahid E (2004): Effect of endothelin1 on apoptosis, proliferation, and protein synthesis in cardiomyocytes of newborn albino rats. Bull Exp Biol Med 137, 606-608

Menaouar A, Florian M, Wang D, Danalache B, Jankowski M, Gutkowska J (2014): Anti-hypertrophic effects of oxytocin in rat ventricular myocytes. Int J Cardiol $\underline{175}, 38-49$

Meng X, Clews J, Kargas V, Wang X, Ford RC (2017): The cystic fibrosis transmembrane conductance regulator (CFTR) and its stability. Cell Mol Life Sci $\underline{74}$, 23-38

Mestril R, Chi SH, Sayen MR, O’Reilly K, Dillmann WH (1994): Expression of inducible stress protein 70 in rat heart myogenic cells confers protection against simulated ischemia-induced injury. J Clin Invest 23 , 759-767 
Meyer T, Hanson PI, Stryer L, Schulman H (1992): Calmodulin Trapping by Calcium-CalmodulinDependent Protein Kinase. Science 256, 1199-1202

Michel MC, Hanft G, Gross G (1994): Radioligand binding studies of alpha 1-adrenoceptor subtypes in rat heart. Br J Pharmacol 111, 533-538

Mindell JA (2012): Lysosomal acidification mechanisms. Annu Rev Physiol 74, 69-86

Miska EA, Karlsson C, Langley E, Nielsen SJ, Pines J, Kouzarides T (1999): HDAC4 deacetylase associates with and represses the MEF2 transcription factor. EMBO J 18, 5099-5107

Mizushima N, Ohsumi Y, Yoshimori T (2002): Autophagosome Formation in Mammalian Cells. Cell Struct Funct 27, 421-429

Mohamed BA, Barakat AZ, Zimmermann W-H, Bittner RE, Mühlfeld C, Hünlich M, Engel W, Maier LS, Adham IM (2012): Targeted disruption of Hspa4 gene leads to cardiac hypertrophy and fibrosis. J Mol Cell Cardiol 53, 459-468

Molkentin JD (2004): Calcineurin-NFAT signaling regulates the cardiac hypertrophic response in coordination with the MAPKs. Cardiovasc Res $\underline{63}$, 467-475

Molkentin JD, Lu J-R, Antos CL, Markham B, Richardson J, Robbins J, Grant SR, Olson EN (1998): A Calcineurin-Dependent Transcriptional Pathway for Cardiac Hypertrophy. Cell $\underline{93}$, 215

Mollova M, Bersell K, Walsh S, Savla J, Das LT, Park S-Y, Silberstein LE, dos Remedios CG, Graham D, Colan S, Kühn B (2013): Cardiomyocyte proliferation contributes to heart growth in young humans. Proc Natl Acad Sci U S A $\underline{110}, 1446-1451$

Mony VK, Benjamin S, O’Rourke EJ (2016): A lysosome-centered view of nutrient homeostasis. Autophagy 12, 619-631

Mukai H, Kuno T, Tanaka H, Hirata D, Miyakawa T, Tanaka C (1993): Isolation and characterization of SSE1 and SSE2, new members of the yeast HSP70 multigene family. Gene 132, 57-66

Murata S, Yashiroda H, Tanaka K (2009): Molecular mechanisms of proteasome assembly. Nat Rev Mol Cell Biol 10, 104-115 
Nakagawa O, Ogawa Y, Itoh H, Suga S, Komatsu Y, Kishimoto I, Nishino K, Yoshimasa T, Nakao K (1995): Rapid transcriptional activation and early mRNA turnover of brain natriuretic peptide in cardiocyte hypertrophy. Evidence for brain natriuretic peptide as an „emergency“ cardiac hormone against ventricular overload. J Clin Invest 뜨, 1280-1287

Nakaoka M, Iwai-Kanai E, Katamura M, Okawa Y, Mita Y, Matoba S (2015): An alpha-adrenergic agonist protects hearts by inducing Akt1-mediated autophagy. Biochem Biophys Res Commun 456, $250-256$

Neyses L, Nouskas J, Vetter H (1991): Inhibition of endothelin-1 induced myocardial protein synthesis by an antisense oligonucleotide against the early growth response gene-1. Biochem Biophys Res Commun 181, 22-27

Noda T, Suzuki K, Ohsumi Y (2002): Yeast autophagosomes: de novo formation of a membrane structure. Trends Cell Biol 12, 231-235

Noguchi H, Muraoka R, Kigoshi S, Muramatsu I (1995): Pharmacological characterization of alpha 1-adrenoceptor subtypes in rat heart: a binding study. Br J Pharmacol 114, 1026-1030

Nonoguchi K, Itoh K, Xue J-H, Tokuchi H, Nishiyama H, Kaneko Y, Tatsumi K, Okuno H, Tomiwa K, Fujita J (1999): Cloning of human cDNAs for Apg-1 and Apg-2, members of the Hsp110 family, and chromosomal assignment of their genes. Gene 237, 21-28

Oancea E, Bezzerides VJ, Greka A, Clapham DE (2003): Mechanism of Persistent Protein Kinase D1 Translocation and Activation. Dev Cell 4, 561-574

O'Connell TD, Rokosh DG, Simpson PC (2001): Cloning and characterization of the mouse alpha1C/A-adrenergic receptor gene and analysis of an alpha1C promoter in cardiac myocytes: role of an MCAT element that binds transcriptional enhancer factor-1 (TEF-1). Mol Pharmacol $\underline{59}, 1225-$ 1234

Oh M, Choi I-K, Kwon HJ (2008): Inhibition of histone deacetylase1 induces autophagy. Biochem Biophys Res Commun $\underline{369}, 1179-1183$

Orlowski M, Wilk S (2000): Catalytic Activities of the 20 S Proteasome, a Multicatalytic Proteinase Complex. Arch Biochem Biophys $\underline{383}, 1-16$ 
Orr HT, Zoghbi HY (2007): Trinucleotide Repeat Disorders. Annu Rev Neurosci $\underline{30}$, 575-621

O-Uchi J, Komukai K, Kusakari Y, Obata T, Hongo K, Sasaki H, Kurihara S (2005): $\alpha 1$-Adrenoceptor stimulation potentiates L-type $\mathrm{Ca} 2+$ current through $\mathrm{Ca} 2+/$ calmodulin-dependent PK II (CaMKII) activation in rat ventricular myocytes. Proc Natl Acad Sci U S A 102, 9400-9405

Ozawa Y, Towatari M, Tsuzuki S, Hayakawa F, Maeda T, Miyata Y, Tanimoto M, Saito H (2001): Histone deacetylase 3 associates with and represses the transcription factor GATA-2. Blood $\underline{98}$, 2116-2123

Park JM, Kim JW, Hahm KB (2015): HSPA4, the "Evil Chaperone" of the HSP Family, Delays Gastric Ulcer Healing. Dig Dis Sci $\underline{60}$, 824-826

Passier R, Zeng H, Frey N, Naya FJ, Nicol RL, McKinsey TA, Overbeek P, Richardson JA, Grant SR, Olson EN (2000): CaM kinase signaling induces cardiac hypertrophy and activates the MEF2 transcription factor in vivo. J Clin Invest 105, 1395-1406

Patterson C, Ike C, Willis PW, Stouffer GA, Willis MS (2007): The Bitter End: The Ubiquitin-Proteasome System and Cardiac Dysfunction. Circulation $\underline{115}, 1456-1463$

Pattison JS, Robbins J (2008): Protein Misfolding and Cardiac Disease. Autophagy 4, 821-823

Pattison JS, Sanbe A, Maloyan A, Osinska H, Klevitsky R, Robbins J (2008): Cardiomyocyte Expression of a Polyglutamine Pre-amyloid Oligomer Causes Heart Failure. Circulation 117, 2743-2751

Peter AK, Bjerke MA, Leinwand LA (2016): Biology of the cardiac myocyte in heart disease. Mol Biol Cell $\underline{27}, 2149-2160$

Pickart CM (2001): Mechanisms underlying ubiquitination. Annu Rev Biochem 므, 503-533

Pipkin W, Johnson JA, Creazzo TL, Burch J, Komalavilas P, Brophy C (2003): Localization, macromolecular associations, and function of the small heat shock-related protein HSP20 in rat heart. Circulation $\underline{107}, 469-476$

Plumier JC, Ross BM, Currie RW, Angelidis CE, Kazlaris H, Kollias G, Pagoulatos GN (1995): Transgenic mice expressing the human heat shock protein 70 have improved post-ischemic myocardial recovery. J Clin Invest 모, 1854-1860 
Polier S, Dragovic Z, Hartl FU, Bracher A (2008): Structural Basis for the Cooperation of Hsp70 and Hsp110 Chaperones in Protein Folding. Cell 133, 1068-1079

Predmore JM, Wang P, Davis F, Bartolone S, Westfall MV, Dyke DB, Pagani F, Powell SR, Day SM (2010): Ubiquitin Proteasome Dysfunction in Human Hypertrophic and Dilated Cardiomyopathies. Circulation 121, 997-1004

Qian J, Vafiadaki E, Florea SM, Singh VP, Song W, Lam CK, Wang Y, Yuan Q, Pritchard TJ, Cai W, et al. (2011): The Small Heat Shock Protein 20 (Hsp20) Interacts with Protein Phosphatase-1 and Enhances Sarcoplasmic Reticulum Ca-Cycling. Circ Res $\underline{108}, 1429-1438$

Quarles EK, Dai D-F, Tocchi A, Basisty N, Gitari L, Rabinovitch PS (2015): Quality Control Systems in Cardiac Aging. Ageing Res Rev $\underline{23}, 101-115$

Rafiee P, Theriot ME, Nelson VM, Heidemann J, Kanaa Y, Horowitz SA, Rogaczewski A, Johnson CP, Ali I, Shaker R, Binion DG (2006): Human esophageal microvascular endothelial cells respond to acidic $\mathrm{pH}$ stress by PI3K/AKT and p38 MAPK-regulated induction of Hsp70 and Hsp27. Am J Physiol Cell Physiol 291, C931-945

Rampelt H, Kirstein-Miles J, Nillegoda NB, Chi K, Scholz SR, Morimoto RI, Bukau B (2012): Metazoan Hsp70 machines use Hsp110 to power protein disaggregation. EMBO J $\underline{31}, 4221-4235$

Raviol H, Sadlish H, Rodriguez F, Mayer MP, Bukau B (2006): Chaperone network in the yeast cytosol: Hsp110 is revealed as an Hsp70 nucleotide exchange factor. EMBO J 25, 2510-2518

Richards HA, Halfhill MD, Millwood RJ, Stewart CN (2003): Quantitative GFP fluorescence as an indicator of recombinant protein synthesis in transgenic plants. Plant Cell Rep 22, 117-121

Ritossa F (1962): A new puffing pattern induced by temperature shock and DNP in drosophila. Experientia $\underline{18}, 571-573$

Rock KL, Gramm C, Rothstein L, Clark K, Stein R, Dick L, Hwang D, Goldberg AL (1994): Inhibitors of the proteasome block the degradation of most cell proteins and the generation of peptides presented on MHC class I molecules. Cell $\underline{78}, 761-771$ 
Rolfe M, McLEOD LE, Pratt PF, Proud CG (2005): Activation of protein synthesis in cardiomyocytes by the hypertrophic agent phenylephrine requires the activation of ERK and involves phosphorylation of tuberous sclerosis complex 2 (TSC2). Biochem J $\underline{388}$, 973-984

Rujano MA, Bosveld F, Salomons FA, Dijk F, van Waarde MAWH, van der Want JJL, de Vos RAI, Brunt ER, Sibon OCM, Kampinga HH (2006): Polarised Asymmetric Inheritance of Accumulated Protein Damage in Higher Eukaryotes. PLOS Biol $\underline{4}$, e417

Rykx A, Kimpe LD, Mikhalap S, Vantus T, Seufferlein T, Vandenheede JR, Lint JV (2003): Protein kinase D: a family affair. FEBS Lett $\underline{546}, 81-86$

Sakai S, Kimura T, Wang Z, Shimojo N, Maruyama H, Homma S, Kuga K, Yamaguchi I, Aonuma K, Miyauchi T (2012): Endothelin-1-induced cardiomyocyte hypertrophy is partly regulated by transcription factor II-F interacting C-terminal domain phosphatase of RNA polymerase II. Life Sci 91, 572-577

Sakurai T, Kashida H, Hagiwara S, Nishida N, Watanabe T, Fujita J, Kudo M (2015): Heat Shock Protein A4 Controls Cell Migration and Gastric Ulcer Healing. Dig Dis Sci $\underline{60}, 850-857$

Salvador N, Aguado C, Horst M, Knecht E (2000): Import of a cytosolic protein into lysosomes by chaperone-mediated autophagy depends on its folding state. J Biol Chem 275, 27447-27456

Sanbe A, Osinska H, Saffitz JE, Glabe CG, Kayed R, Maloyan A, Robbins J (2004a): Desmin-related cardiomyopathy in transgenic mice: A cardiac amyloidosis. Proc Natl Acad Sci U S A 101, 10132 10136

Sanbe A, Osinska H, Saffitz JE, Glabe CG, Kayed R, Maloyan A, Robbins J (2004b): Desmin-related cardiomyopathy in transgenic mice: a cardiac amyloidosis. Proc Natl Acad Sci U S A $\underline{101}, 10132$ 10136

Sandri M, Robbins J (2014): Proteotoxicity: An underappreciated pathology in cardiac disease. J Mol Cell Cardiol $\underline{71}, 3-10$

Schiebinger RJ, Gomez-Sanchez CE (1990): Endothelin: A Potent Stimulus of Atrial Natriuretic Peptide Secretion by Superfused Rat Atria and Its Dependency on Calcium. Endocrinology 127, 119125 
Schuermann JP, Jiang J, Cuellar J, Llorca O, Wang L, Gimenez LE, Jin S, Taylor AB, Demeler B, Morano KA, et al. (2008): Structure of the Hsp110:Hsc70 Nucleotide Exchange Machine. Mol Cell $\underline{31}, 232-243$

Sei CA, Glembotski CC (1990): Calcium dependence of phenylephrine-, endothelin-, and potassium chloride-stimulated atrial natriuretic factor secretion from long term primary neonatal rat atrial cardiocytes. J Biol Chem 265, 7166-7172

Sengupta N, Seto E (2004): Regulation of histone deacetylase activities. J Cell Biochem 3ㅜ , 57-67

Senyo SE, Steinhauser ML, Pizzimenti CL, Yang VK, Cai L, Wang M, Wu T-D, Guerquin-Kern J-L, Lechene CP, Lee RT (2013): Mammalian Heart Renewal by Preexisting Cardiomyocytes. Nature $\underline{493}$, 433-436

Shaner L, Sousa R, Morano KA (2006): Characterization of Hsp70 binding and nucleotide exchange by the yeast Hsp110 chaperone Sse1. Biochemistry $\underline{45}$, 15075-15084

Shen P, Feng X, Zhang X, Huang X, Liu S, Lu X, Li J, You J, Lu J, Li Z, et al. (2016): SIRT6 suppresses phenylephrine-induced cardiomyocyte hypertrophy though inhibiting p300. J Pharmacol Sci $\underline{132}, 31-40$

Shubeita HE, McDonough PM, Harris AN, Knowlton KU, Glembotski CC, Brown JH, Chien KR (1990): Endothelin induction of inositol phospholipid hydrolysis, sarcomere assembly, and cardiac gene expression in ventricular myocytes. A paracrine mechanism for myocardial cell hypertrophy. J Biol Chem 265, 20555-20562

Shvets E, Fass E, Scherz-Shouval R, Elazar Z (2008): The N-terminus and Phe52 residue of LC3 recruit p62/SQSTM1 into autophagosomes. J Cell Sci 121, 2685-2695

Simonson MS, Dunn MJ (1990): Cellular signaling by peptides of the endothelin gene family. FASEB J 4 , 2989-3000

Sin YY, Martin TP, Wills L, Currie S, Baillie GS (2015): Small heat shock protein 20 (Hsp20) facilitates nuclear import of protein kinase D 1 (PKD1) during cardiac hypertrophy. Cell Commun Signal 13, 16 
Smith DM, Chang S-C, Park S, Finley D, Cheng Y, Goldberg A (2007): Docking of the Proteasomal ATPases' C-termini in the 20S Proteasomes alpha Ring Opens the Gate for Substrate Entry. Mol Cell 27, 731-744

Smith MC, Scaglione KM, Assimon VA, Patury S, Thompson AD, Dickey CA, Southworth DR, Paulson HL, Gestwicki JE, Zuiderweg ERP (2013): The E3 Ubiquitin Ligase CHIP and the Molecular

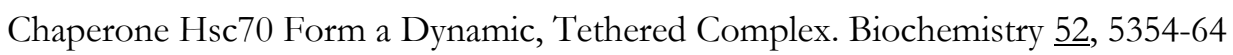

Snabaitis AK, Muntendorf A, Wieland T, Avkiran M (2005): Regulation of the extracellular signalregulated kinase pathway in adult myocardium: differential roles of $\mathrm{G}(\mathrm{q} / 11)$, Gi and $\mathrm{G}(12 / 13)$ proteins in signalling by alpha1-adrenergic, endothelin-1 and thrombin-sensitive protease-activated receptors. Cell Signal 17, 655-664

Soboleski MR, Oaks J, Halford WP (2005): Green fluorescent protein is a quantitative reporter of gene expression in individual eukaryotic cells. FASEB J 19, 440-442

Stangl K, Günther C, Frank T, Lorenz M, Meiners S, Röpke T, Stelter L, Moobed M, Baumann G, Kloetzel P-M, Stangl V (2002): Inhibition of the ubiquitin-proteasome pathway induces differential heat-shock protein response in cardiomyocytes and renders early cardiac protection. Biochem Biophys Res Commun 291, 542-549

Statistisches Bundesamt (2015): Gesundheit - Todesursachen in Deutschland, Wiesbaden. 2017 www.destatis.de/DE/Themen/Gesellschaft/Umwelt/Gesundheit/Todesursachen/PublikationenDownloads-Todesursachen/todesursachen-2120400157004.pdf?_blob=publicationFile (Zugriff am 25.08.2019)

Steinfath M, Chen YY, Lavický J, Magnussen O, Nose M, Rosswag S, Schmitz W, Scholz H (1992): Cardiac alpha 1-adrenoceptor densities in different mammalian species. Br J Pharmacol $\underline{107}, 185-$ 188

Stewart AF, Rokosh DG, Bailey BA, Karns LR, Chang KC, Long CS, Kariya K, Simpson PC (1994): Cloning of the rat alpha $1 \mathrm{C}$-adrenergic receptor from cardiac myocytes. alpha 1C, alpha 1B, and alpha $1 \mathrm{D}$ mRNAs are present in cardiac myocytes but not in cardiac fibroblasts. Circ Res $\underline{75}, 796-802$

Stuart MJ, Nagel RL (2004): Sickle-cell disease. Lancet 364, 1343-1360 
Su H, Wang X (2010): The ubiquitin-proteasome system in cardiac proteinopathy: a quality control perspective. Cardiovasc Res $\underline{85}$, 253-262

Sun M, Ouzounian M, de Couto G, Chen M, Yan R, Fukuoka M, Li G, Moon M, Liu Y, Gramolini A, et al. (2013): Cathepsin-L ameliorates cardiac hypertrophy through activation of the autophagylysosomal dependent protein processing pathways. J Am Heart Assoc 2, e000191

Tang M, Li J, Huang W, Su H, Liang Q, Tian Z, Horak KM, Molkentin JD, Wang X (2010): Proteasome functional insufficiency activates the calcineurin-NFAT pathway in cardiomyocytes and promotes maladaptive remodelling of stressed mouse hearts. Cardiovasc Res $\underline{88}, 424-433$

Tannous P, Zhu H, Nemchenko A, Berry JM, Johnstone JL, Shelton JM, Miller FJ, Rothermel BA, Hill JA (2008): Intracellular Protein Aggregation Is a Proximal Trigger of Cardiomyocyte Autophagy. Circulation 117, 3070-3078

Teiger E, Than VD, Richard L, Wisnewsky C, Tea BS, Gaboury L, Tremblay J, Schwartz K, Hamet P (1996): Apoptosis in pressure overload-induced heart hypertrophy in the rat. J Clin Invest 97, 28912897

Thibaudeau TA, Anderson RT, Smith DM (2018): A common mechanism of proteasome impairment by neurodegenerative disease-associated oligomers. Nat Commun $\underline{2}$ 1038-1097

Thum T, Galuppo P, Wolf C, Fiedler J, Kneitz S, van Laake LW, Doevendans PA, Mummery CL, Borlak J, Haverich A, et al. (2007): MicroRNAs in the Human Heart: A Clue to Fetal Gene Reprogramming in Heart Failure. Circulation 116, 258-267

Tomita T, Hamazaki J, Hirayama S, McBurney MW, Yashiroda H, Murata S (2015): Sirt1-deficiency causes defective protein quality control. Sci Rep $\underline{5}, 12613$

Tsukamoto O, Minamino T, Okada K, Shintani Y, Takashima S, Kato H, Liao Y, Okazaki H, Asai M, Hirata A, et al. (2006): Depression of proteasome activities during the progression of cardiac dysfunction in pressure-overloaded heart of mice. Biochem Biophys Res Commun $\underline{340}, 1125-1133$

Tucker NR, Shelden EA (2009): Hsp27 associates with the titin filament system in heat-shocked zebrafish cardiomyocytes. Exp Cell Res $\underline{315}$, 3176-3186 
Uemura S, lizuka R, Ueno T, Shimizu Y, Taguchi H, Ueda T, Puglisi JD, Funatsu T (2008): Singlemolecule imaging of full protein synthesis by immobilized ribosomes. Nucleic Acids Res $\underline{36}$, e70

Vafiadaki E, Arvanitis DA, Sanoudou D, Kranias EG (2013): Identification of a Protein Phosphatase1/Phospholamban Complex That Is Regulated by cAMP-Dependent Phosphorylation. PLOS ONE $\underline{8}, \mathrm{e} 80867$

Valverde AM, Sinnett-Smith J, Van Lint J, Rozengurt E (1994): Molecular cloning and characterization of protein kinase D: a target for diacylglycerol and phorbol esters with a distinctive catalytic domain. Proc Natl Acad Sci U S A $\underline{91}, 8572-8576$

Verschuure P, Croes Y, van den IJssel PRLA, Quinlan RA, de Jong WW, Boelens WC (2002): Translocation of small heat shock proteins to the actin cytoskeleton upon proteasomal inhibition. J Mol Cell Cardiol $\underline{34}, 117-128$

Vettel C, Wittig K, Vogt A, Wuertz CM, El-Armouche A, Lutz S, Wieland T (2012): A novel player in cellular hypertrophy: Gi $\beta \gamma /$ PI3K-dependent activation of the RacGEF TIAM-1 is required for $\alpha 1$ adrenoceptor induced hypertrophy in neonatal rat cardiomyocytes. J Mol Cell Cardiol $\underline{53}, 165-175$

Villarreal F, Lew WYW (2010): Protein quality control in heart disease - using established drugs to target novel mechanisms. J Am Coll Cardiol 투, 1427-1429

Vos MJ, Hageman J, Carra S, Kampinga HH (2008): Structural and Functional Diversities between Members of the Human HSPB, HSPH, HSPA, and DNAJ Chaperone Families. Biochemistry 47, 7001-7011

Walker LC, LeVine H (2000): The cerebral proteopathies. Neurobiol Aging 21, 559-561

Walter S, Buchner J (2002): Molecular Chaperones-Cellular Machines for Protein Folding. Angew Chem Int Ed $\underline{41}, 1098-1113$

Wang AH, Bertos NR, Vezmar M, Pelletier N, Crosato M, Heng HH, Th'ng J, Han J, Yang X-J (1999): HDAC4, a Human Histone Deacetylase Related to Yeast HDA1, Is a Transcriptional Corepressor. Mol Cell Biol 19, 7816-7827

Wang C, Wang X (2015): The interplay between autophagy and the ubiquitin-proteasome system in cardiac proteotoxicity. Biochim Biophys Acta $\underline{1852}, 188-194$ 
Wang J, Maldonado MA (2006): The ubiquitin-proteasome system and its role in inflammatory and autoimmune diseases. Cell Mol Immunol $\underline{3}, 255-261$

Wang X, Cui T (2017): Autophagy modulation: a potential therapeutic approach in cardiac hypertrophy. Am J Physiol-Heart Circ Physiol $\underline{313}$, H304-H319

Wang X, Osinska H, Klevitsky R, Gerdes AM, Nieman M, Lorenz J, Hewett T, Robbins J (2001): Expression of R120G-alphaB-crystallin causes aberrant desmin and alphaB-crystallin aggregation and cardiomyopathy in mice. Circ Res $\underline{89}, 84-91$

Wang X, Klevitsky R, Huang W, Glasford J, Li F, Robbins J (2003): AlphaB-crystallin modulates protein aggregation of abnormal desmin. Circ Res $\underline{93}$, 998-1005

Wang X, Su H, Ranek MJ (2008): Protein Quality Control and Degradation in Cardiomyocytes. J Mol Cell Cardiol 45, 11-27

Wang X, Zingarelli B, Connor MO, Zhang P, Adeyemo A, Kranias EG, Wang Y, Fan G-C (2009): Overexpression of Hsp20 Prevents Endotoxin-Induced Myocardial Dysfunction and Apoptosis via Inhibition of NF-xB Activation. J Mol Cell Cardiol 47, 382-390

Wang X, Pattison JS, Su H (2013): Posttranslational modification and quality control. Circ Res $\underline{112}$, $367-381$

Wang Y, Chen P, Wang L, Zhao J, Zhong Z, Wang Y, Xu J (2018): Inhibition of Histone Deacetylases Prevents Cardiac Remodeling After Myocardial Infarction by Restoring Autophagosome Processing in Cardiac Fibroblasts. Cell Physiol Biochem 49, 1999-2011

Wang ZV, Hill JA (2015): Protein Quality Control and Metabolism: Bidirectional Control in the Heart. Cell Metab 21, 215-226

Weekes J, Morrison K, Mullen A, Wait R, Barton P, Dunn MJ (2003): Hyperubiquitination of proteins in dilated cardiomyopathy. Proteomics $\underline{3}, 208-216$

Wehmer M, Rudack T, Beck F, Aufderheide A, Pfeifer G, Plitzko JM, Förster F, Schulten K, Baumeister W, Sakata E (2017): Structural insights into the functional cycle of the ATPase module of the 26S proteasome. Proc Natl Acad Sci USA 114, 1305-1310 
Welchman RL, Gordon C, Mayer RJ (2005): Ubiquitin and ubiquitin-like proteins as multifunctional signals. Nat Rev Mol Cell Biol $\underline{6}$, 599-609

Whitley D, Goldberg SP, Jordan WD (1999): Heat shock proteins: A review of the molecular chaperones. J Vasc Surg $\underline{29}, 748-751$

Wilk S, Orlowski M (1983): Evidence that Pituitary Cation-Sensitive Neutral Endopeptidase Is a Multicatalytic Protease Complex. J Neurochem 40, 842-849

Willis MS, Patterson C (2006): Into the heart: The emerging role of the ubiquitin-proteasome system. J Mol Cell Cardiol 41, 567-579

Willis MS, Patterson C (2013): Proteotoxicity and cardiac dysfunction--Alzheimer's disease of the heart? N Engl J Med $\underline{368}, 455-464$

Wójcik C (2002): Regulation of apoptosis by the ubiquitin and proteasome pathway. J Cell Mol Med 6, 25-48

Wu DQ, Lee CH, Rhee SG, Simon MI (1992): Activation of phospholipase C by the alpha subunits of the Gq and G11 proteins in transfected Cos-7 cells. J Biol Chem $\underline{267}, 1811-1817$

Wu H, Rothermel B, Kanatous S, Rosenberg P, Naya FJ, Shelton JM, Hutcheson KA, DiMaio JM, Olson EN, Bassel-Duby R, Williams RS (2001): Activation of MEF2 by muscle activity is mediated through a calcineurin-dependent pathway. EMBO J 20, 6414-6423

Wu X, Zhang T, Bossuyt J, Li X, McKinsey TA, Dedman JR, Olson EN, Chen J, Brown JH, Bers DM (2006): Local InsP3-dependent perinuclear Ca2+ signaling in cardiac myocyte excitationtranscription coupling. J Clin Invest 116, 675-682

Wu X, Zheng D, Qin Y, Liu Z, Zhang G, Zhu X, Zeng L, Liang Z (2017): Nobiletin attenuates adverse cardiac remodeling after acute myocardial infarction in rats via restoring autophagy flux. Biochem Biophys Res Commun 쓰, 262-268

Xie M, Morales CR, Lavandero S, Hill JA (2011): Tuning flux: autophagy as a target of heart disease therapy. Curr Opin Cardiol 26, 216-222 
Xue J-H, Fukuyama H, Nonoguchi K, Kaneko Y, Kido T, Fukumoto M, Fujibayashi Y, Itoh K, Fujita J (1998): Induction of Apg-1, a Member of the Heat Shock Protein 110 Family, Following Transient Forebrain Ischemia in the Rat Brain. Biochem Biophys Res Commun 247, 796-801

Yagita Y, Kitagawa K, Taguchi A, Ohtsuki T, Kuwabara K, Mabuchi T, Matsumoto M, Yanagihara T, Hori M (1999): Molecular Cloning of a Novel Member of the HSP110 Family of Genes, IschemiaResponsive Protein 94 kDa (irp94),Expressed in Rat Brain After Transient Forebrain Ischemia. J Neurochem $\underline{72}, 1544-1551$

Yagita Y, Kitagawa K, Ohtsuki T, Tanaka S, Hori M, Matsumoto M (2001): Induction of the HSP110/105 Family in the Rat Hippocampus in Cerebral Ischemia and Ischemic Tolerance Induction of the HSP110/105 Family in the Rat Hippocampus in Cerebral Ischemia and Ischemic Tolerance. J Cereb Blood Flow Metab 21, 811-819

Yakubu UM, Morano KA (2018): Roles of the nucleotide exchange factor and chaperone Hsp110 in cellular proteostasis and diseases of protein misfolding. Biol Chem $\underline{399}$, 1215-1221

Yamazaki T, Komuro I, Kudoh S, Zou Y, Shiojima I, Hiroi Y, Mizuno T, Maemura K, Kurihara H, Aikawa R, et al. (1996): Endothelin-1 Is Involved in Mechanical Stress-induced Cardiomyocyte Hypertrophy. J Biol Chem 271, 3221-3228

Yang Z, Zhuang L, Szatmary P, Wen L, Sun H, Lu Y, Xu Q, Chen X (2015): Upregulation of Heat Shock Proteins (HSPA12A, HSP90B1, HSPA4, HSPA5 and HSPA6) in Tumour Tissues Is Associated with Poor Outcomes from HBV-Related Early-Stage Hepatocellular Carcinoma. Int J Med Sci $12,256-263$

Yoon S, Kim M, Min H-K, Lee Y-U, Kwon D-H, Lee M, Lee S, Kook T, Joung H, Nam K-I, et al. (2018): Inhibition of heat shock protein 70 blocks the development of cardiac hypertrophy by modulating the phosphorylation of histone deacetylase 2. Cardiovasc Res $\underline{20}, 1329$ - 1337

Zhang T, Kohlhaas M, Backs J, Mishra S, Phillips W, Dybkova N, Chang S, Ling H, Bers DM, Maier LS, et al. (2007): CaMKIIdelta isoforms differentially affect calcium handling but similarly regulate HDAC/MEF2 transcriptional responses. J Biol Chem 282, 35078-35087

Zhao X, Sternsdorf T, Bolger TA, Evans RM, Yao T-P (2005): Regulation of MEF2 by Histone Deacetylase 4- and SIRT1 Deacetylase-Mediated Lysine Modifications. Mol Cell Biol 25, 8456-8464 
Zhong Y, Wang QJ, Li X, Yan Y, Backer JM, Chait BT, Heintz N, Yue Z (2009): Distinct regulation of autophagic activity by Atg14L and Rubicon associated with Beclin 1-phosphatidylinositol-3-kinase complex. Nat Cell Biol $\underline{11}, 468-476$

Zobel C, Kassiri Z, Nguyen T-TT, Meng Y, Backx PH (2002): Prevention of hypertrophy by overexpression of Kv4.2 in cultured neonatal cardiomyocytes. Circulation 106, 2385-2391 


\section{Kongressbeiträge}

Teile dieser Dissertation wurden veröffentlicht:

Gersch S, Elkenani M, Hasenfuss G, Lutz S, Toischer K, Mohamed BA*: HSPA4 ameliorates pathological cardiomyocyte remodeling possibly via activation of autophagy flux. American-Heart-Association-Kongress, Anaheim USA, 09.06.2017

Gersch S, Elkenani M, Sadrach E, Hasenfuss G, Lutz S, Toischer K, Mohamed BA*: HSPA4 ameliorates pathological cardiomyocyte remodeling possibly via activation of autophagy flux. DGK-Frühjahrstagung, Mannheim, 12.04.2018

(*) Vortragender 


\section{Danksagung}

Herrn Prof. Toischer möchte ich für die Möglichkeit danken in seinem Labor zu diesem spannenden Thema forschen zu können und einen Einblick in die Welt der Grundlagenforschung zu erhalten. Auch für seine stets zielführende Hilfe während des experimentellen Teils und während der Anfertigung der Dissertation möchte ich mich bedanken.

Mein besonderer Dank gilt Dr. Mohamed für seine Betreuung meiner Dissertation, seine unermüdlichen Tipps und Hilfestellungen bei den Experimenten. Sein Interesse an meiner Arbeit und sein Engagement haben maßgeblich zum Gelingen dieser Dissertation beigetragen.

Ganz herzlich möchte ich auch meiner Zweitbetreuerin Frau Prof. Lutz danken für ihre stets offene Art mich bei den Virus- und Zellkulturarbeiten zu unterstützen.

Weiterhin bedanke ich mich bei den Mitarbeiterinnen und Mitarbeitern der AG Toischer, die mir jederzeit mit Rat und Tat bei den Experimenten zur Seite standen. 
